University of South Florida

DIGITAL COMMONS @ UNIVERSITY OF SOUTH FLORIDA
Digital Commons @ University of South Florida

$12-1-2011$

\title{
Improving Value of Travel Time Savings Estimation for More Effective Transportation Project Evaluation
}

CUTR

Follow this and additional works at: https://digitalcommons.usf.edu/cutr_nctr

\section{Recommended Citation}

"Improving Value of Travel Time Savings Estimation for More Effective Transportation Project Evaluation," National Center for Transit Research (NCTR) Report No. CUTR-NCTR-RR-2010-07, Center for Urban Transportation Research, University of South Florida, 2011. DOI: https://doi.org/10.5038/CUTR-NCTR-RR-2010-07 Available at: https://scholarcommons.usf.edu/cutr_nctr/126

This Technical Report is brought to you for free and open access by the National Center for Transit Research (NCTR) Archive (2000-2020) at Digital Commons @ University of South Florida. It has been accepted for inclusion in Research Reports by an authorized administrator of Digital Commons @ University of South Florida. For more information, please contact digitalcommons@usf.edu. 


\section{Improving Value of Travel Time Savings Estimation for More Effective Transportation Project Evaluation}
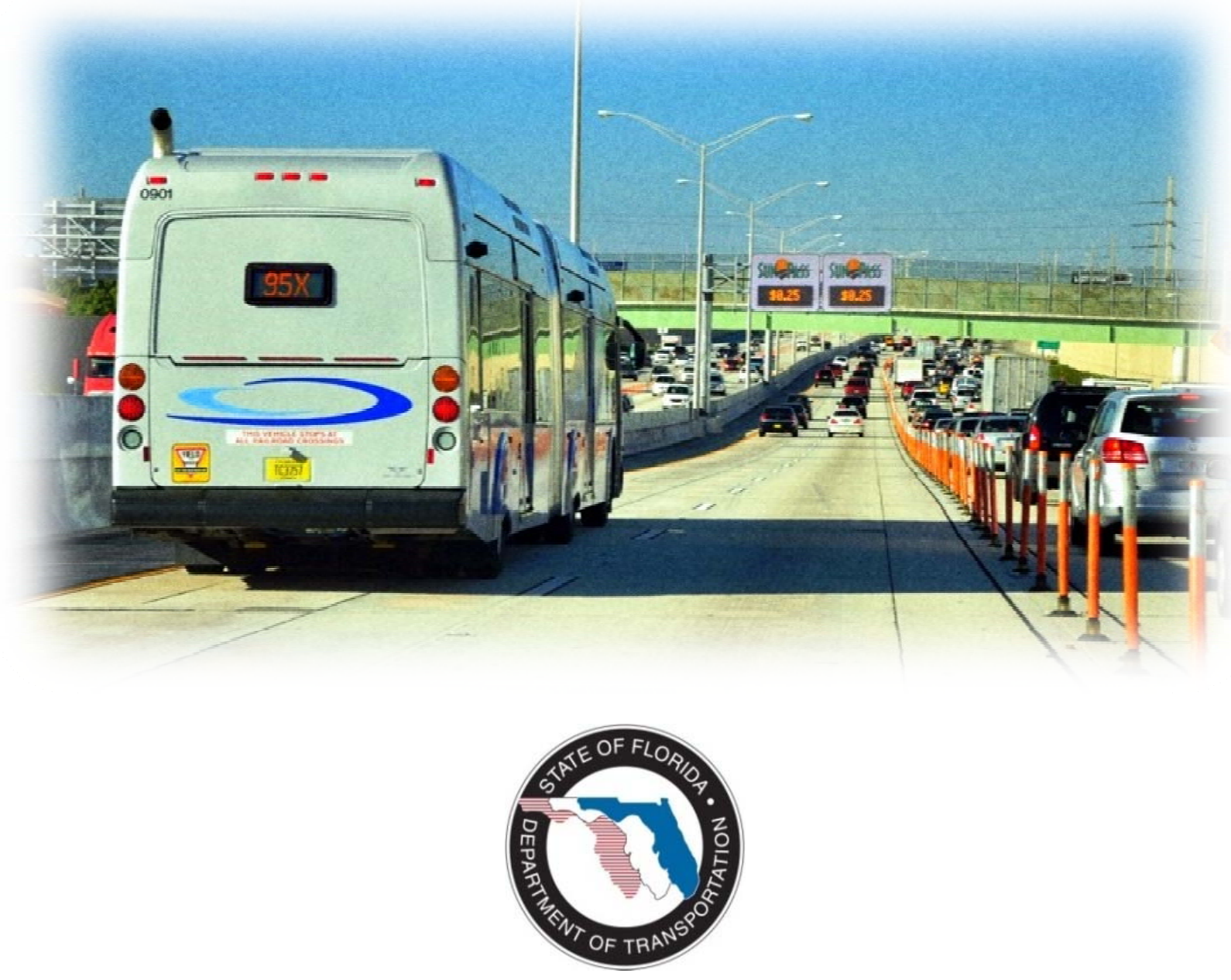

$\|_{\text {cur }}$ NCTRR USF

BDK85 977-21

Final Report

December 2011 


\section{Improving Value of Travel Time Savings Estimation for More Effective Transportation Project Evaluation}

BDK85 977-21

Final Report

Prepared for:

Florida Department of Transportation

Research Center

605 Suwannee Street, MS 30

Tallahassee, FL 32399-0450

Project Manager: Amy Datz

Prepared by:

Victoria A. Perk

Joseph S. DeSalvo, Ph.D.

Tara A. Rodrigues

Nina M. Verzosa

Steven C. Bovino

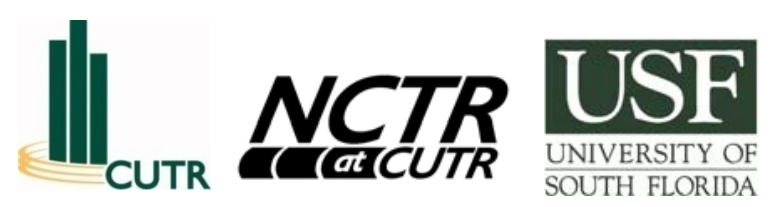

Center for Urban Transportation Research

University of South Florida

4202 E. Fowler Avenue, CUT-100

Tampa, FL 33620-5375

December 2011 



\section{DISCLAIMER}

The opinions, findings, and conclusions expressed in this publication are those of the authors and not necessarily those of the State of Florida Department of Transportation. 


\begin{tabular}{|c|c|}
\hline \multicolumn{2}{|c|}{ METRICIENGLISH CONVERSION FACTORS } \\
\hline ENGLISH TO METRIC & METRIC TO ENGLISH \\
\hline $\begin{aligned} \text { LENGTH (APPROXIMATE) } \\
1 \text { inch }(\mathrm{in})=2.5 \text { centimeters }(\mathrm{cm}) \\
1 \text { foot }(\mathrm{ft})=30 \text { centimeters }(\mathrm{cm}) \\
1 \text { yard }(\mathrm{yd})=0.9 \text { meter }(\mathrm{m}) \\
1 \text { mile }(\mathrm{mi})=1.6 \text { kilometers }(\mathrm{km})\end{aligned}$ & $\begin{aligned} & \text { LENGTH (APPROXIMATE) } \\
& 1 \text { millimeter }(\mathrm{mm})=0.04 \text { inch }(\mathrm{in}) \\
& 1 \text { centimeter }(\mathrm{cm})=0.4 \text { inch }(\mathrm{in}) \\
& 1 \text { meter }(\mathrm{m})=3.3 \text { feet }(\mathrm{ft}) \\
& 1 \text { meter }(\mathrm{m})=1.1 \text { yards }(\mathrm{yd}) \\
& 1 \text { kilometer }(\mathrm{km})=0.6 \text { mile }(\mathrm{mi})\end{aligned}$ \\
\hline & \multirow{2}{*}{$\begin{array}{c}\text { AREA (APPROXIMATE) } \\
1 \text { square centimeter }\left(\mathrm{cm}^{2}\right)=0.16 \text { square inch }\left(\mathrm{sq} \text { in, } \mathrm{in}^{2}\right)\end{array}$} \\
\hline $\begin{array}{c}\text { AREA (APPROXIMATE) } \\
1 \text { square inch }\left(\mathrm{sq} \mathrm{in}, \mathrm{in}^{2}\right)=\begin{array}{l}6.5 \text { square centimeters } \\
\left(\mathrm{cm}^{2}\right)\end{array}\end{array}$ & \\
\hline 1 square foot $\left(\mathrm{sq} \mathrm{ft}, \mathrm{ft}^{2}\right)=0.09$ square meter $\left(\mathrm{m}^{2}\right)$ & 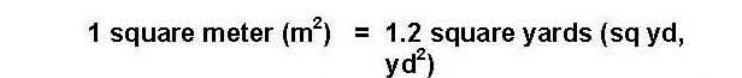 \\
\hline 1 square yard $\left(\mathrm{sq} y \mathrm{y}, \mathrm{yd}^{2}\right)=0.8$ square meter $\left(\mathrm{m}^{2}\right)$ & 1 square kilometer $\left(\mathrm{km}^{2}\right)=0.4$ square mile $\left(\mathrm{sq} \mathrm{mi}, \mathrm{mi}^{2}\right)$ \\
\hline $\begin{aligned} & 1 \text { square mile }\left(\mathrm{sq} \mathrm{mi}, \mathrm{mi}^{2}\right)= \begin{array}{l}2.6 \text { square kilometers } \\
\left(\begin{array}{l}\left.\mathrm{km}^{2}\right)\end{array}\right.\end{array} \\
& 1 \text { acre }=0.4 \text { hectare }(\mathrm{he})=4,000 \text { square meters }\left(\mathrm{m}^{2}\right)\end{aligned}$ & 10,000 square meters $\left(m^{2}\right)=1$ hectare $($ ha $)=2.5$ acres \\
\hline $\begin{aligned} & \text { MASS - WEIGHT (APPROXIMATE) } \\
& 1 \text { ounce (oz) }=28 \text { grams }(\mathrm{gm}) \\
& 1 \text { pound }(\mathrm{lb})=0.45 \text { kilogram }(\mathrm{kg}) \\
& 1 \text { short ton =2,000 pounds }= 0.9 \text { tonne }(\mathrm{t}) \\
&(\mathrm{lb})\end{aligned}$ & $\begin{aligned} & \text { MASS - WEIGHT (APPROXIMATE) } \\
& 1 \text { gram (gm) }=0.036 \text { ounce }(\mathrm{oz}) \\
& 1 \text { kilogram }(\mathrm{kg})=2.2 \text { pounds }(\mathrm{lb}) \\
& 1 \text { tonne }(\mathrm{t})=1,000 \text { kilograms }(\mathrm{kg}) \\
&=1.1 \text { short tons }\end{aligned}$ \\
\hline VOLUME (APPROXIMATE) & VOLUME (APPROXIMATE) \\
\hline 1 teaspoon $(\mathrm{tsp})=5$ milliliters $(\mathrm{ml})$ & \\
\hline 1 tablespoon $($ tbsp) $=15$ milliliters $(\mathrm{ml})$ & $\begin{aligned} 1 \text { millinter }(\mathrm{ml}) & =0.03 \text { fludd ounce }(\mathrm{tl} \text { oz) } \\
1 \text { liter }(\mathrm{l}) & =2.1 \text { pints }(\mathrm{pt})\end{aligned}$ \\
\hline 1 fluid ounce $(\mathrm{fl}$ oz) $=30$ milliliters $(\mathrm{ml})$ & 1 liter $(I)=1.06$ quarts $(q t)$ \\
\hline 1 cup $(\mathrm{c})=0.24$ liter $(\mathrm{l})$ & 1 liter $(I)=0.26$ gallon (gal) \\
\hline 1 pint $(\mathrm{pt})=0.47$ liter $(\mathrm{l})$ & \\
\hline 1 quart (qt) $=0.96$ liter $(\mathrm{l})$ & \\
\hline 1 gallon $($ gal) $=3.8$ liters $(\mathrm{l})$ & \\
\hline 1 cubic foot $\left(\mathrm{cu} \mathrm{ft}, \mathrm{ft}^{3}\right)=0.03$ cubic meter $\left(\mathrm{m}^{3}\right)$ & 1 cubic meter $\left(\mathrm{m}^{3}\right)=36$ cubic feet $\left(\mathrm{cu} \mathrm{ft}, \mathrm{ft}^{3}\right)$ \\
\hline 1 cubic $y$ ard $\left(\right.$ cu $\left.y d, y^{3}\right)=0.76$ cubic meter $\left(m^{3}\right)$ & 1 cubic meter $\left(m^{3}\right)=1.3$ cubic yards $\left(\right.$ cu $\left.y d, y d^{3}\right)$ \\
\hline 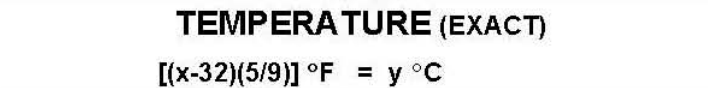 & $\begin{array}{l}\text { TEMPERATURE (EXACT) } \\
{[(9 / 5) y+32]^{\circ} \mathrm{C}=x^{\circ} \mathrm{F}}\end{array}$ \\
\hline \multicolumn{2}{|c|}{ QUICK INCH - CENTIMETER LENGTH CONVERSION } \\
\hline \multicolumn{2}{|c|}{$\begin{array}{lllll}0 & 1 & 2 & 3 & 4 \\
& \mid & \mid & \mid & \mid\end{array}$} \\
\hline 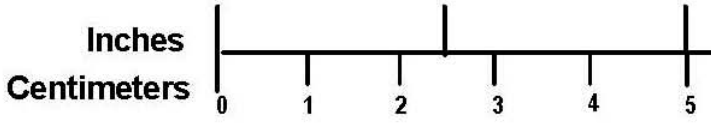 & \begin{tabular}{ll|l|l}
$T$ & & & \\
9 & 10 & 11 & 12
\end{tabular} \\
\hline \multicolumn{2}{|c|}{ QUICK FAHRENHEIT - CELSIUS TEMPERATURE CONVERSION } \\
\hline${ }^{\circ} \mathrm{F} \stackrel{-40^{\circ}-22^{\circ}}{-4^{\circ}}{\stackrel{14}{14^{\circ}}}_{1}^{32^{\circ}}$ & ${\stackrel{104^{\circ}}{12}}^{122^{\circ}} 140^{\circ} 158^{\circ} 176^{\circ} 194^{\circ} 212^{\circ}$ \\
\hline 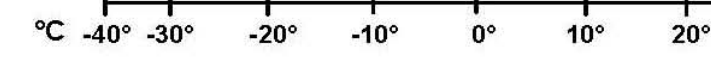 & $\begin{array}{ccccccc}40^{\circ} & 50^{\circ} & 60^{\circ} & 70^{\circ} & 80^{\circ} & 90^{\circ} & 100^{\circ}\end{array}$ \\
\hline $\begin{array}{l}\text { For more exact and or other conversion factors, see NIST } \\
\text { Price } \$ 2.50 \text { SD Catalog No. C13 } 10286\end{array}$ & $\begin{array}{l}\text { cellaneous Publication 286, Units of Weights and Measures. } \\
\text { updated 6/177 }\end{array}$ \\
\hline
\end{tabular}


Technical Report Documentation Page

\begin{tabular}{|c|c|c|c|c|}
\hline 1. Report No. & \multicolumn{2}{|c|}{ 2. Government Accession No. } & \multicolumn{2}{|l|}{ 3. Recipient's Catalog No. } \\
\hline \multirow{2}{*}{\multicolumn{3}{|c|}{$\begin{array}{l}\text { 4. Title and Subtitle } \\
\text { Improving Value of Travel Time Savings Estimation for More } \\
\text { Effective Transportation Project Evaluation }\end{array}$}} & \multicolumn{2}{|l|}{$\begin{array}{l}\text { 5. Report Date } \\
\text { December } 2011\end{array}$} \\
\hline & & & \multicolumn{2}{|c|}{ 6. Performing Organization Code } \\
\hline \multicolumn{3}{|c|}{$\begin{array}{l}\text { 7. Author(s) } \\
\text { Victoria A. Perk, Joseph S. DeSalvo, Tara A. Rodrigues, } \\
\text { Nina M. Verzosa, Steven C. Bovino }\end{array}$} & \multicolumn{2}{|c|}{ 8. Performing Organization Report No. } \\
\hline \multirow{3}{*}{\multicolumn{3}{|c|}{$\begin{array}{l}\text { 9. Performing Organization Name and Address } \\
\text { Center for Urban Transportation Research } \\
\text { University of South Florida } \\
4202 \text { E. Fowler Avenue, CUT-100 } \\
\text { Tampa, FL } 33620\end{array}$}} & \multirow{2}{*}{\multicolumn{2}{|c|}{ 10. Work Unit No. (TRAIS) }} \\
\hline & & & & \\
\hline & & & \multicolumn{2}{|l|}{$\begin{array}{l}\text { 11. Contract or Grant No. } \\
\text { BDK85 977-21 }\end{array}$} \\
\hline \multicolumn{3}{|c|}{$\begin{array}{l}\text { 12. Sponsoring Agency Name and Address } \\
\text { Florida Department of Transportation } \\
\text { Research Center } \\
605 \text { Suwannee Street, MS } 30 \\
\text { Tallahassee, FL } 32399\end{array}$} & \multicolumn{2}{|c|}{$\begin{array}{l}\text { 13. Type of Report and Period Covered } \\
\text { Final Report } \\
\text { March } 2010 \text { - December } 2011\end{array}$} \\
\hline \multicolumn{5}{|l|}{ 15. Supplementary Notes } \\
\hline \multicolumn{5}{|c|}{$\begin{array}{l}\text { 16. Abstract } \\
\text { Estimates of value of time (VOT) and value of travel time savings (VTTS) are critical elements in benefit- } \\
\text { cost analyses of transportation projects and in developing congestion pricing policies. In addition, } \\
\text { differences in VTTS among various modes of transportation can provide information to planners and } \\
\text { others on the likely success of diverting trips from single-occupant vehicles to alternatives. The goal of } \\
\text { this research is to present an improved estimation of VTTS. By using information from the first survey to } \\
\text { collect trip-specific data on the } 95 \text { Express corridor in Miami, Florida, it was found that the estimated } \\
V T T S \text { of those travelers is approximately } 49 \text { percent of their hourly wage based on annual household } \\
\text { income, with a range of } \$ 2.27 \text { to } \$ 79.32 \text { per hour and a mean of approximately } \$ 32.00 \text { per hour. This } \\
\text { result is in the range of estimated values for VTTS found in the recent literature and represents actual } \\
\text { behavior of the survey respondents rather than the more commonly found stated preferences. While the } \\
\text { primary objective of this research is to estimate VTTS using revealed preference data from the } 95 \text { Express } \\
\text { corridor, a significant secondary objective is to provide a synthesis of managed lane operations in the } \\
\text { United States. The report contains information on several existing projects around the country as well as } \\
\text { information on cities that have been named part of the federal Urban Partnership Agreement (UPA) or } \\
\text { Congestion Reduction Demonstration (CRD) program. }\end{array}$} \\
\hline \multicolumn{2}{|c|}{$\begin{array}{l}\text { 17. Key Word } \\
\text { Value of time, value of travel time savings, HOT } \\
\text { lanes, managed lanes, congestion pricing }\end{array}$} & \multicolumn{3}{|c|}{$\begin{array}{l}\text { 18. Distribution Statement } \\
\text { No restrictions }\end{array}$} \\
\hline $\begin{array}{l}\text { 19. Security Classif. (of this report) } \\
\text { Unclassified }\end{array}$ & $\begin{array}{l}\text { 20. Security C } \\
\text { Unclassifie }\end{array}$ & (of this pa & $\begin{array}{c}\text { 21. No. of Pages } \\
90\end{array}$ & 22. Price \\
\hline
\end{tabular}

Form DOT F 1700.7 (8-72) $\quad$ Reproduction of completed page authorized 


\section{ACKNOWLEDGEMENTS}

The authors would like to thank Alicia Torrez, Public Information Specialist, Rory Santana, P.E., District ITS Manager, FDOT District Six, Sunguide Transportation Management Center, Jim Udvardy, Project Director, South Florida Commuter Services, and Gregg Letts, P.E., ITS Project Manager, AECOM for invaluable assistance in distributing the survey analyzed in this report and for providing additional data and information necessary to complete this project. 


\section{EXECUTIVE SUMMARY}

Estimates of value of time (VOT) and value of travel time savings (VTTS) are critical elements in benefit-cost analyses of transportation projects. In addition, differences in VTTS among various modes of transportation and among the residential collection, line haul, and distribution portions of a commute can provide information to transportation planners and others on the likely success of diverting trips from single-occupant vehicles to alternatives.

One criticism of the commonly-used methods of measuring VOT and VTTS is the reporting of average values for entire populations or very large subgroups of travelers. According to a current research needs statement from the National Academies' Transportation Research Board (TRB) Committee on Transportation Economics, while the use of average values of VOT and VTTS is straightforward and relatively simple, it assumes a normal distribution when the true distribution is likely skewed. If, for example, the true VTTS distribution is skewed, the traffic redistribution and revenue outcomes of pricing measures will be incorrectly estimated. The research needs statement also states that there is evidence that individual VOT and VTTS can vary considerably for the same individual depending on trip characteristics. This evidence can be observed in the patterns of use of optional toll facilities that use dynamic pricing, where the same people can make different route choices at different times on different days.

In addition to demographic characteristics, individual VOT or VTTS can be dependent on trip characteristics such as trip time, trip purpose, amount of time saved per trip, who is paying (the traveler or the employer), and the possibility of engaging in other productive or enjoyable activities while traveling. Clearly, there are also quality of life issues related to how people value their time. How much people might spend to save time illustrates the ever-present tradeoffs in deciding where to live, where to work, and how to travel between home, work, and other locations.

This project begins where a previous National Center for Transit Research (NCTR) synthesis of literature on VOT/VTTS ends (1). The literature does not find, overall, a unique definition of the value of time. Common themes in the literature show that VOT depends on the assumption of a minimum-time constraint that requires individuals to travel more than they would otherwise choose without the constraint. The body of literature continues to evolve with research accounting explicitly for the minimum-time constraint and the trade-offs between discretionary and non-discretionary travel (9) (10). In addition, some theoretical assumptions applied in previous research can be challenged, including the minimum travel time constraint, as well as a 
minimum consumption constraint (11) (4), and effective leisure time (12) (13). Other research relates the value of time to the monocentric model in urban economic theory and to the relationships among wages, employment location, and commute times (14) (15). In examining the possibility of finding a non-zero share of respondents with a negative valuation of traveltime savings, which is one of the major issues arising from the computation of VTTS in mixed multinomial logit models, Hess et al. (16) argue that, under the microeconomic theory of time allocation, zero and positive estimates of VTTS are possible, but not negative measures. Most recently, Abou-Zeid, Ben-Akiva, Choudhury, and Hess (17) have demonstrated a model wherein the VOT distribution depends not only on demographic and trip characteristics, but also on attitudes towards travel.

There exists a need to improve the theory, leading to more correct measures of VOT and, in particular, VTTS, and to improve the accuracy of their estimation. This project will result in estimates of VTTS based on economic theory using actual market data (observed data and revealed preference) instead of the typical approach using stated preference survey data. It is believed that the revealed preference data will lead to more robust results. By better understanding the market and distribution of VTTS, decision-makers will be able to more accurately estimate traffic and revenue impacts of various transportation projects, including high-occupancy toll (HOT) and managed lanes. The results of this research effort will be highly beneficial for communities around the country with existing or planned congestion pricing initiatives and, in particular, in Florida, with its 95 Express Lanes projects.

The site for this effort was the 95 Express facility, which operates in Miami-Dade County, Florida. The 95 Express is part of an overall long-term strategy of initiatives with a goal of improving safety, person throughput, and reliability along I-95 in South Florida. Further, the 95 Express has a goal to encourage carpooling and transit usage/performance along the corridor. The project operates with a combination of HOT lanes, carpooling and public transit incentives, ramp metering, rapid incident detection, and other enhanced operational management strategies.

The success of the 95 Express has resulted in improvements in transit usage and performance along the corridor. The increase in traffic speed along the Express Lanes not only saves time for auto drivers, but also has attracted 53 percent new transit riders to the 95 Express Bus service (44). According to the FDOT 95 Express Annual Report, transit travel times between downtown Miami and the Golden Gate Interchange have dropped from 25 minutes to just 8 minutes (41). User perception on travel time, reliability, and seat availability of 95 Express Bus Service has further improved. Through the federal Urban Partnership Agreement (UPA) program, there 
have been new routes, improved park-and-ride facilities, and the implementation of transit signal priority (TSP) along some corridors to provide an advantage to the 95 Express Bus service.

Further, between 2008 and 2010, ridership on 95 Express Bus service increased 57 percent while travel in local lanes along I-95 and system-wide Miami-Dade Transit (MDT) Metrobus ridership decreased (45). This result shows the success of the Miami UPA program in linking its two main projects - the HOT lanes and the 95 Express Bus Service - to encourage transit patronage, which will bring Miami closer to its goal of reducing congestion along its major roadways.

A part of this research effort also involved compiling data and information on managed lane projects that operate in the United States. While the primary objective of this research is to estimate VTTS using revealed preference data from the 95 Express corridor, a significant secondary objective is to synthesize information from managed lane operations and concisely provide a wide selection of this information in one report. The resulting synthesis contains information on several existing projects around the country, including Lee County (Florida), Loudon County (Virginia), Houston, Salt Lake City, San Diego, Denver, and New Jersey. Second, information on cities that have been named part of the federal UPA or Congestion Reduction Demonstration (CRD) is presented. Those cities include Miami, Minneapolis, Atlanta, Los Angeles, San Francisco, and Seattle.

Because no data existed on individual trips along the I-95 corridor in Miami-Dade County, an online survey was conducted to gather the necessary data to complete this project. A link to the survey was distributed by email via databases maintained by South Florida Commuter Services and Florida Department of Transportation (FDOT) District 6. The survey instrument was carefully designed to collect the appropriate data on individual trips made along the facility, whether in the Express Lanes or general purpose lanes. Participants were asked to (voluntarily) provide information on up to two recent trips they made on I-95. Questions related to demographic information and some attitudinal questions were included, as well. While respondents were asked to estimate their travel speeds and toll fees within narrow ranges, it must be noted that data for the dates of the survey were acquired from FDOT District 6 to validate the information provided by the survey respondents. Clearly, in estimating VTTS, it is critical to have accurate data on costs and travel times. For the estimation of the VTTS, these actual data on tolls and speeds were used, based on the time of the trip as reported by the survey respondents. 
It was determined that 4,586 individuals opened the survey link and there were 818 total responses, resulting in a nearly 18 percent response rate. The 818 responses yielded 208 usable trip responses for the estimation of the VTTS distribution. For a trip to be included, it needed to occur on one of five specified days in August (Wednesday the $17^{\text {th }}$ through Sunday the $21^{\text {st) }}$ by someone driving a private vehicle who either paid a toll to use the Express Lanes, or drove in the general purpose lanes. As such, those who use the Express Lanes for free, including hybrid vehicle owners, motorcyclists, and carpool/vanpool participants, were excluded. In addition, because there are limited entry and exit points for the Express Lanes, the trips had to cover a long enough stretch of I-95 so that using the Lanes was an option for the driver. Finally, all relevant questions needed to be answered by the respondent for the trip to be included in the analysis. Of the 208 final trips, 106 occurred in the general purpose lanes, and 102 were made in the Express Lanes.

Part of the survey involved asking respondents to gauge their attitudes regarding public transportation. The results indicate that many respondents view public transportation favorably. For example, 41 percent of respondents agreed or strongly agreed that "it feels safe to travel by public transportation." In addition, 33 percent agreed or strongly agreed that "it is comfortable to travel by public transportation for work." Further, 89 percent of respondents believe that public transportation should be improved, and 45 percent agreed or strongly agreed that public transportation is worth the price compared to auto travel.

To collect a rich set of data that can be used for other applications in the future, several additional questions were included that went beyond those necessary for the VTTS estimation. Because this was the first effort to collect data on individual trips made on the 95 Express facility, it was important to collect as much information as possible while still keeping the survey length manageable for the respondents. In addition to the basic trip and demographic characteristics, respondents were asked to provide trip origin and destination information, including a location defined by the nearest major intersection or landmark. This information was also collected for the respondents' home and work locations.

The method of discrete choice modeling was used to estimate VTTS based on the survey results. In this research, the traveler's choice was limited to driving in the 95 Express Lanes and paying the prevailing toll or driving in the adjacent general purpose lanes and paying no toll. Travel time savings was defined as the difference in travel time, in minutes, to cover the 7.3 mile distance of the 95 Express facility using the Express Lanes versus the general purpose lanes at a given point in time. It was computed using the actual speeds on the lanes. Those who used the 
Express Lanes experienced a travel time savings over those who traveled in the general purpose lanes. For those who drove only in the general purpose lanes, the travel time savings was zero. It is further assumed that VTTS varies with wage rates. In the survey, respondents were asked to provide information on both their annual household income and their annual personal income. For the models estimated as part of this effort, those that included the annual household income performed better and are included in the final result.

By using information from the first survey to collect trip-specific data on the 95 Express corridor, it was found that the estimated VTTS of those travelers is approximately 49 percent of their hourly wage based on annual household income, with a range of $\$ 2.27$ to $\$ 79.32$ per hour and a mean of approximately $\$ 32.00$ per hour. These results are in the range of estimated values for VTTS found in the recent literature and represent actual behavior of the survey respondents rather than the more commonly found stated preferences.

The goal of this research is to present an improved estimation of VTTS, which is a critical component of travel behavior analysis and transportation project evaluation. Having the most accurate estimations of VTTS is beneficial for the development of successful congestion pricing policies. VTTS has an important role in a traveler's choice among competing modes or travel alternatives. 


\section{TABLE OF CONTENTS}

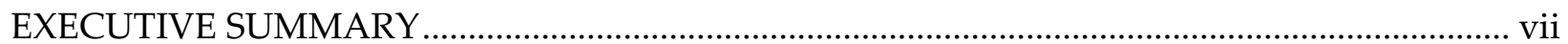

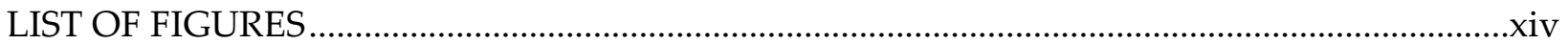

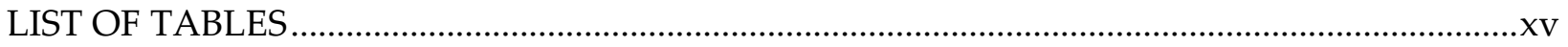

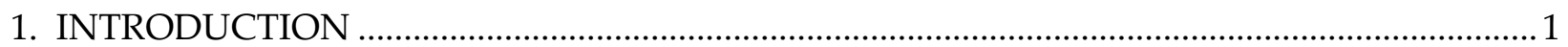

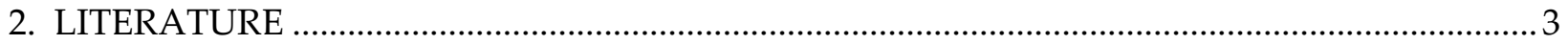

3. SYNTHESIS OF MANAGED LANE PROJECTS IN THE U.S...................................................... 5

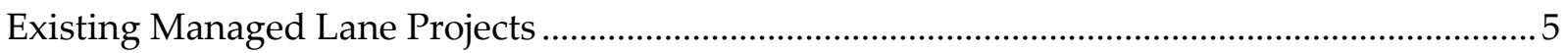

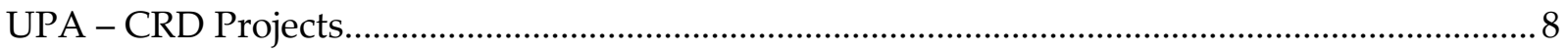

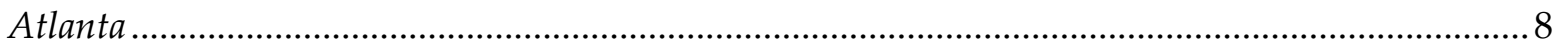

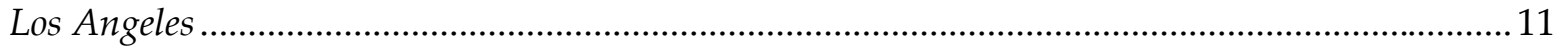

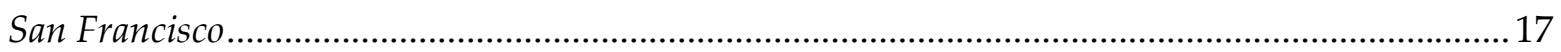

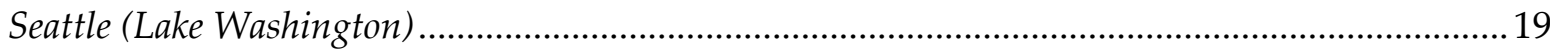

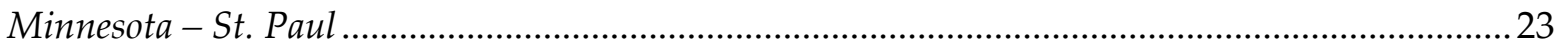

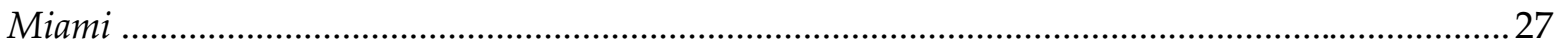

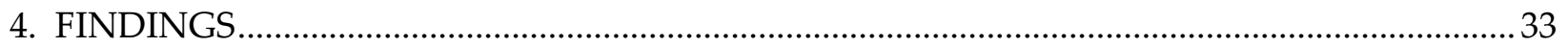

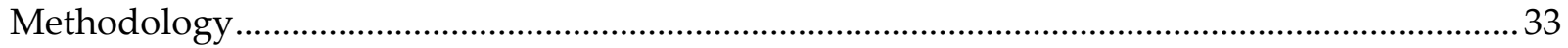

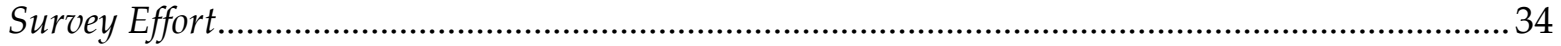

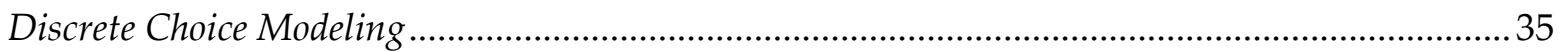

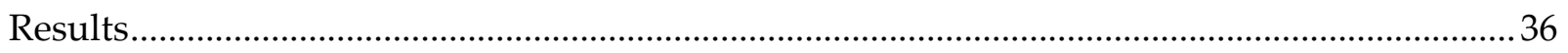

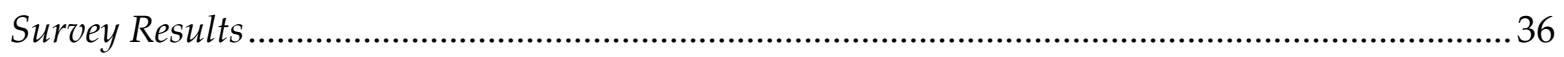

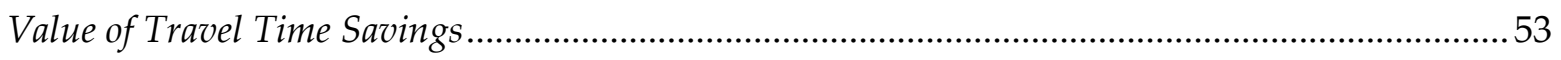

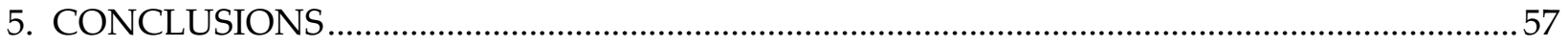

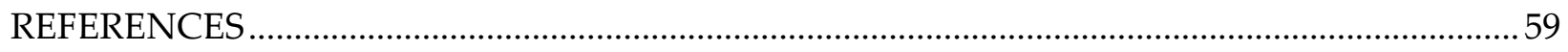

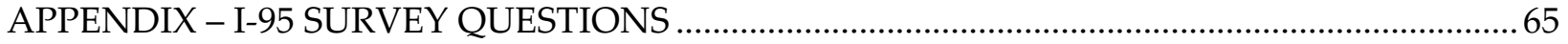




\section{LIST OF FIGURES}

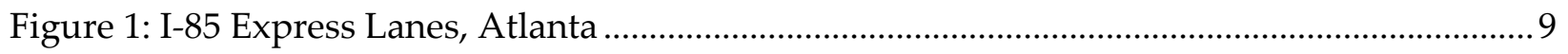

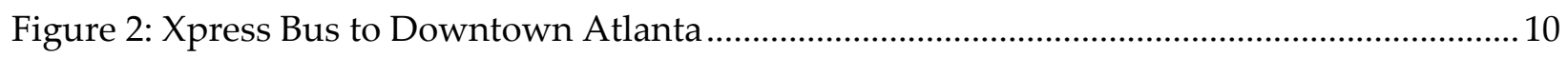

Figure 3: I-110 HOV lanes (top left), I-10 HOV lane (top right) ................................................. 13

Figure 4: New Los Angeles Metro Silver Line BRT Vehicle.......................................................... 14

Figure 5: Simulated Image of the Proposed El Monte Transit Center ............................................ 15

Figure 6: Downtown L.A. Parking Dynamic Message Signs .......................................................... 16

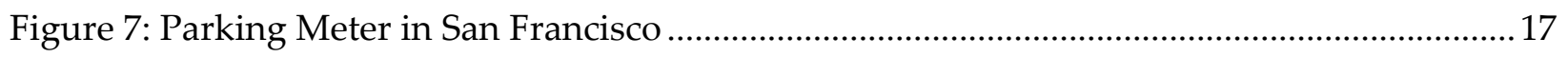

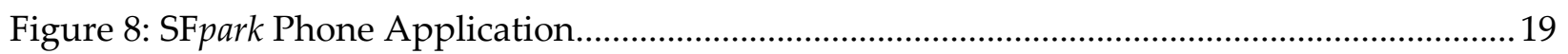

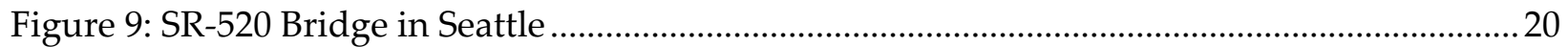

Figure 10: Visualization of Seattle Active Traffic Management (ATM) Signs...............................22

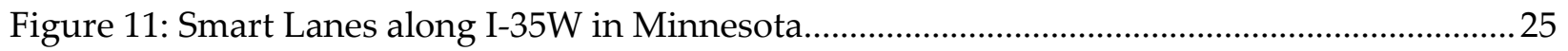

Figure 12: 95 ${ }^{\text {th }}$ Street Park-and-Ride Lot along I-35W ….................................................................26

Figure 13: South Florida I-95 Express Lanes Project .................................................................... 28

Figure 14: 95 Express Facility (Northbound) .................................................................................. 30

Figure 15: 95 Express Facility (Northbound) ................................................................................. 30

Figure 16: Miami-Dade Transit's Route 95X Operating Along the 95 Express Facility ................. 32

Figure 17: It feels safe to travel by public transportation .............................................................. 37

Figure 18: It is comfortable to travel by public transportation for work.......................................38

Figure 19: Measures should be taken to improve public transportation ........................................ 38

Figure 20: Traveling by public transportation is worth its price compared to traveling by car ...39

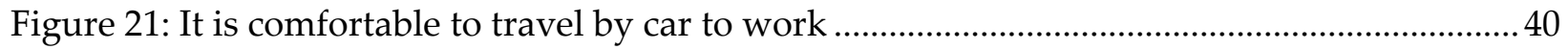

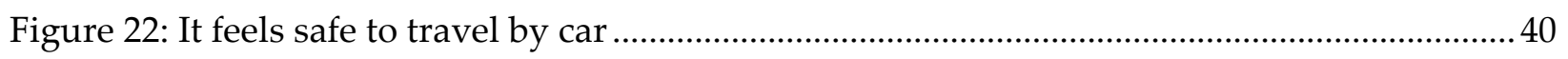

Figure 23: I consciously limit my car use to reduce emissions ...................................................... 41

Figure 24: It is important that traffic speed limits are not violated ................................................ 41

Figure 25: I support the use of lanes with tolls that vary depending on the traffic congestion.... 42

Figure 26: Charging tolls that vary with the level of traffic is an effective way to reduce

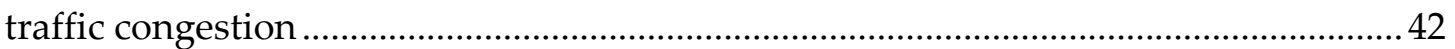

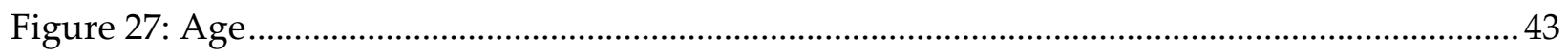

Figure 28: How many people live in your household? ................................................................ 44 
Figure 29: How many people under 16 live in your household?. 44

Figure 30: How many cars, motorcycles, minivans, pickup trucks, etc. do you have in your household? 45

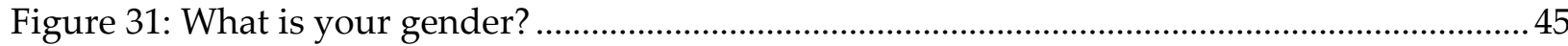

Figure 32: What is the highest level of education or degree that you have completed?................46

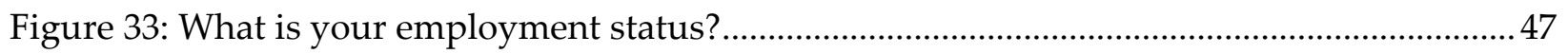

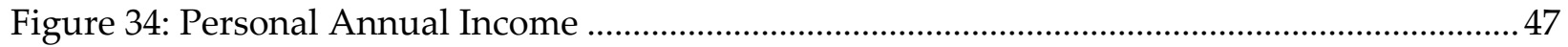

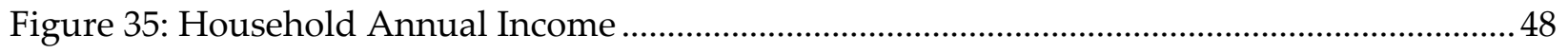

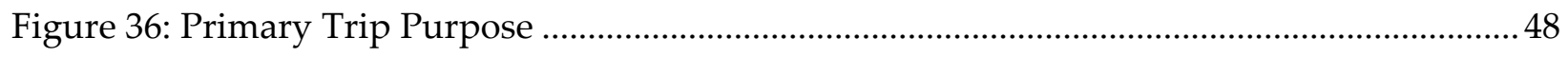

Figure 37: Self-Reported Speed in 95 Express Lanes .................................................................. 49

Figure 38: Self-Reported Speed in General Purpose Lanes.......................................................... 49

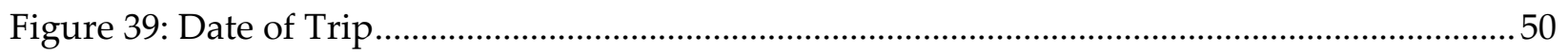

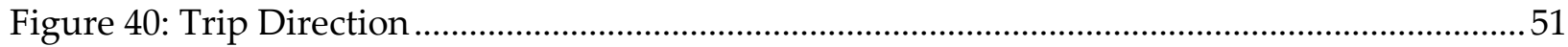

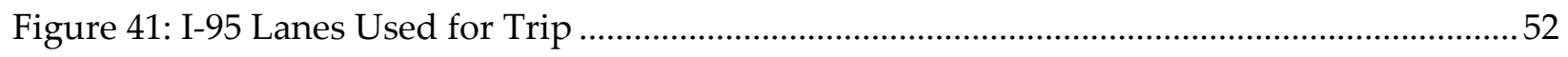

Figure 42: Start County and End County …............................................................................ 52

Figure 43: VTTS Distribution for Survey Respondents Traveling on I-95 ....................................54

\section{LIST OF TABLES}

Table 1: 95 Express Model Results 55 


\section{INTRODUCTION}

Estimates of value of time (VOT) and value of travel time savings (VTTS) are critical elements in benefit-cost analyses of transportation projects. In addition, differences in VTTS among various modes of transportation and among the residential collection, line haul, and distribution portions of a commute can provide information to transportation planners and others on the likely success of diverting trips from single-occupant vehicles to alternatives.

One criticism of the commonly-used methods of measuring VOT and VTTS is the reporting of average values for entire populations or very large subgroups of travelers. According to a current research needs statement from the National Academies' Transportation Research Board (TRB) Committee on Transportation Economics, while the use of average values of VOT and VTTS is straightforward and relatively simple, it assumes a normal distribution when the true distribution is likely skewed. If, for example, the true VTTS distribution is skewed, the traffic redistribution and revenue outcomes of pricing measures will be incorrectly estimated. The research needs statement also states that there is evidence that individual VOT and VTTS can vary considerably for the same individual depending on trip characteristics. This evidence can be observed in the patterns of use of optional toll facilities that use dynamic pricing, where the same people can make different route choices at different times on different days.

In addition to demographic characteristics, individual VOT or VTTS can be dependent on trip characteristics such as trip time, trip purpose, amount of time saved per trip, who is paying (the traveler or the employer), and the possibility of engaging in other productive or enjoyable activities while traveling. Clearly, there are also quality of life issues related to how people value their time. How much people might spend to save time illustrates the ever-present tradeoffs in deciding where to live, where to work, and how to travel between home, work, and other locations.

There exists a need to improve the theory, leading to more correct measures of VOT and, in particular, VTTS, and to improve the accuracy of their estimation. This project will result in estimates of VTTS based on economic theory using actual market data (observed data and revealed preference) instead of the typical approach using stated preference survey data. It is believed that the revealed preference data will lead to more robust results. 
By better understanding the market and distribution of VTTS, decision-makers will be able to more accurately estimate traffic and revenue impacts of various transportation projects, including high-occupancy toll (HOT) and managed lanes. The results of this research effort will be highly beneficial for communities around the country with existing or planned congestion pricing initiatives and, in particular, in Florida, with its 95 Express Lanes projects that operate along I-95.

An excellent site for gathering data for this effort is the 95 Express facility, which operates in Miami-Dade County, Florida. The 95 Express is part of an overall long-term strategy of initiatives with a goal of improving safety, person throughput, and reliability along I-95 in South Florida. Further, the 95 Express has a goal to encourage carpooling and transit usage/performance along the corridor. The project operates with a combination of HOT lanes, carpooling and public transit incentives, ramp metering, rapid incident detection, and other enhanced operational management strategies.

This report is organized into five chapters. This first chapter contains the introduction to the report. The second chapter provides a brief summary of existing literature on VOT and VTTS. A third chapter provides a comprehensive synthesis of managed lane projects operating in the United States. Findings are contained in the fourth chapter, which summarizes the methodologies for the survey and discrete choice modeling efforts, and also presents the results of the survey and the VTTS estimation. Finally, the fifth chapter provides a conclusion for the report. 


\section{LITERATURE}

This section provides a brief summary of literature relevant to this research effort. This project begins where a previous National Center for Transit Research (NCTR) synthesis of literature on VOT/VTTS ends (1). Concas and Kolpakov provide a comprehensive review of the large body of literature encompassing VOT, as well as the value of reliability. The synthesis includes more than 60 articles and serves as a summary of the current state of knowledge of VOT theory, modeling, and estimation.

Concas and Kolpakov (1) find that, theoretically, the value of time (VOT) is derived from a budget-constrained allocation of time across work and non-work (leisure) activities and the time necessary for the consumption of goods and services. In the earliest research, time is considered as a finite resource that can be used for work or non-work (leisure) in the framework of labor supply and demand. In this sense, the value of time is equivalent to the opportunity cost (i.e., wages forgone) of an additional unit of non-work, or leisure, time. This result is the origin of the idea of the value of time being equal to an hourly wage rate.

As Concas and Kolpakov (1) summarized, Becker (2) explicitly introduced the concept of time as an input, instead of simply a commodity, by treating time as an input in tasks such as child care and household chores (i.e., household production). This was an important development because it recognized that, in making consumption decisions, people must also consider that consumption usually requires travel, and travel itself requires time. DeSerpa (3) expanded this idea further by implying that the consumption of goods requires the allocation of a minimum amount of time, leading to the distinction between the value of saving time, the value of time as a resource, and the value of time as a commodity (4). Most of the early literature identifies the value of time as ranging from zero at a minimum, to some fraction of the hourly wage rate, to a maximum of the wage rate, as indicated by Shaw (5). Empirically, in most cases, Concas and Kolpakov (1) find that the valuation of time is significantly higher when measured by revealed preference data rather than stated preference data.

These developments in consumer theory relating to the value of time have considerable implications in the field of transportation research, as noted by Concas and Kolpakov (1). They show that the value of time can differ among individuals and also differ for the same individual depending on the timing of a particular trip (among other trip characteristics). It is acknowledged that a prevailing average wage rate is not an accurate measure of the true value 
of time. Jara-Diaz (6) indicates that the actual value of time can be much higher or lower than an individual's wage rate.

Because people make trade-offs at the margin, many researchers contend that the value of time depends primarily on the marginal wage rate rather than the average wage rate, the latter of which only provides a rough approximation of that value (7). From an empirical perspective, however, the issue is that the marginal wage rate is not directly observable, while an average wage rate is observable. According to Gronau (7), the difference between the marginal and average value of time can be determined by factors including costs incurred via work, the marginal disutility of work, the marginal utility of travel, the chance to engage in other activities while traveling, and institutional barriers to changing the number of working hours, among others. People also like to be able to control their time, regardless of its utility or opportunity cost (8). It becomes clear, then, as Concas and Kolpakov (1) summarize, that the value people place on saving time is multi-dimensional and encompasses much more than just the opportunity cost of time as measured by the wage rate.

The literature does not find, overall, a unique definition of the value of time. Common themes in the literature show that VOT depends on the assumption of a minimum-time constraint that requires individuals to travel more than they would otherwise choose without the constraint. The body of literature continues to evolve with research accounting explicitly for the minimumtime constraint and the trade-offs between discretionary and non-discretionary travel (9) (10). In addition, some theoretical assumptions applied in previous research can be challenged, including the minimum travel time constraint, as well as a minimum consumption constraint (11) (4), and effective leisure time (12) (13). Other research relates the value of time to the monocentric model in urban economic theory and to the relationships among wages, employment location, and commute times (14) (15). In examining the possibility of finding a non-zero share of respondents with a negative valuation of travel-time savings, which is one of the major issues arising from the computation of VTTS in mixed multinomial logit models, Hess, et al. (16) argues that, under the microeconomic theory of time allocation, zero and positive estimates of VTTS are possible, but not negative measures. Most recently, Abou-Zeid, Ben-Akiva, Choudhury, and Hess (17) have demonstrated a model wherein the VOT distribution depends not only on demographic and trip characteristics, but also on attitudes towards travel. 


\section{SYNTHESIS OF MANAGED LANE PROJECTS IN THE U.S.}

A part of this research effort involved compiling data and information on managed lane projects that operate in the United States. While the primary objective of this research is to estimate VTTS using revealed preference data from the 95 Express corridor, a significant secondary objective is to synthesize information on managed lane operations and concisely provide a wide selection of this information in one report. The resulting synthesis is contained in this chapter. First, information is provided on several existing projects around the country. Second, information on cities that have been named part of the federal Urban Partnership Agreement (UPA) or Congestion Reduction Demonstration (CRD) is presented. The discussion of the UPA/CRD cities goes beyond managed lane projects and provides further information on all the congestion reduction strategies being applied in those areas.

\section{Existing Managed Lane Projects}

Managed lanes projects are underway across the country as part of an effort to alleviate growing traffic congestion. Transportation agencies have limited options for dealing with traffic congestion, as expanding freeways is often not an option due to a multitude of factors including construction costs, right-of-way constraints, and environmental and/or societal impacts. Faced with these limitations, transportation agencies have increasingly turned toward solutions which involve a mix of limited capacity expansion along with operational strategies intended to both manage congestion more effectively and promote ridesharing. Managed lane projects are unique in that the traffic flow and capacity are actively controlled, generally via a method of variable pricing. Variably-priced tolls charge motorists more to access managed lanes when the lanes are more congested, and/or charge more during peak hours of travel (such as rush hour). The projects summarized in this section are listed below.

- Cape Coral Bridge, Midpoint Memorial Bridge, and Sanibel Causeway, Lee County, FL

- Dulles Greenway, VA

- Katy Managed Lanes, TX

- I-15 Express Lanes, Salt Lake City, UT

- I-15 Managed Lanes, San Diego, CA

- I-25 Express Lanes, Denver, CO

- New Jersey Turnpike 
There are three electronic toll plazas set up in Lee County: at the Cape Coral Bridge, the Midpoint Memorial Bridge, and the Sanibel Causeway. These plazas allow drivers with a LeeWay transponder to move through toll plazas without stopping, similar to the SunPass system utilized elsewhere in Florida. A small, removable electronic transponder attaches to a vehicle's windshield and is linked to a personal account that is automatically charged as the vehicle passes through a toll plaza. Drivers with a LeeWay transponder can also use electronic toll lanes elsewhere in the state where the SunPass and E-Pass systems are used. Paying tolls electronically with a LeeWay transponder costs exactly the same as paying cash, and users can actually save money depending on when they drive due to the variable pricing of the tolls. Monday through Friday, during off peak hours, those paying via a LeeWay transponder receive a 25 percent discount off the price of the toll (18).

The Dulles Greenway highway in Loudon County, Virginia, allows commuters to save time as a result of the implementation of congestion management tolls. In addition, several improvements have been made to general safety, including the elimination of at-grade intersections and separation from oncoming traffic, resulting in lower accident rates on the Greenway than neighboring State Routes 7 and 28. The variable pricing of the tolls gives commuters an incentive to travel during off-peak hours when the toll rates are cheaper, helping to alleviate traffic in the already heavily congested Washington, D.C. area. The Greenway VIP program rewards frequent users of the highway by reimbursing a portion of toll expenses for those users. Specifically, a commuter who travels on the Greenway 15 times per month over a 12-month period receives a bonus check for 5 percent of his or her toll expenses. Discounts are also offered on toll rates for EZ-Pass holders (19).

The Katy Managed Lanes project in Houston, Texas, involves four managed lanes, two going in each direction, covering 12 miles of highway from State Highway (SH) 6 to Interstate Highway (IH) 610. Tolls rates for the managed lanes are variable and are based on the time of day, vehicle occupancy, and axle count. High-occupancy vehicles (HOVs) are allowed free access on weekdays during peak travel hours, specifically 5:00 a.m. to 11:00 a.m. and 2:00 p.m. to 8:00 p.m. Single-occupant vehicles (SOVs), on the other hand, must pay a toll, while Houston METRO transit vehicles enjoy free access 24 hours per day. The Katy Managed Lanes tollway is completely electronic and requires an EZ-Pass; cash payment is not accepted (20).

The Express Lanes on the I-15 highway in Salt Lake City, Utah, utilize an electronic Express Pass, similar to the EZ-Pass. The Express Lanes cover approximately 40 miles of highway and are intended to promote carpooling, as carpoolers, buses, motorcycles, and Utah Clean Fuel Vehicles (which are issued a C Decal) have priority in the Express Lanes. It should be noted 
that, as of July 2011, SOVs with a C Decal can no longer use the Express Lanes toll free (21). If the Express Lanes are not filled to peak capacity (which is easily managed in real time due to the electronic Express Pass) single-occupant vehicles may also use the Express Lanes, albeit for a variable toll (the tolls vary based on the level of congestion, ranging from a minimum of $\$ 0.25$ to a maximum of \$1.00). The Express Lanes are designed to maintain speeds of at least $55 \mathrm{mph}$, and commuters save an average of 10 minutes on travel time while using the Express Lanes during peak travel hours (21).

In San Diego, California, a 20-mile cutting-edge managed lanes project is currently being constructed along I-15 in between SR 163 and SR 78. The project, costing over \$1 billion, is being funded in part by Transnet, a half-cent sales tax for transportation voted for by the people of San Diego in 1988, which was recently extended in 2004 for another 40 years. The I-15 managed lanes project, currently still under construction (set for completion in 2012), will involve four express lanes, with multiple access points to the general purpose highway lanes. In addition, bus rapid transit (BRT) service will enjoy direct access ramps to the managed lanes, as well as to newly constructed BRT stations (22).

The I-25 Express Lanes project in Denver, Colorado, was completed in 2006. The Express Lanes cover seven miles of I-25 in between downtown Denver and US 36. Single-occupant vehicles are restricted from using the Express Lanes, which gives greater incentive to form carpools and travel in HOVs. The Express Lanes are free to use for HOVs, motorcycles, and buses. Similar to previously mentioned projects, the I-25 express tolls utilize an electronic transponder system which allows motorists to be billed electronically as they pass through toll areas, thus eliminating the need to stop and pay in person, thereby cutting down on travel time and congestion (23).

The New Jersey Turnpike covers nearly the entire length of the state, which in its entirety serves to connect New York to Philadelphia. The Turnpike is an extensive highway, as wide as 14 lanes in some portions (7 in each direction), which receives considerable traffic, particularly due to commuters to and from New York City and Philadelphia. The turnpike employs a "dualdual" lane configuration over large portions of the turnpike, where the outer lanes are open to all vehicles, while the inner lanes are designated for compact cars only. In addition, EZ-Pass express toll lanes enable motorists with an EZ-Pass electronic transponder to travel through specially designated EZ-Pass express toll lanes at highway speeds, cutting down even further on congestion and travel time associated with stopping to pay tolls. Variable toll pricing has recently been implemented, which offers less expensive tolls to motorists traveling during nonpeak hours; additionally, a further discount is offered to EZ-Pass holders. Other programs also 
encourage both congestion and pollution mitigation; the Green Pass discount (only available for EZ-Pass holders) offers a 10 percent discount on off-peak toll rates for motorists driving vehicles which both meet the California Super Ultra Low Emission Vehicle standard (SULEV), and are rated at 45 miles per gallon or better (24).

\section{Urban Partnership Agreement (UPA) - Congestion Reduction Demonstration (CRD) Projects}

The U. S. Department of Transportation (USDOT) awarded funding to six cities, including Miami, Minneapolis, Atlanta, Los Angeles, San Francisco, and Seattle, through the Urban Partnership Agreement/Congestion Reduction Demonstration (UPA/CRD) Program. The focus is on what is referred to as the "Four T's": Tolling, Transit, Technology, and Telecommuting.

\section{Atlanta}

In November 2008, USDOT announced Atlanta, Georgia, as a Congestion Reduction Demonstration (CRD) partner, awarding the City a \$110 million grant to fund congestion management and transit improvement projects. Local CRD partners include the Georgia Department of Transportation (GDOT), the State Road and Tollway Authority (SRTA), and the Georgia Regional Transportation Authority (GRTA). These entities are jointly responsible for the management, implementation, and maintenance of the different CRD project components. The two main project components of the Atlanta CRD are the conversion of HOV lanes to dynamically-priced HOT lanes and transit improvement projects (25).

\section{Conversion of HOV Lanes to HOT Lanes}

The long-term goal of the Atlanta region is to create a 49-mile network of dynamically-priced HOT lanes along I-85, I-75, and I-20. Phase 1 of the project focuses on the approximately 16mile HOV-to-HOT lane conversion along I-85, from Chamblee Tucker Road, south of I-285, to Old Peach Tree Road. Construction of the HOT lanes, which are also known as the I-85 Express Lanes, began in September 2010 and is expected to be completed in fall 2011. Figure 1 shows a photo of the recently opened I-85 Express Lanes.

Prior to the opening of the I-85 Express Lanes, a decision on the HOT requirement along the Express Lanes had been made by GDOT in April 2009. The HOT requirement was set to allow vehicles with more than three occupants to use the Express Lanes for free while vehicles with occupants below the requirement would have to pay the toll fee. Other types of vehicles that 
are allowed to use the Express Lanes with no charge are vanpools, motorcycles, alternative fuel vehicles (but not hybrids), and public transportation vehicles.

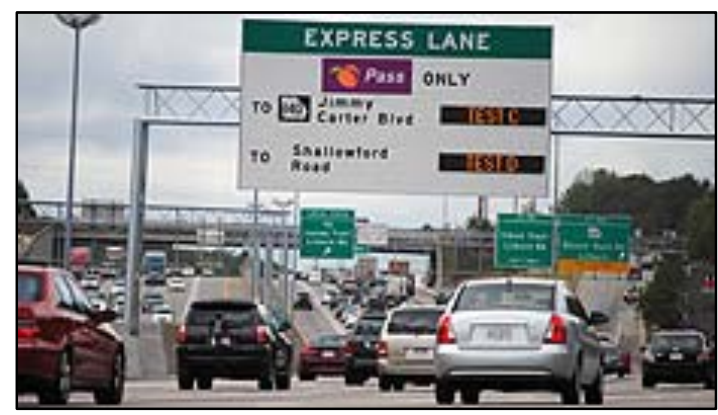

Source: GDOT

Figure 1: I-85 Express Lanes, Atlanta

To use the HOT lanes, however, a vehicle must be registered with a PeachPass account and must have a PeachPass transponder mounted on the vehicle. Online and phone registration started in July 2011, while PeachPass customer service centers were opened in August 2011, in Atlanta, Norcross, and Lawrenceville. The first 300,000 PeachPass transponders will be issued by the SRTA for free. For convenience and faster service, toll payment will be done electronically. When a vehicle uses the HOT lanes, the toll amount is deducted electronically from the PeachPass prepaid account of the vehicle owner; there is no need to stop and pay through a toll booth. Such measures ensure the free-flowing service of the HOT lanes and maintenance of highway speeds (25).

The toll amount will vary based on the congestion level along the I-85 Express Lanes. Toll prices, which will range from $\$ 0.10$ to $\$ 0.90$ per mile, are expected to be higher during peak hours and lower during off-peak hours when traffic density is low. A traffic study available on the GDOT I-85 HOT Lanes website estimates that the average trip length of HOT lane users would be six to seven miles with a toll fee ranging from $\$ 0.60$ to $\$ 6.00$ per trip depending on the demand for HOT lanes usage. The study also approximates that 25 percent of the customers will use HOT lanes for free. Tolling will occur in five northbound sections, which have seven entry and exit points, and in four southbound sections, which have six entry and exit points (26).

To support toll operations along the I-85 Express Lanes, construction of sign structures, overhead gantries and roadside communication equipment began in 2010. Local CRD partners contracted with World Fiber Technologies, Inc. of Alpharetta for both the conversion of HOV- 
to-HOT lanes and for the installation of new tolling technology, guard rail signs, and sign structures. The highway signs are designed to show the real-time toll prices in the I-85 Express Lanes.

The I-85 Express Lanes will also be equipped with technologies that are intended to automatically enforce HOT lane and toll violations. To identify toll violators, radio frequency identification (RFID) will read transponders and cameras along the I-85 Express Lanes to collect images of vehicle license plates. Mobile automatic license plate readers (ALPR) will also be installed in patrol vehicles to assist police officers with enforcement (26). These mechanisms are intended to deter individuals from evading toll fees and violating the HOT requirement, thus maximizing the revenues from the use of the I-85 Express Lanes and minimizing traffic congestion along the I-85 corridor.

\section{Transit Improvement Projects}

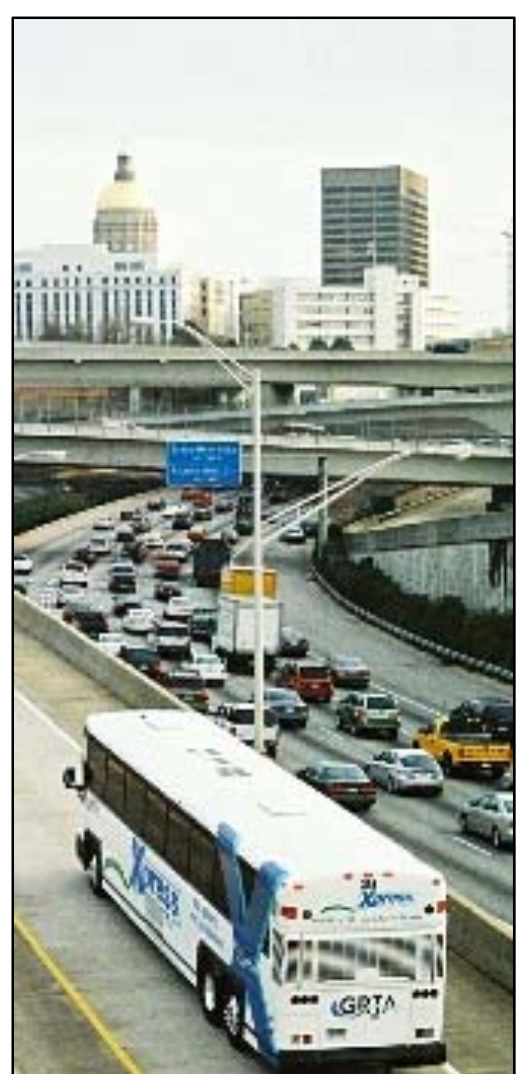

Source: Xpress GA

Figure 2: Xpress Bus to Downtown Atlanta
Atlanta local CRD partners recognize that an efficient bus system, in addition to the newly constructed I-85 Express Lanes, is vital to the success of the CRD project. Among the local partners, GRTA handles most of the tasks involving transit improvement and expansion, including the procurement of new passenger coaches and the expansion of new Xpress Regional Commuter Service routes. To support the expansion of the Xpress routes, local CRD partners proposed to purchase 36 new coaches. Twenty of these new passenger coaches were delivered in April 2011; the rest were ordered during 2011. Also, expansion of existing park-andride lots and construction of new ones began in 2010 .

In 2010, four new park-and-ride lots outside of the I-85 corridor with a total of 2,500 parking spaces were completed. In the same year, expansion of park-and-ride lots at the Mall of Georgia, Hebron Baptist Church, and I-985/GA20, as well as construction of new park-and-ride lots at Hamilton Mill, commenced. The Hamilton Mill park-and-ride lots, which provide 918 additional parking spaces, opened in August 2011. These expanded and new park-and-ride lots are 
anticipated to support new Xpress routes serving midtown and downtown Atlanta, which include Xpress routes 411, 413, and 416 (26).

Xpress Route 411 service began in August 2010 and runs from the Mall of Georgia to midtown Atlanta. Xpress route 416, from Hebron Baptist Church in Dacula to downtown Atlanta started its operations in June 2011. Xpress Route 413, however, began its services on August 1, 2011 along with the opening of the Hamilton Mill park-and-ride station. This new route provides bus service from Hamilton Mill Station at I-85 to downtown Atlanta. Figure 2 shows an Xpress bus serving downtown Atlanta.

Alternative commute programs have also been considered by the local CRD partners. To accomplish these, the local CRD partners have collaborated with the Clean Air Campaign to promote carpooler formation. In spring 2009, market research that included an e-mail survey of transit riders, carpoolers, and single drivers, was conducted by the CRD local partners in coordination with the Clean Air Campaign. The survey results show that 45 percent of I-85 carpoolers use the HOV lanes three or more times per week and that 64 percent would continue to carpool even if the HOV lanes did not exist. From the survey data, it is clear that there exist frequent carpoolers along the I-85 corridor who would benefit greatly from the reduced congestion and increased speed promised by the new I-85 Express Lanes (27).

Although the SRTA Kickoff event for the I-85 Express Lanes is not until fall 2011, commuters and drivers along the I-85 corridor have already shared their expectations of the new Express Lanes. Research on these HOT lanes show that both commuters and non-commuters associate the HOT Lanes with efficiency, saving time, and providing extra time with family (28). Initial revenues generated from the Atlanta CRD project will be used to cover the costs of construction, operations, and maintenance of the lanes while beneficiaries of future revenues currently remain undecided as of the writing of this report (28).

\section{Los Angeles}

USDOT announced the designation of Los Angeles as a CRD partner in April 2008. Local CRD partners include the following: the Los Angeles County Metropolitan Transportation Authority (LACMTA), California Department of Transportation (Caltrans), and the Los Angeles Department of Transportation (LADOT). Under the partnership, USDOT is providing \$210.6 million in federal grants to fund CRD projects in Los Angeles while local CRD partners committed \$131 million in non-Federal funds for the HOV-to-HOT lane construction along the 
I-10 and I-110 corridors (29). The project aims to ease congestion levels, improve the transit system and facilities, and implement an intelligent parking management system along the I-10 and I-110 corridors. The three main components of the Los Angeles CRD, discussed below, include: conversion of HOV lanes to HOT lanes, transit improvement projects, and intelligent parking management (IPM). IPM systems use real-time parking information to reduce congestion in and near parking areas and to assist drivers in quickly and safely locating available parking.

\section{Conversion of HOV Lanes to HOT Lanes}

The length of Los Angeles' HOV-to-HOT lanes conversion, at 61 miles, is the longest among CRD and UPA sites that use this strategy. Phase 1 of the project is composed of HOV-to-HOT lane conversion along two corridors, I-10 and I-110. Similar to the Miami UPA discussed at the end of this section, the Los Angeles UPA will include the re-striping of lanes in the corridors between I-605 and I-710 along the I-10 El Monte Busway to create a second HOT lane. This will expand the freeway during peak hours. Re-striping will also be carried out along the I-110 Adams off-ramp to create a second right-hand turning lane, which will be accompanied by a road-widening initiative along Adams Boulevard. New HOT transition lanes will also be added along I-110 to ensure a smooth flow of traffic from the general purpose lanes to the HOT lanes and vice-versa (29).

Construction in both the I-10 and I-110 corridors began in 2011. The 28-mile I-10 El Monte Busway HOT lanes between Alameda Street and I-605 will be open in February 2013. The 33mile I-110 Harbor Transitway HOT lanes from Adams Boulevard to the Artesia Transit Center is expected to begin its operations in October 2012, four months earlier than the I-10 HOT lanes. Figure 3, on the following page, illustrates the existing HOV lanes along I-10 and I-110 and the visualization of the HOV-to-HOT lanes conversion, also referred to as Metro Express Lanes.

Similar to HOT lanes at other UPA and CRD sites, the Metro Express Lanes also follow a pricing strategy wherein toll fees are adjusted dynamically based on the congestion level in the lanes. Price increases as the traffic conditions along the Express Lanes worsen or when demand for Express Lanes usage increases. However, unlike other HOT lanes, the Metro Express Lanes have a stricter toll exemption rule. The I-10 El Monte Busway Express Lanes, in particular, only allow carpools with three or more occupants to use the Express Lanes for free, while charging two-person carpools during peak hours (5:00 a.m. - 9:00 a.m.; 4:00 p.m. - 7:00 p.m.). However, two-person carpools may use the Express Lanes for free during off-peak hours, while singleoccupant vehicles are required to pay a fee to access these lanes during all hours. Such a 
strategy aims to free more space in the HOT lanes when congestion levels are greater. In contrast, the toll exemption rule along the I-110 Harbor Transitway follows that of most other UPA and CRD sites with a HOT requirement that all carpools with two or more occupants, vanpools, transit vehicles, and motorcycles can use the I-110 Metro Express Lanes toll-free. To access the Metro Express Lanes, vehicles must have a FasTrak transponder. The proposed toll price per mile ranges from $\$ 0.25$ to $\$ 1.40$ depending on congestion level-an amount substantially greater than the toll price per mile of the Atlanta CRD (29).

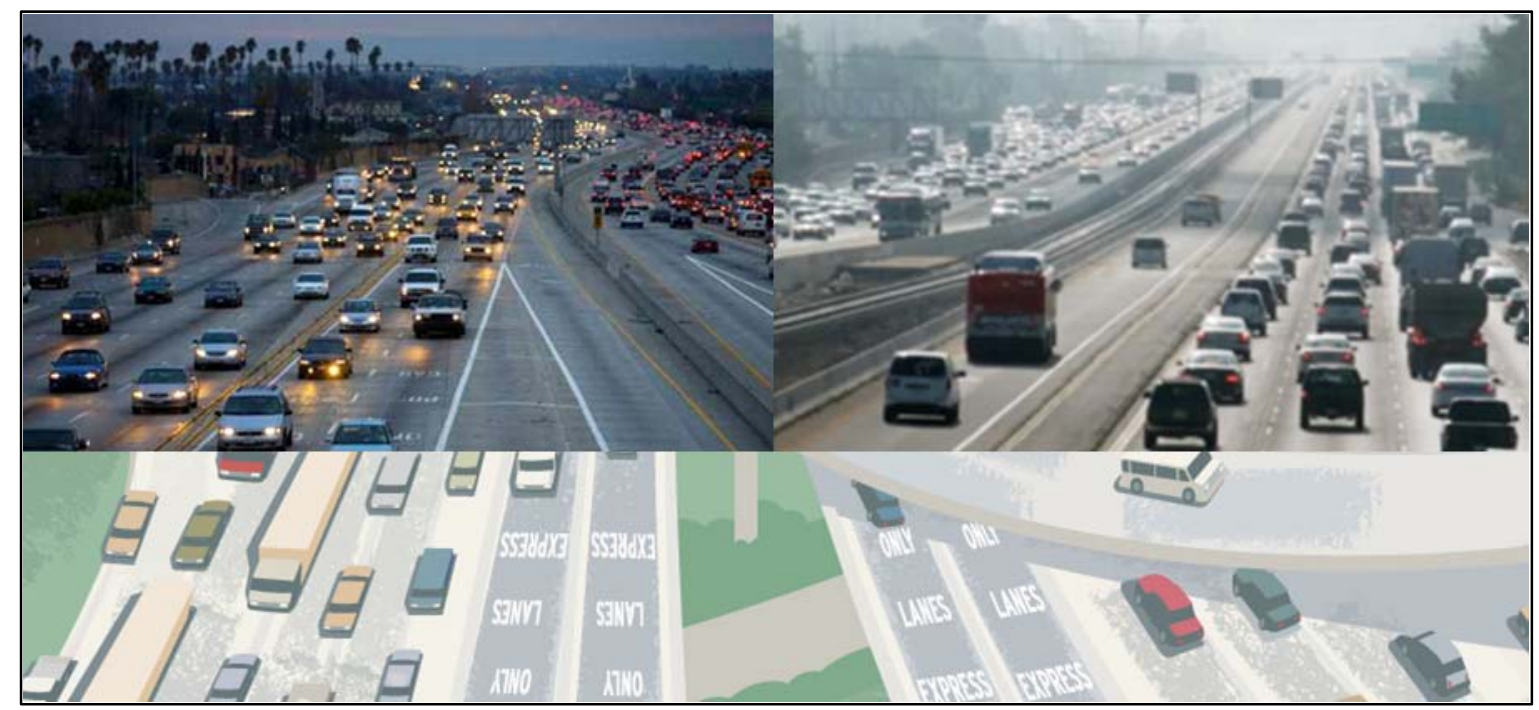

Source: top photos, Toll Roads News; bottom picture, LACMTA

Figure 3: I-110 HOV lanes (top left), I-10 HOV lane (top right), Simulated Metro Express Lanes (bottom)

Another unique element of the Los Angeles CRD project is the Toll Credit Program. Under this program, those with annual household incomes (family of three) below $\$ 35,000$ will be credited $\$ 25.00$ for setting up an account to use the Express Lanes. This credit may be used either as a transponder deposit or prepaid toll deposit. Additionally, the $\$ 3.00$ monthly maintenance fee for the Express Lanes account will be waived (29). A first of its kind in the state, the Toll Credit Program is a response to California Senate Bill 1422's requirement to promote initiatives that give equal opportunity to low income residents to access the Metro Express Lanes. Senate Bill 1422 authorized the Los Angeles CRD project along I-10 and I-110 in September 2008.

By utilizing the dynamic pricing strategy along the I-10 and I-110 corridors, local CRD partners aim to maintain the federally required $45 \mathrm{mph}$ minimum speed in the Metro Express Lanes. Technology that will determine HOT lane capacity and support the tolling process along the 
I-10 and I-110 Express Lanes is also expected to be installed in conjunction with the opening of the Metro Express Lanes. Caltrans oversees the first phase of these CRD HOT lane projects.

\section{Transit Improvement Projects}

Over half of the CRD federal funding for Los Angeles was allocated for transit improvements. Among the three main local CRD partners, LACMTA is responsible for the transit and ridesharing elements of the project, which include the expansion of the BRT system and commuter bus service, installation of transit traffic signal priority, improvement and expansion of transit facilities, and promotion of ridesharing programs.

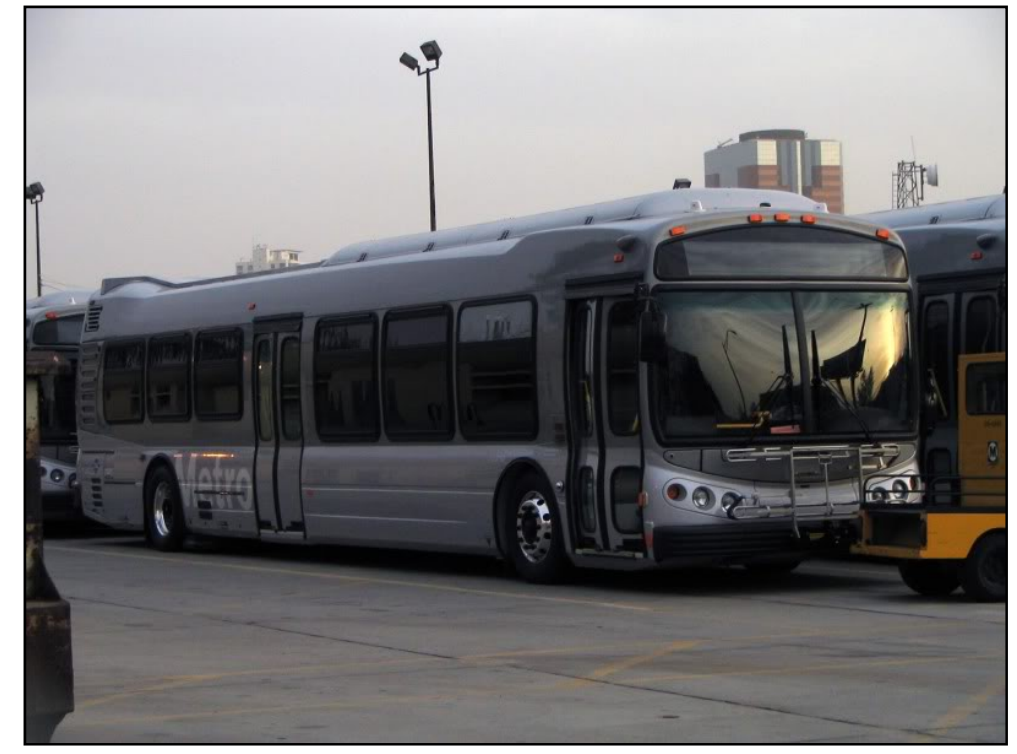

Source: Canadian Public Transit

Figure 4: New Los Angeles Metro Silver Line BRT Vehicle

With emissions reduction as one of its CRD goals, LACMTA ordered 41 new vehicles powered by compressed natural gas (CNG), which are both fuel-efficient and environmentally friendly, for the Silver Line BRT. These additional Silver Line vehicles, one of which is shown in Figure 4, will be operational in December 2011 ahead of the opening of the I-110 Express Lanes in October 2012. To ensure improved operating efficiency of the additional BRT vehicles, 19 bus priority signals will be installed by LADOT in downtown Los Angeles. The installment of this transit signal priority (TSP) technology is expected to be partially completed by February 2012. In addition to the BRT system expansion, local transit agencies such as Foothill Transit, Gardena Transit, and Torrance Transit will also increase their commuter service by ordering a total of 18 additional buses for their local routes. 
To provide an exceptional experience for commuters who will be using the additional BRT and commuter services along the I-10 and I-110 Express Lanes, expansion and improvement of transit facilities and park-and-ride stations were undertaken. In 2010, 143 new parking spaces, pedestrian access, and a platform extension were added to the Pomona Metrolink Station. In the same year, bus stop relocation and improvements in lighting and security commenced at eight park-and-ride lots along the Harbor Transitway. Also in 2010, construction of the new El Monte Transit Center, which includes a 30-bay bus terminal, began. The El Monte Transit Center, visualized in Figure 5, intends to support an increase in passenger capacity, preempting the effects of the bus system expansion and Express Lanes construction. It is scheduled to open in July 2012. Furthermore, an enhancement to the Patsaouras Plaza Connector to the El Monte Busway, which includes pedestrian improvements, and the I-110 Harbor Transitway Park enhancements are expected to be completed in 2011.

In addition to structural and technological transit improvements, local CRD partners in Los Angeles started to further promote ridesharing programs including vanpools. Recent data provided by the LACMTA Research and Development Department indicate that there are 49 and 74 vanpools registered for the I-10 and I-110 freeways, respectively (29). In 2010, local CRD partners started activities to support the formation of 100 new vanpools.

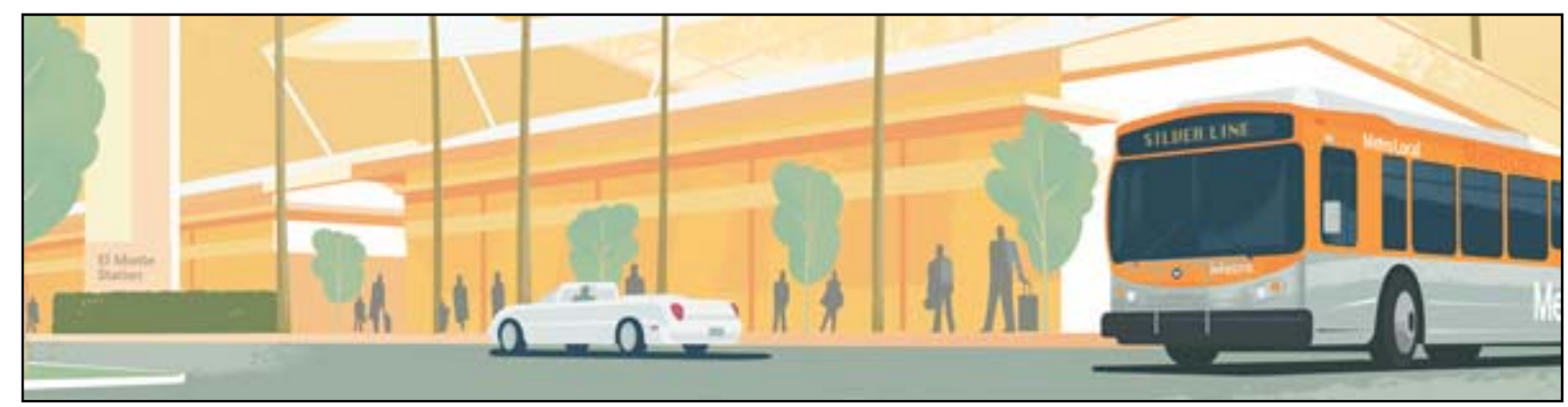

Source: LACMTA

Figure 5: Simulated Image of the Proposed El Monte Transit Center

\section{Intelligent Parking Management (IPM) System}

Among the six UPA and CRD sites, only the California cities, Los Angeles and San Francisco, adopted an intelligent parking management system as part of their congestion management strategy. LADOT is in charge of the planning, implementation, and maintenance of the Intelligent Parking Management (IPM) component of the CRD project. The Los Angeles IPM program has been branded as ExpressPark, which bases parking prices on the demand for parking spaces during certain hours. Parking prices are expected to be higher during peak 
hours and lower during off-peak hours. Alameda Street and Adams Boulevard, enclosed by the I-10 and I-110 freeways, will be the launching area of the one-year pilot program. A total of 5,500 on-street metered spaces and 7,500 off-street public parking spaces along these corridors will be impacted by the pilot program (30).

This parking initiative aims to increase the availability of on-street parking by 10 to 30 percent per block, reduce the amount of time that drivers spend looking for open parking spaces, curb pollution, improve flow of traffic for both transit and private vehicles, and encourage a "shift in personal travel choices" to alternative commute methods (29). The pilot program will be launched in April 2012. Visible in the ExpressPark project areas are updated meters, vehicle sensors and electronic signage that support the operations of the variably-priced parking system or IPM.

The dynamic message sign shown in Figure 6 reflects the number of available on-street parking spaces on Market/San Pedro Street and $3^{\text {rd }}$ Street. Other real-time parking information will also be provided online through the ExpressPark website and through mobile phone applications. The LADOT Parking Management Center provides real-time parking information for all parking areas involved in the pilot program and administers the parking management system, which makes variable parking pricing possible by analyzing on-site parking data.

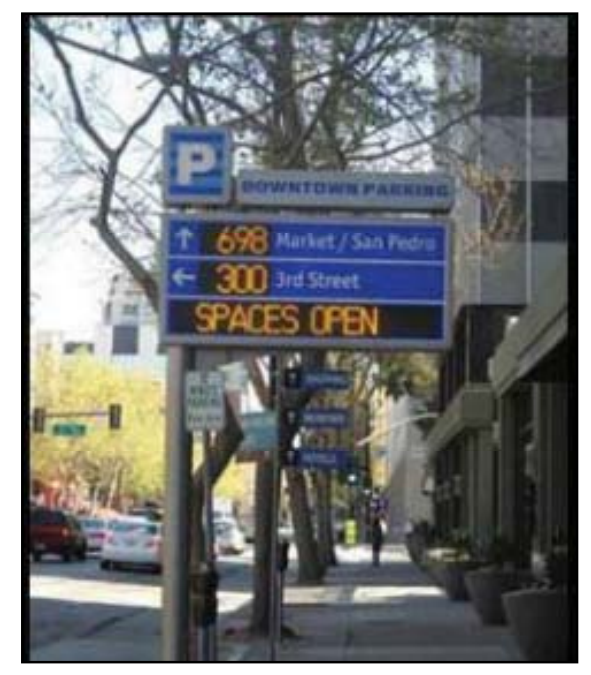

Source: $L A D O T$

Figure 6: Downtown L.A. Parking Dynamic Message Signs

While the main components of the Los Angeles CRD project are not yet fully functional, necessary equipment and technology that will support the Metro Express Lanes, expanded Silver Line BRT, and ExpressPark operations are mostly available. Because the construction of the Metro Express Lanes is still ongoing, studies or reports that discuss the effects of the I-10 and I-110 express lanes to travelers are not yet developed. However, based on recent data on the I-10 and I-110 HOV time savings, it may be assumed that conversion of HOV lanes to HOT lanes would save travelers more time. According to the 2007 HOV Annual Report, time savings of HOV travelers along I-10 and I-110 corridors are 46 percent and 53 percent, respectively (31). With the creation of a second HOT lane along I-10 and road widening projects along I-110, it is 
expected that the percentage of time HOT lane travelers would save will increase as there would be more freeway space during peak hours.

\section{San Francisco}

In contrast to other UPA and CRD sites, San Francisco's UPA program focuses solely on parking management instead of roadway or lane management as a congestion pricing strategy. Note that Los Angeles also utilizes parking management as a congestion pricing strategy but has done so in combination with lane management. San Francisco was awarded a \$158.7 million federal grant by USDOT to finance projects that aim to reduce both congestion and greenhouse gas emissions in the region (32). The San Francisco Municipal Transportation Agency (SFMTA), San Francisco County Transportation

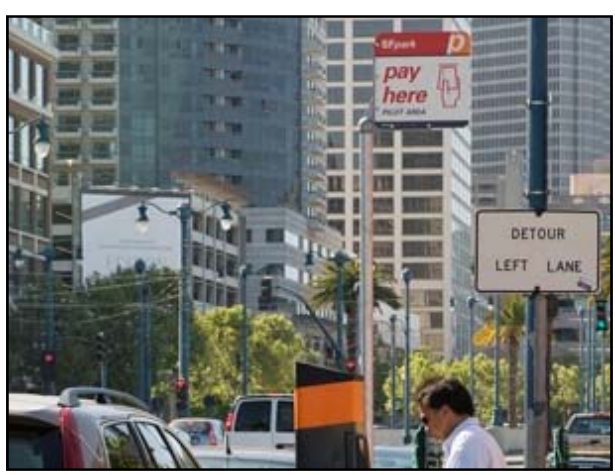

Source: SFMTA

Figure 7: Parking Meter in San Francisco Authority (SFCTA), and Metropolitan Transportation Commission (MTC) partnered with USDOT and other local San Francisco agencies to supervise the various components of the project. The two main components of the San Francisco UPA are its intelligent parking management system and a real-time parking and traffic information system.

\section{Intelligent Parking Management (IPM) System}

San Francisco branded its IPM system as SFpark. SFMTA began the installation of IPM technology such as new parking meters and parking sensors in summer 2010, ensuring that the technology needed to operate the SFpark system was ready before April 2011 when the pilot program was launched. An example of a parking meter in San Francisco is shown in Figure 7. The pilot program provides variably priced parking in 15 garages with 12,250 parking spaces and 6,000 on-street parking spaces around the specified pilot program area in San Francisco (33). An evaluation of the program will be made in mid-2012 before implementing the SFpark system city-wide.

Parking prices in SFpark parking garages are predetermined based on the time of the day. Prices during peak hours are higher as parking demand is expected to increase during these hours. In contrast to HOT lane tolling fees, SFpark garage fees do not change dynamically every 15 minutes or so based on current demand. Instead, garage fees are adjusted quarterly based on 
the demand for a particular parking area within a certain time period. Price changes will be posted on the SFpark website one week prior to implementation of the new parking prices. It is important to note, however, that parking fees for cars vary from motorcycles and that there is no uniformity in the prices employed in different SFpark locations. Most on-street or metered parking, for instance, assesses parking fees based on the level of demand, similar to the HOT lanes. Hourly parking rates goes up by $\$ 0.25$ when the parking occupancy is approximately 80 percent to 100 percent and the rate goes down by $\$ 0.50$ when occupancy is below 30 percent (33).

Drivers can use cash, credit, and debit cards to pay for SFpark fees. As a result of collaboration between SFMTA and MTC, Translink cards, originally used to pay for transit payments, can also be applied for SFpark parking payments. One problem, however, is the separation of pretax transit benefits loaded in the Translink cards when it used as a payment for parking (32). Nonetheless, the Translink Parking Payment offers convenience for individuals who both use the SFpark garages and the transit system consistently.

Early bird and off-peak discounts are also given to individuals who park in SFpark lots prior to peak hours (before 7:30 a.m.) and leave during off-peak hours (after 7:00 p.m.). Such discounts are implemented by the local UPA partners to encourage drivers to use the streets during offpeak hours, freeing more road space during rush hour for both transit and private vehicles. In addition to discounts, real-time parking information is also expected to lessen the driving time of drivers who are looking for parking spaces and possibly persuade drivers to use transit because the filled parking spaces or expensive parking fees might discourage them from driving, thus accomplishing the program's goal of influencing the travel behavior of drivers (32). Although there are no published studies regarding the actual effects of the pricing congestion strategy employed by San Francisco as the SFpark system has just recently launched, a December 2010 SFCTA Mobility, Accessibility and Pricing Study suggests that individuals are optimistic about the effects of congestion pricing. The study reveals that 40 percent of the respondents believe that a potential congestion charging or tolling program would lessen congestion, while 24 percent believe that the program will increase transit speed and frequency (34). Real-time information on parking occupancy and parking fees are available online through the SFpark and 511 websites, by phone through Android and iPhone applications and text alerts, and also through the electronic message boards installed along major roadways around San Francisco. 


\section{Real-Time Parking and Traffic Information System}

Under the UPA, local partners are required to upgrade San Francisco's 511 traffic information system. The MTC leads the enhancement initiatives for the regional 511 system, which offers real-time traffic and parking information as well as multi-modal information to San Francisco drivers and commuters. The system is available online through the 511 website and by phone, through phone applications, and the 511 hotline. Figure 8 illustrates an SFpark phone application.

The 511 system also promotes alternative commute programs, providing information on commuter tax benefits, carpooling and vanpooling. The 511 website offers a link to the

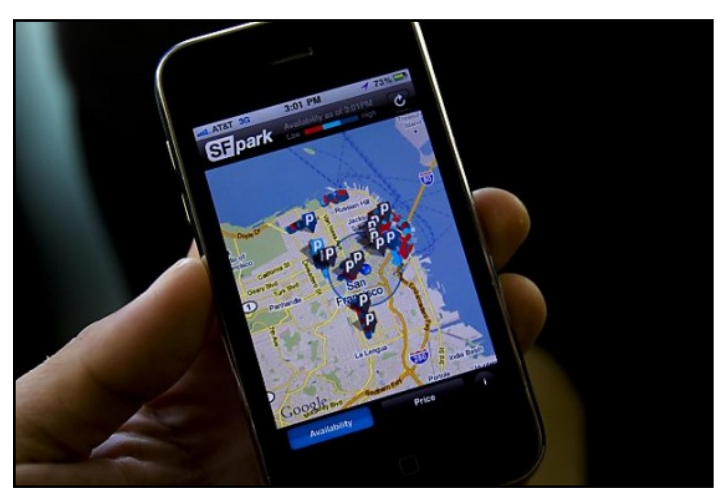

Source: SFpark.org

Figure 8: SFpark Phone Application Rideshare program wherein individuals can find carpooling or vanpooling partners. Furthermore, SFCTA is collaborating with San Francisco's Department of Environment to promote telecommuting in the Bay area. Expansion of similar travel demand management (TDM) initiatives is planned during 2011.

Other projects included in the San Francisco UPA are the following: (1) reconstruction of Doyle Drive, which serves as the southern access to the Golden Gate Bridge, (2) SFCTA's coordination of informational activities promoting HOV-to-HOT lane conversion in San Francisco, (3) improvement to the Marin-San Francisco Ferry, (4) improvements to travel forecasting in Oakland, and (5) construction of a vehicle infrastructure integration (VII) test for a HOT lane tolling application facilitated by the MTC (32). Revenue from the San Francisco UPA project will be added to the Doyle Drive Replacement Project Fund, which is expected to be completed by 2014 .

\section{Seattle (Lake Washington)}

Seattle received a \$154.5 million federal grant for the UPA program. Three local UPA partners are leading each of the three main components of Seattle's UPA project. The Washington Department of Transportation (WSDOT) takes responsibility over the SR-520 tolling system, including the installation of active traffic management technology. On the other hand, King 
County and the Puget Sound Regional Council (PSRC) are in charge of the transit improvement projects and TDM projects, respectively. The UPA strategies adopted by Seattle are designed to reduce congestion by enhancing transit amenities that encourage bus ridership, promoting alternative commute methods, and providing safer highways that limit collision-related congestion.

\section{SR-520 tolling system}

Seattle proposes to toll SR-520, shown in Figure 9, between I-5 and I-405. The SR520 tolling system, unlike the dynamic pricing used by HOT lane tolls, determines the toll fee based on the time of the day; tolls are set higher during peak hours. Although the toll exemption rule is not yet final as of the writing of this report, local UPA partners proposed to set the HOV requirement to three. This would allow carpools with three or more persons to drive on the bridge for free. Motorcycles, however,

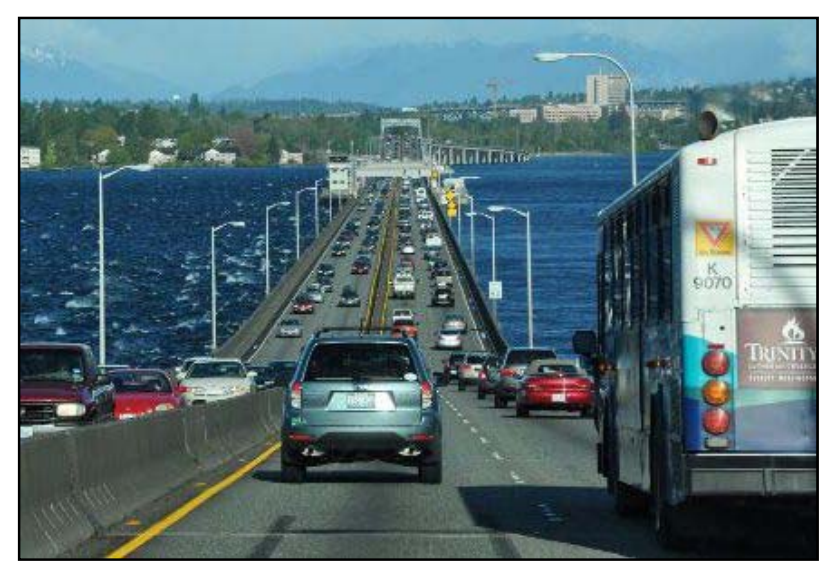

Source: WSDOT

Figure 9: SR-520 Bridge in Seattle are not included in the toll exemption while multi-axle vehicles pay a higher, pro-rated toll rate.

Similar to the HOT lane tolling systems in other UPA and CRD cities, tolling along SR-520 will be done electronically in both directions of the bridge, eliminating the need for toll booths. In contrast to other UPA and CRD sites, however, Seattle allows cars that do not have "Good To Go!" passes to use the SR-520 Bridge. Registered owners of vehicles with no "Good To Go!" passes will receive a bill by mail whenever they use the bridge. Other UPA and CRD sites require a tolling account and a transponder or a toll pass to use the HOT lanes or tolled highway. Another unique feature of Seattle's tolling strategy is its scheme to toll all vehicles that use the bridge, excluding the aforementioned exceptions. The toll fee is set at $\$ 3.50$ each way during peak hours and is lower during off-peak hours (35).

The revenue of the proposed SR-520 tolling system will be directed to the SR-520 Bridge Replacement Project. According to the 2006 Washington State Transportation Commission, 74 percent of the public support the SR-520 tolling program to pay for the bridge's replacement (35). The SR-520 tolling system is scheduled to open in December 2011. 


\section{Transit Improvement Projects}

The 2007 Urban Mobility Report suggests that the steady number of eastbound trips in Seattle between 2005 and 2007 is related to the increase of bus ridership in eastbound services during the same period (36). This report shows the optimism of Seattle residents towards riding buses. Local UPA partners understand the importance of improving the transit system service along the SR-520 Bridge in reducing congestion in the corridor. Thus, the partners have adopted a transit improvement strategy, which includes transit-oriented development (TOD), as a means to encourage ridership.

To support the anticipated increase in bus ridership generated by the UPA projects, King County Metro and Sound Transit purchased 45 new hybrid-electric diesel buses for use in the SR-520 corridor. These new buses will be utilized in the expansion of current King County bus services by increasing the daily number of trips along SR-520 from 600 trips to 730 trips. New bus services have been added between Redmond and the University District, and in 2010, the daily number of trips along these two routes increased. Furthermore, the UPA projects also include transit infrastructure enhancements that support bus service expansion and sustain an increase in passenger capacity. In 2009, a parking garage was added to the Redmond Transit Center. Meanwhile, construction of the South Kirkland park-and-ride lot is expected to be completed in 2014. Improvements in bus stops and freeway stations along SR-520 will also be made. These improvements in transit facilities are intended to improve the service quality for current bus riders and hopefully attract new transit riders (35).

Beyond the usual bus service and bus facility enhancement strategies implemented by other UPA and CRD sites (excluding San Francisco), Seattle introduced the use of Active Traffic Management (ATM), or what is also known as Smarter Highways technology. WSDOT installed ATM technology along the SR-520 and I-90 corridors. Electronic message signs will be installed in 19 locations between I-5 and 130 ${ }^{\text {th }}$ Avenue NE in Bellevue along the SR-520 corridor. The electronic signs dynamically display the speed limit based on the congestion level in each of the locations. In addition, the signs also direct drivers to better routes, ensuring a smooth flow of traffic. The signs do not only provide real-time traffic information to drivers but also aim to reduce the occurrence of collision-related congestion. Smarter Highways, visualized in Figure 10 on the following page, started its operations along some parts of SR-520 in November 2010. 


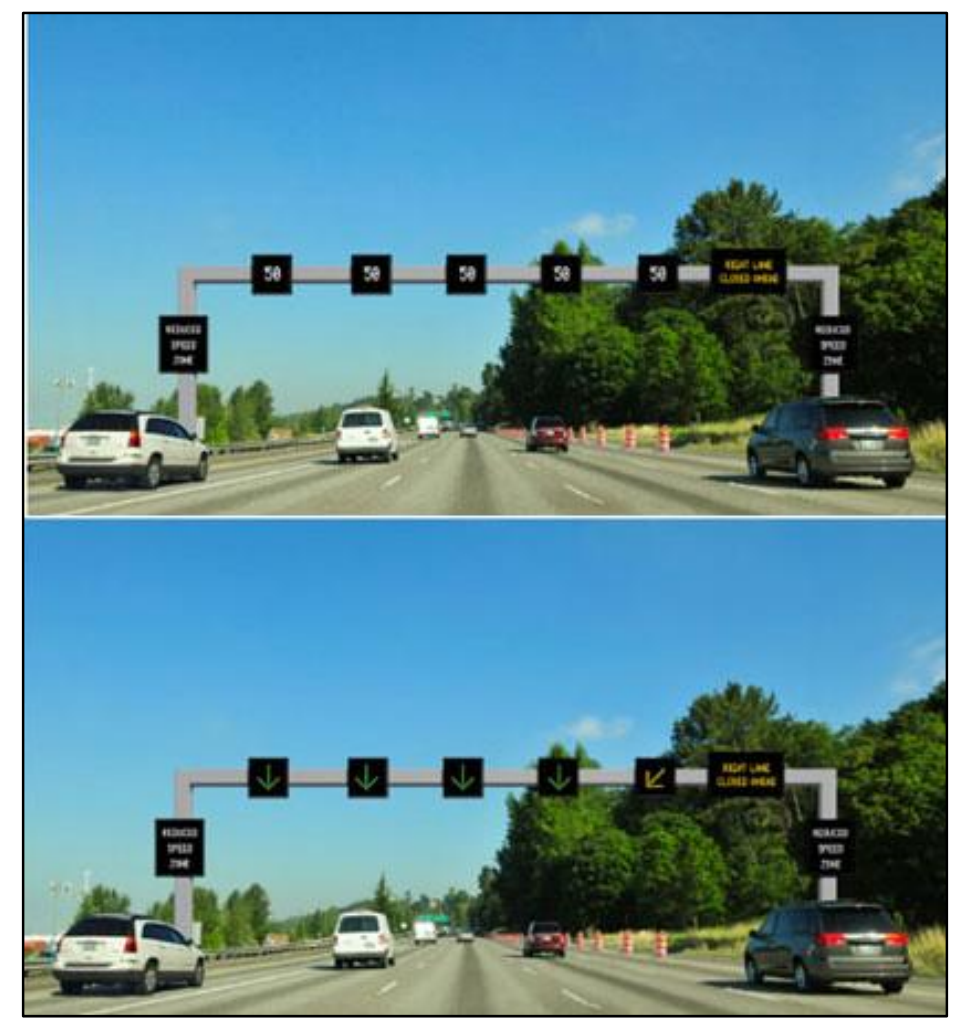

Source: WSDOT

Figure 10: Visualization of Seattle Active Traffic Management (ATM) Signs:

Smarter Highways

\section{Travel Demand Management (TDM)}

Local UPA partners are proactive in implementing both telecommuting and alternative commute programs. The Commute Trip Reduction (CTR) law in the state of Washington, for example, allows individuals to have a flexible schedule if they live in a county with a population of 150,000 or more and work for an employer or at a major worksite that has 100 workers who are arriving at work between 6:00 a.m. and 9:00 a.m. Carpooling and vanpooling are also widely promoted through the RideshareOnline.com website, which was launched in March 2010. With more than 14,000 registered individuals participating, the website provides individuals a better chance to find carpooling or vanpooling partners. Other TDM programs administered by local UPA partners include the Downtown Seattle e-park and King County Telework Outreach programs.

Like other UPA sites, Seattle has utilized the four congestion reduction strategies: Tolling, Transit, Technology and Telecommuting/Travel Demand Management. What separates Seattle 
from other UPA and CRD sites, however, are policy differences such as the exclusion of preregistration to use the SR-520 tolling system and Washington State's CTR law.

\section{Minnesota - St. Paul}

Congestion pricing, as promoted by the UPA program, is not a new concept to Minnesota. In May 2005, an 11-mile HOT lane along I-394 West in Minnesota began operations. It was the first HOV-to-HOT lane conversion in Minnesota and was called the MnPass Lane. A 2005 MnPass study confirms the success of the MnPass Lanes in reducing congestion but warns that the revenue from this tolling system will not sufficiently cover the costs of HOV-to-HOT lanes construction. Nonetheless, both MnPass users and non-users thought positively of the I-394 MnPass Lane, and extension of the HOT lanes has been entertained (37). In August 2007, Minnesota was announced as one of the five recipients of USDOT's UPA grant. For the UPA program, Minnesota received a \$133 million federal grant from USDOT and an additional \$50.2 million from the Minnesota State Legislature (38). The UPA grant allowed Minnesota to create a network of HOT lanes, which applies congestion pricing as a means to ease congestion along I-35 West. Even before the implementation of the HOT lanes along the corridor, existing MnPass users already approved of tolling I-35 West. A customer satisfaction survey administered by MnPass reveals that 73 percent of MnPass users are either extremely supportive or very supportive of extending MnPass Lanes to I-35 West (39).

Minnesota Department of Transportation (MDOT) oversees the overall planning and implementation of the UPA program. The three main components of the Minnesota UPA are HOV-to-HOT lane conversion, transit improvement projects, and TDM strategies.

\section{Conversion of HOV Lanes to HOT Lanes}

A major component of the Minnesota UPA includes HOV-to-HOT lane conversion, new HOT lane construction, and the conversion of narrow bus-only shoulder lanes to wider Priced Dynamic Shoulder Lanes (PDSLs). In contrast to other UPA and CRD sites, Minnesota implements congestion pricing for both HOT lanes and PDSLs. The combination of PDSLs and HOT lanes widens the network of managed lanes in Minnesota which, then, allows the city to efficiently reduce congestion on more major highways and increase time savings for more drivers and commuters.

What is the difference between HOT lanes and a PDSLs tolling system? Both types of lanes utilize dynamic pricing whereby vehicles using the lane have to pay a toll that changes based on 
the congestion level along the corridor. The main difference, however, is that HOT lanes are open to traffic at all times while PDSLs are not. During off-peak hours, PDSLs revert to busonly shoulder lanes.

Local UPA partners proposed an HOV-to-HOT lane conversion along I-35 West from Burnsville Parkway to I-494, while new HOT lanes will be added on I-35 from 1-494 to $46^{\text {th }}$ Street. HOT lanes are available to traffic at all times but it is important to note that dynamic pricing will only be implemented during peak hours: 6:00 a.m. to 10:00 a.m. in the northbound direction and 2:00 p.m. to 7:00 p.m. in the southbound direction. Similarly, dynamic pricing will also be implemented in PDSLs during peak hours but, unlike the HOT lanes, during off-peak hours the PDSLs are closed to regular traffic and are exclusively dedicated to bus services. Such an approach ensures the steady flow of traffic along PDSLs, especially that of buses. Local UPA partners estimate that PDSLs will allow bus speeds to increase from $35 \mathrm{mph}$ or less in the current narrow bus-only shoulder lanes to $50 \mathrm{mph}$. Conversion of bus-only shoulder lanes to PDSLs will be made along I-35 West from $46^{\text {th }}$ Street to downtown Minneapolis. A 15-mile corridor of dynamically-priced, managed lanes will be the result of the converted and new HOT lanes and PDSLs. However, this is just a minimal feat compared to the larger plan of Minnesota to complete 260 miles of PDSLs, which highly depends on budget and legislative actions (37).

To use both HOT lanes and PDSLs, vehicles are required to pre-register and must hold a MnPass. Since the local UPA partners set the HOV requirement to two, carpools with two persons or more are allowed to use the HOT lanes and PDSLs for free. Other vehicles exempt from paying the toll are vanpools, buses, and motorcycles. The toll exemption encourages participants of alternative commuting methods to use the managed lanes frequently. According to the Minnesota: Innovative Choices for Congestion Relief Annual Report, in 2010, the number of toll-exempt vehicles in the lanes during morning peak hours has reached approximately 2,100 (40). The I-35 West HOT lanes and PDSLs were opened to the public in September 2009 while the newly constructed HOT lanes along I-35 were operational in November 2010. The Annual Report also states that the I-35 West MnPass Lanes recorded an increase in revenue, from $\$ 19,609$ in October 2009 to $\$ 54,541$ in November 2010 (40). Such a change represents the positive response of drivers and commuters toward the dynamically-priced managed lanes.

Similar to the Smarter Highways of Seattle, Minneapolis also has an active traffic management (ATM) system referred to as Smart Lanes, shown in Figure 11 on the following page. Smart Lanes utilize electronic signs, which are installed every half-mile, to provide drivers along I-35 West better driving options and to reduce the occurrence of auto accidents. 


\section{Transit Improvement Projects}

Arguably, among all UPA and CRD sites, Minnesota employs the most comprehensive strategy to increase bus speeds and thus encourage bus ridership by providing transit at a speed and safety advantage over regular vehicles. One aspect of this strategy is that local UPA partners allow transit on special runningways such as contraflow lanes and bus-only shoulder

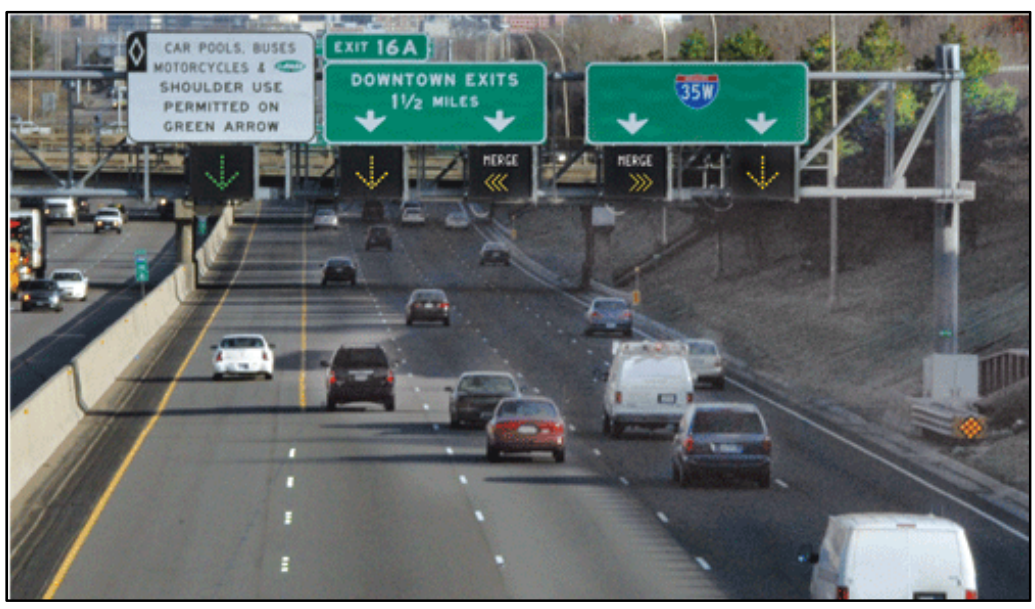

Source: $M n D O T$

Figure 11: Smart Lanes along I-35W in Minnesota lanes. Double contraflow lanes were added on Marquette and $2^{\text {nd }}$ Avenues (MARQ2 lanes) in Minneapolis, which opened to buses operating on that route in December 2009. MARQ2 lanes saved buses up to 10 minutes during morning and afternoon peak periods (38). Moreover, a bus bypass lane that allows buses to make a left turn from Highway 77 to Highway 62 was added at this intersection. This bypass lane has been referred to as a "Transit Advantage" Bus Bypass Lane which, according to the Minnesota Annual Report, saves buses 60 to 90 seconds during morning peak hours(40). Furthermore, transit signal priority (TSP) technology was added on Cedar Avenue in Minneapolis, Columbia Heights, and Roseville to provide smoother traffic flow for bus services. To ensure the safety of bus riders, a lane guidance system was also added along Cedar Avenue.

To provide convenience to transit passengers and to further promote bus ridership, park-andride facilities together with transit stations have been expanded and enhanced. Six park-andride facilities with a total of 2,347 parking spaces were added under the UPA project: three along the I-35 West corridor and three along Cedar Avenue in Minneapolis. In addition, realtime traffic and transit information along the I-35 West corridor is also available through dynamic message signs in park-and-ride lots and transit stations.

To support the anticipated increase in transit demand, the local UPA partners ordered 27 new buses which are a mix of standard, hybrid, and coach buses. In September 2009, two new Metro Transit express routes were added: (1) Lakeville park-and-ride lot to downtown Minneapolis and (2) $95^{\text {th }}$ North park-and-ride lot to the University of Minnesota, which is illustrated in 
Figure 12. Routes will also be added for a BRT system along I-35 West and Cedar Avenue, which is currently undergoing construction.

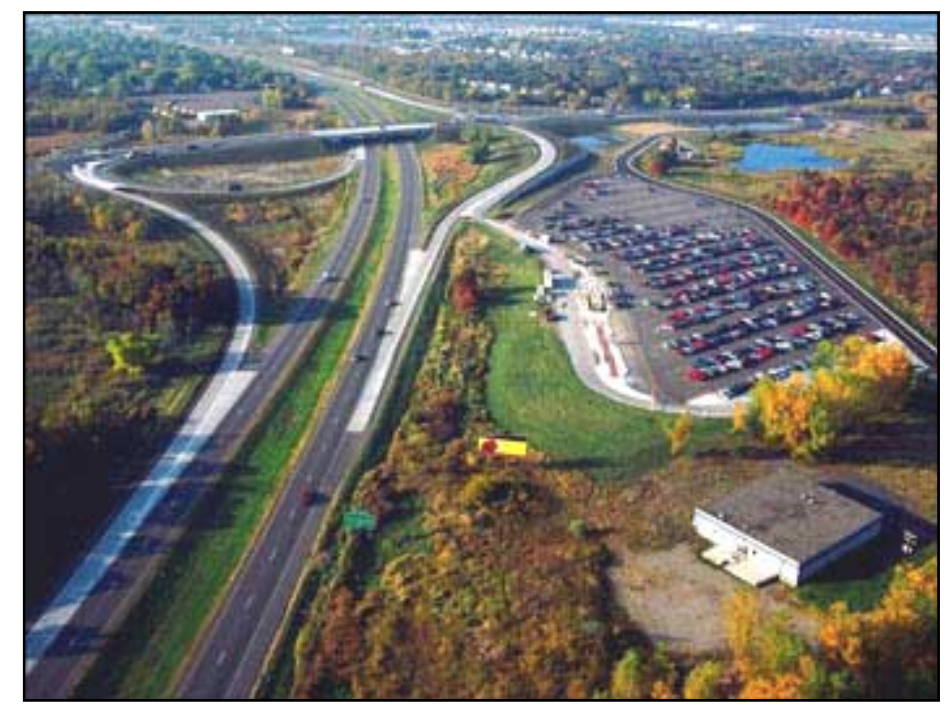

Source: Metro Council

Figure 12: $9^{\text {th }}$ Street Park-and-Ride Lot along I-35W

\section{Travel Demand Management (TDM)}

Under the UPA, local partners agreed to promote telecommuting to businesses located within the region. Minnesota's TDM program employs "Results Only Work Environment" (ROWE) employer-based techniques, telework, and flexible work arrangements. Best Buy headquarters in downtown Minnesota is actively involved in the program, with 75 percent of its 4,500 corporate office employees participating in telecommuting. Minnesota branded its TDM program as eWorkPlace and aims to convince Fortune 500 and Fortune 1000 companies within the region to participate.

The strategies employed by the Minnesota UPA model could be a basis for other cities that are planning to develop congestion management strategies. As mentioned previously, based on the 2011 Minneapolis UPA Annual Report, the "transit advantage" strategy employed by Minnesota has saved time for buses and bus passengers. Time savings was also the reason cited by most of the current MnPass holders for using the I-394 Express Lanes toll road, which was the predecessor of the I-35 West HOT lanes and PDSLs. The MnPass Customer Satisfaction Results showed that 63 percent of MnPass holders use the I-394 Express Lanes to save time (39). Hence, MnPass users are optimistic about the extension of MnPass Lanes to I-35 West. The increase in the number of toll-exempt vehicles using the I-35 West HOT lanes and PDSLs, as 
mentioned previously, could be attributed to the efficiency of the originally tolled lanes such as the I-394 Express Lanes.

\section{Miami}

The Miami UPA is being implemented by the Florida Department of Transportation (FDOT) with support from Florida's Turnpike Enterprise, Miami-Dade Transit, Broward County Transit and South Florida Commuter Services. The 95 Express employs the "Four T's" through HOVto-HOT lane conversion utilizing a variable toll/congestion pricing strategy, the promotion of BRT and carpooling, the introduction of ramp metering, rapid incident detection, and other enhanced operational management strategies. The 95 Express is the first congestion pricing project in Florida with variable tolls using dynamic pricing. Miami, of all the UPA and CRD sites, received the least amount of federal grant. The City only received $\$ 62$ million from the USDOT UPA grant, of which $\$ 19.5$ million is for transit. To finance Phase 1 of the UPA project, the Florida Legislature contributed \$35 million (41). The dynamically priced HOT lanes in Miami are, as discussed in this report, also known as the 95 Express Lanes. The Miami UPA includes HOV-to-HOT lanes conversion and transit improvement projects.

\section{Conversion of HOV Lanes to HOT Lanes}

Similar to other UPA and CRD sites, Miami HOT lanes are dynamically priced. Tolls are adjusted every 15 minutes depending on the demand for the 95 Express Lanes. FDOT uses "Express Lane Manager" software to collect real-time traffic data from the Express Lanes which helps determine the changes in toll prices. To better inform drivers of the changing toll prices and to further maintain the consistent speed along the Express Lanes, 26 dynamic message signs, showing lane status and toll fee, have been installed along I-95. Vehicles need to register for a SunPass account and purchase a SunPass transponder to be able to use the 95 Express Lanes.

Phase 1 of the 95 Express converted a single HOV lane into two express lanes while maintaining the same number of general purpose lanes and without widening the corridor. The entire facility was re-configured and re-striped to allow room for the additional lane within the existing right-of-way. Phase 1 consists of two-lane, delineator separated, 7.3 mile segments of I95, both northbound and southbound, between State Road (SR) 836/I-395 and the Golden Glades interchange in Miami-Dade County. Phase 1A represents the northbound portion of the facility and was implemented in February 2008 with electronic tolling beginning in December 
2008. Phase 1B began in summer 2008 and comprises the southbound portion of the facility. Electronic tolling on Phase 1B was begun in January 2010 (42). Phase 2 of the 95 Express project is currently in the design phase and will extend the express lanes from the Golden Glades Interchange (GGI) approximately 14 miles north to Broward Boulevard in Broward County. Figure 13 depicts a map of the 95 Express.

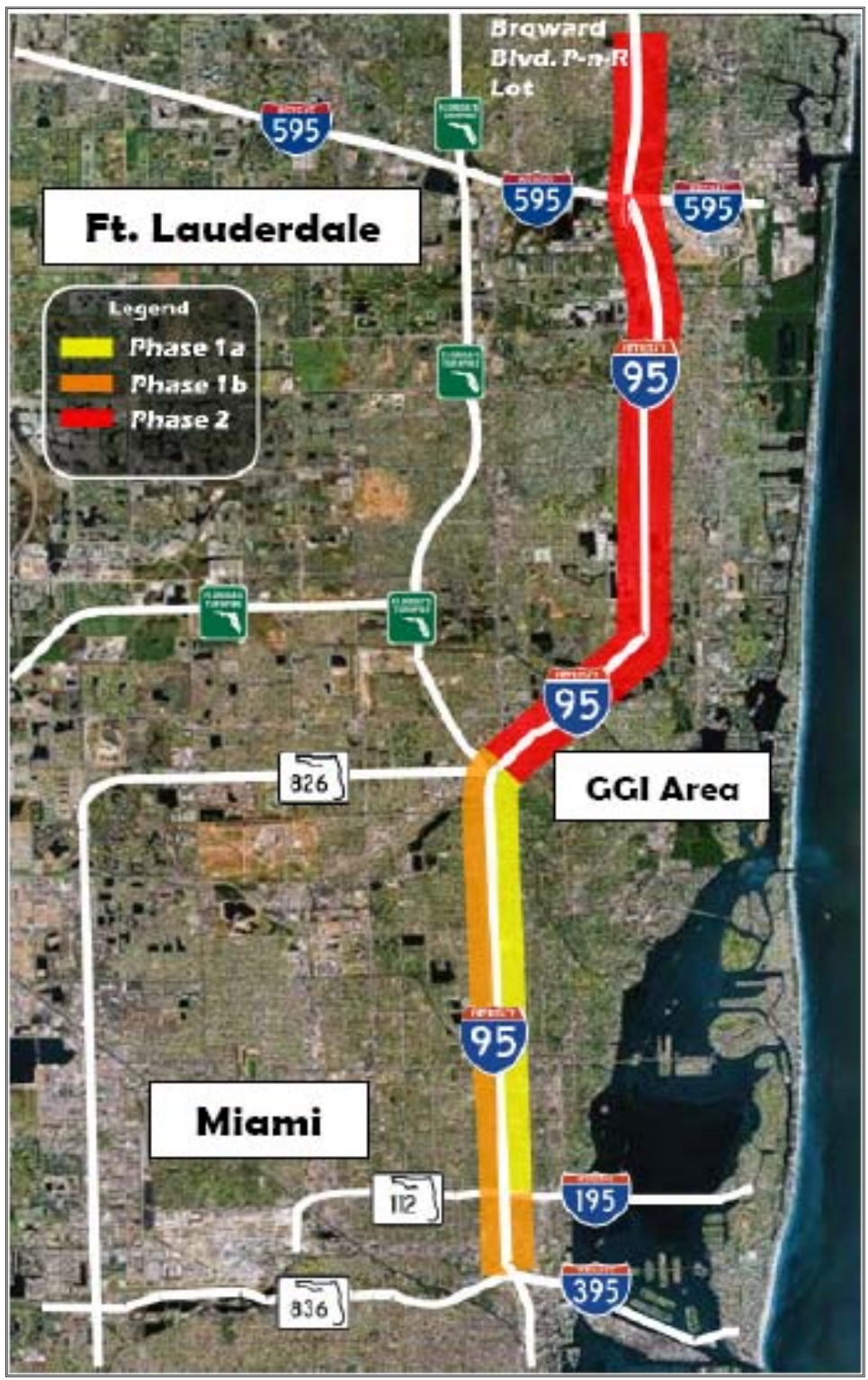

Source: FDOT

Figure 13: South Florida I-95 Express Lanes Project 
Miami UPA partners set the HOV requirement to three, which means that carpools with three or more persons can use the 95 Express Lanes for free. Other vehicle types that may use the Express Lanes toll-free are hybrids, school transit, public transit, and over-the-road coaches. Trucks with three or more axles are not permitted to use the Express Lanes. The toll exemptions are an incentive for drivers to participate in alternative commute programs that will reduce congestion and emissions.

Drivers can choose to use the express lanes with tolls that vary with the level of congestion. The goal is to keep the express lanes moving at a minimum of $45 \mathrm{mph}$ while also maximizing the person throughput along the entire facility. Toll rates are based on traffic conditions in the express lanes only, and not on the general purpose lanes. Continuous information on how many vehicles are in the express lanes, how fast they are moving, and how close together they are is collected and used to determine whether tolls should be increased or decreased to provide the optimal conditions. Dynamic pricing indicates that, as the express lanes become more congested, the toll rates rise, while as the congestion in the express lanes falls, toll rates decrease (43).

Higher tolls are meant to discourage drivers from entering the express lanes because they indicate that the facility is experiencing increased demand (congestion) and possibly slower speeds. However, an interesting phenomenon occurred during the earlier stages of implementation, as some drivers interpreted the higher tolls to mean that they would be able to move faster, and so they were more likely to enter the facility when the toll was relatively higher It was necessary for FDOT to put significant effort into public information campaigns to educate the public on how the congestion pricing works and to correct this misperception. Figures 14 and 15, on the following page, depict photographs of the 95 Express facility; both views are northbound. 


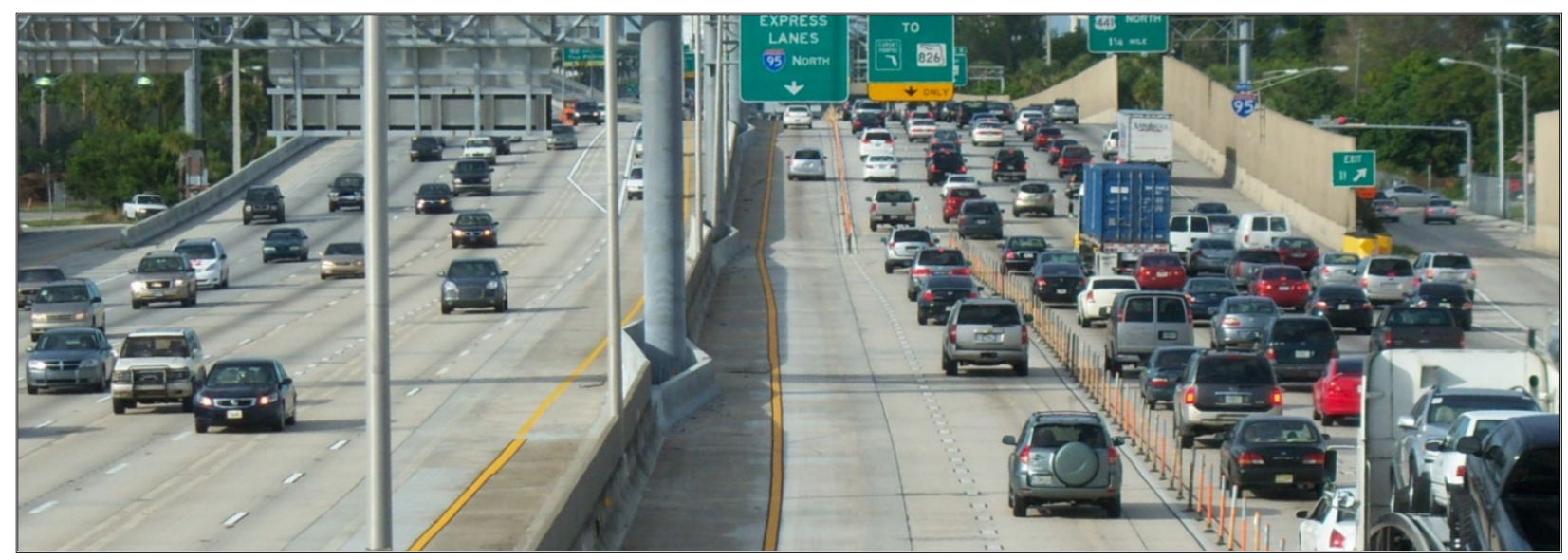

Source: FDOT

Figure 14: 95 Express Facility (Northbound)

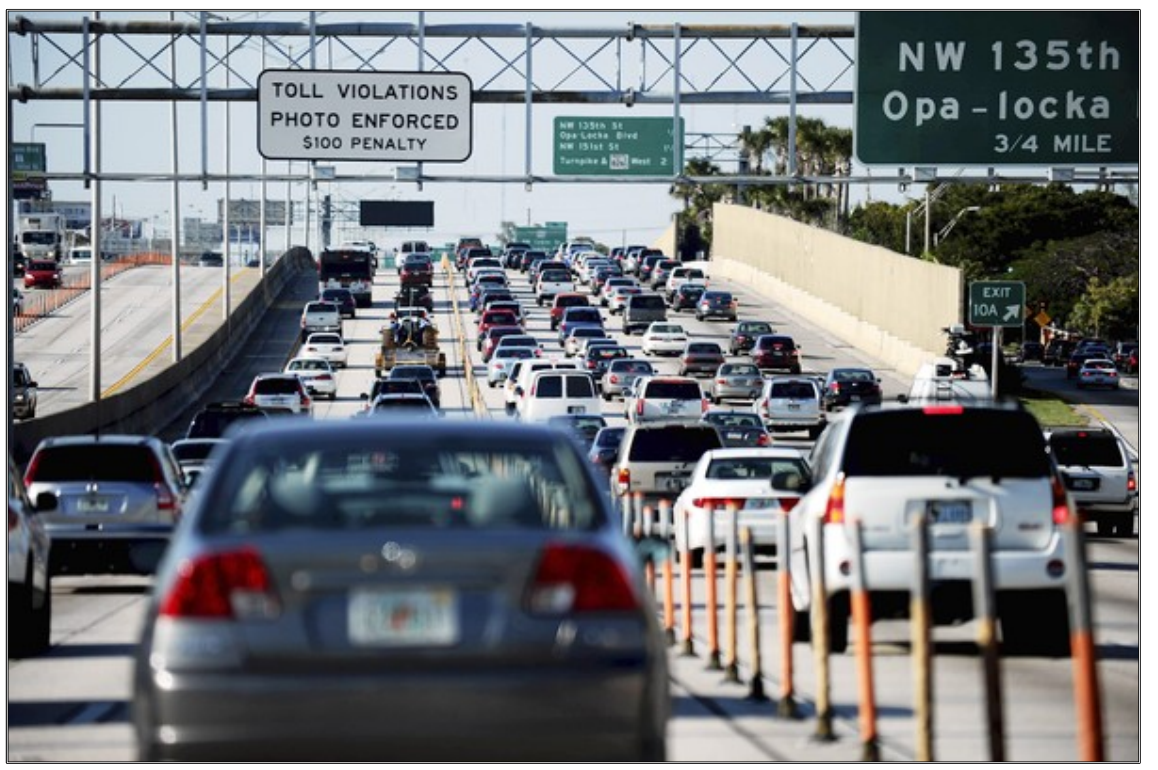

Source: FDOT

Figure 15: 95 Express Facility (Northbound)

The tolls have brought in $\$ 24.4$ million in revenue to FDOT as of January 2011, and the tolls currently fund 20 percent of the operating expenses for the 95 Express Bus service (41). This, however, does not take away the fact that the HOV-to-HOT lane conversion has significantly improved the traffic conditions along the corridor. FDOT reports that all users of I-95 are benefitting from the major performance improvements along the 95 Express corridor. Prior to the implementation of the 95 Express, the general purpose lanes, as well as the single HOV lane, were operating at below 20 miles per hour during the peak periods. Since the Express Lanes 
opened, speeds have improved to more than 40 miles per hour in the general purpose lanes and 50 miles per hour in the Express Lanes, in both directions during the peak periods. The Federal goal for express lanes (HOV-to-HOT lane conversion) is to operate at maintained speeds of at least 45 miles per hour 90 percent of the time; the 95 Express project has exceeded this goal.

In October 2010, as part of the Miami UPA evaluation for USDOT, FDOT conducted its own web-based survey (separate from this NCTR research project) of I-95 commuters on the performance of the 95 Express Lanes (42). The survey link was emailed to SunPass holders, members of a South Florida Commuter Services database, and some area employers. It was found that the top three reasons the 95 Express Lanes are used are: (1) they save time, (2) they are faster than the general purpose lanes, and (3) the Express Lanes are less crowded. Other key results from FDOT's Miami UPA survey include:

- $71 \%$ of the survey respondents are either satisfied or very satisfied with the implementation of the 95 Express Lanes

- $60 \%$ rated the Express Lanes as either safe or very safe

- $68 \%$ rated the Express Lanes as either valuable or very valuable

- $72 \%$ are either confident or very confident that the express lanes improve the reliability of travel on I-95 over the general purpose lanes

- $61 \%$ believe they save at least 10 minutes on their one-way travel time using the Express Lanes

- More than $50 \%$ of the Express Lane users utilize the facility at least three times per week

- $84 \%$ pay a toll to use the Express Lanes.

Results of the online survey conducted for this NCTR research project are included in Chapter 4, Findings.

\section{Transit Improvement Projects}

The increase in traffic speed along the Express Lanes not only saves time for drivers, but also has attracted 53 percent new transit riders to the 95 Express Bus service. According to the FDOT 95 Express Annual Report, transit travel times between downtown Miami and the Golden Gate Interchange have dropped from 25 minutes to just 8 minutes (41). User perception on travel time, reliability, and seat availability of 95 Express Bus Service has further improved. Through the UPA program, there have been new routes, improved park-and-ride facilities, and the implementation of TSP along some corridors to provide an advantage to the 95 Express Bus service. 
Miami-Dade Transit (MDT) and Broward County Transit (BCT) operate three routes that travel on the Express Lanes and are collectively known as the 95 Express Bus. MDT operates Route 95X and Route 195, while Route 107 is operated by BCT. Route 95X provides express service between the Golden Glades Interchange and several locations in downtown Miami, while Route 195 operates between park-and-ride lots in Broward County and downtown Miami. The Route 107 operates from Pines Boulevard in Broward County south to downtown Miami. An evaluation of the impacts of the Miami UPA Phase 1 on public transit services is included in the report, "Miami Urban Partnership Agreement (UPA) Project - Phase 1 Transit Evaluation Report" (44). In fall 2010, TSP was installed along Hollywood/ Pines Boulevard and Broward Boulevard. Figure 16 shows transit service operating along the 95 Express facility.

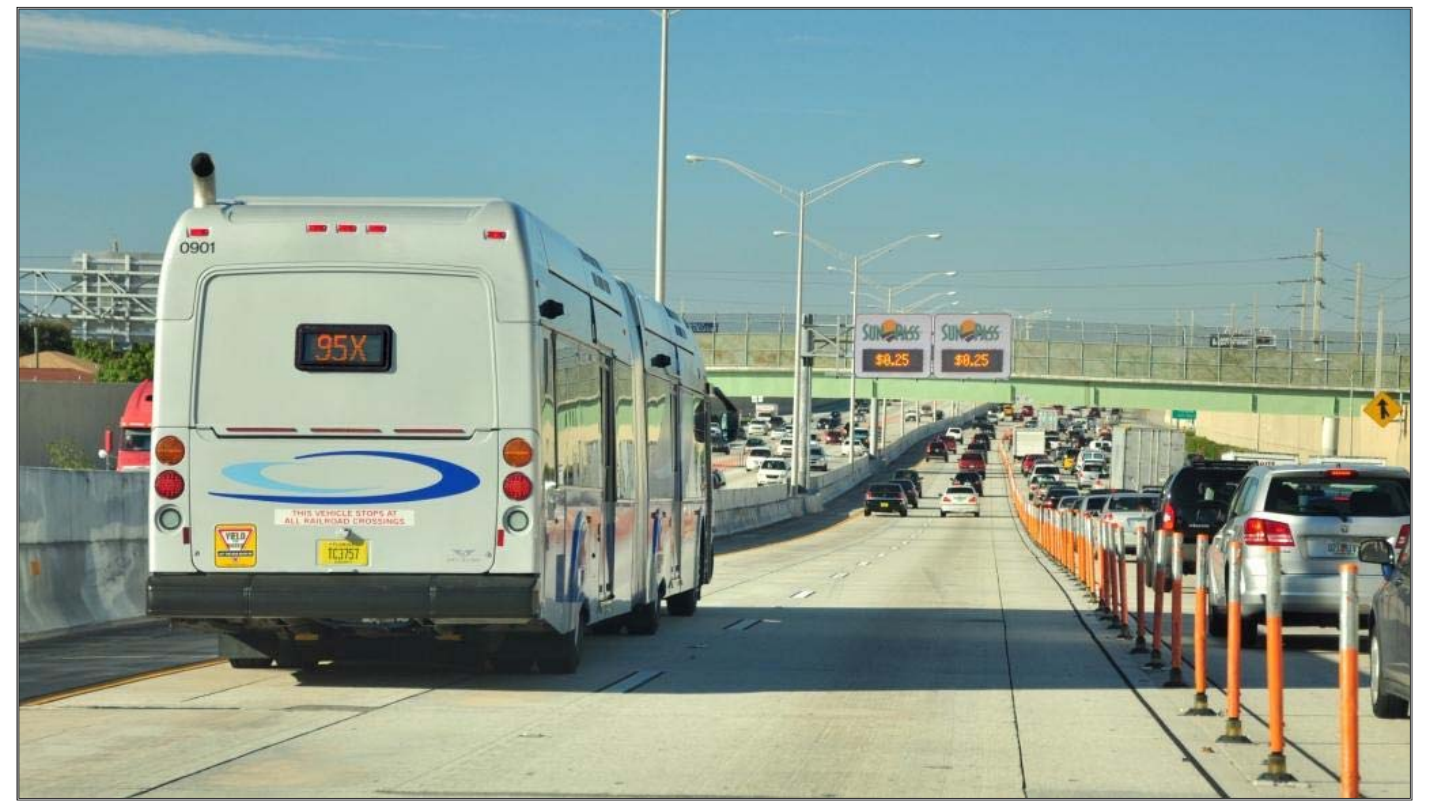

Source: FDOT

Figure 16: Miami-Dade Transit's Route 95X Operating Along the 95 Express Facility

The combination of the 95 Express Lanes operations and the improvements made to the 95 Express Bus service has surely encouraged individuals to use the 95 Express Bus service. Between 2008 and 2010, ridership on 95 Express Bus service increased 57 percent while travel in local lanes along I-95 and system-wide MDT Metrobus ridership decreased (45). This result shows the success of the Miami UPA program in linking its two main projects - the HOT lanes and the 95 Express Bus Service - to encourage transit patronage, which will bring Miami closer to its goal of reducing congestion along its major roadways. For its success, Miami's 95 Express projects received various awards, including the 2010 Best New Innovative Product or Service by the Intelligent Transportation Society of America (ITS America). 


\section{FINDINGS}

This chapter of the document summarizes the methodology and results of the research project. Methodologies discussed include those used for collecting the survey data and for the analysis of the data. Results of the survey are presented and discussed, as are the results of the modeling effort which culminates with the estimation of the VTTS distribution.

\section{Methodology}

The data to be used for this effort were not identified prior to the start of this research project. As such, the purpose of an early task of this work was to determine what data would be available. Much of the previous empirical research on VOT and VTTS has been based on statedpreference approaches. Stated-preference surveys involve asking participants to respond to series of hypothetical scenarios. They ask individuals to estimate what choices they would make or how they would behave given certain situations that they have not necessarily encountered or may never actually encounter. While it is certainly true that people can provide reasonable estimations of how they would behave under certain circumstances, it is always preferable to be able to observe how people actually do behave in various situations, as there is a difference between how people say they will behave and how they actually do behave in a given situation. It is important to note, however, that the use of stated preference approaches is important in estimating traveler behavior prior to the implementation of a particular service or project. The observation of actual behavior is known as a revealed-preference approach, or market-based approach. It was determined that, to provide the most accurate results on VTTS, this project would attempt to use actual market data, i.e., revealed-preference data.

The availability of existing market data was investigated in an early task of this project. Efforts were made to establish whether actual data on lane usage could be obtained or whether any other revealed-preference surveys had been conducted on the 95 Express Lanes. First, it was determined that, while aggregated information on average vehicle occupancy, travel speeds, toll levels, and toll revenue was available for the 95 Express, individual data (without identifiers) was not. Second, it was found that no other revealed-preference surveys or data were available for the 95 Express facility. Some stated-preference survey work has been done by Wilbur Smith and Associates (46) as part of the Comprehensive Traffic and Revenue Study for the I-595 corridor in Broward County being considered for HOT lanes. A recent study on the HOT lanes on I-394 in the Minneapolis-St. Paul region used revealed-preference data to 
estimate the value of reliability (47). However, no similar work had yet been done in South Florida.

\section{Survey Effort}

Given that, according to the recent survey by FDOT, two of the top three reasons why drivers use the 95 Express Lanes are that they can save time and travel faster, it is clear that the 95 Express facility comprises an ideal setting for data collection with the goal of estimating VTTS. While there have been some recent surveys, including the one conducted in October 2010 and briefly summarized in the previous section, no data have been collected on individual trips made along the facility.

Because no data existed on individual trips along the I-95 corridor in Miami-Dade County, a survey was conducted to gather the necessary data to complete this project. The survey instrument was carefully designed to collect the appropriate data on individual trips made along the facility, whether in the Express Lanes (SOV or HOV) or general purpose lanes. The questions used in the survey can be found in the Appendix. Participants were asked to (voluntarily) provide information on up to two recent trips they made on I-95. Questions related to demographic information and some attitudinal questions were included, as well. While respondents were asked to estimate their travel speeds and toll fees within narrow ranges, it must be noted that data for the dates of the survey were acquired from FDOT District 6 to validate the information provided by the survey respondents. A toll chronology, which includes a history of actual toll levels, was used to validate the toll information. Microwave Vehicle Detector System (MVDS) data, which provide speed and volume information for each Express and general purpose lane via a set of detectors along the corridor, were used to validate the reported speeds. Clearly, in estimating VTTS, it is critical to have accurate data on costs and travel times. For the estimation of the VTTS, these actual data on tolls and speeds were used, based on the time of the trip as reported by the survey respondents. Survey results are discussed in the Results section of this chapter.

The survey was conducted online in August 2011. With the assistance of FDOT District 6 staff in Miami, a link to the survey was distributed to the South Florida Commuter Services database and a database of individuals who subscribe to I-95 news and alerts. Unfortunately, the survey was not able to be distributed to all SunPass account holders in Broward and Miami-Dade Counties as originally anticipated due to unforeseen logistical issues between FDOT District 6 and the Turnpike Enterprise. However, as discussed in the Results section below, the collected survey responses were adequate for this project. 


\section{Discrete Choice Modeling}

The method of discrete choice modeling was applied in this effort. There were two choices for the traveler to make: (1) use the 95 Express Lanes and pay the given toll, or (2) drive only in the general purpose lanes and not pay the toll. Using the appropriate data from the online survey responses, the two utility functions were estimated according to Equation 1. These functions represent the utility, or satisfaction, to the traveler from each choice. It is assumed that the traveler would choose to drive in the Express Lanes and pay the toll, or not, based on which option would yield the highest utility. A useful marginal effect that can be derived from this type of analysis is the VTTS, or VOT, which can be estimated by comparing the disutility of higher travel time with the disutility of a toll, as in Equation 2. For this research, there is less interest in which choice a traveler would be predicted to make and more emphasis on the estimation of the VTTS.

$U_{i, j}=\beta_{i} X_{i}+\beta_{j} X_{j}+\varepsilon_{i, j}$

where

$U_{i, j}=$ utility of alternative $i$ to traveler $j$;

$i=$ set of alternatives available to traveler $j$;

$X_{i}=$ vector of measurable attributes of the alternatives (e.g., toll, travel time savings);

$\beta_{i}=$ vector of the coefficients of $X_{i}$;

$X_{j}=$ vector of measurable attributes of the traveler (e.g., income, education);

$\beta_{j}=$ vector of the coefficients of $X_{j} ;$ and

$\varepsilon_{i, j}=$ unobservable factors.

$\operatorname{VOT}_{i, j}=\operatorname{VTTS}_{i, j}=\frac{\partial U_{i, j} / \partial T T S_{i}}{\partial U_{i, j} / \partial \text { toll }_{i}}=\frac{\beta_{\text {TTS }_{i}}}{\beta_{\text {toll }_{i}}}$

Data analysis was conducted using both Microsoft Excel and SPSS (formerly known as Statistical Package for the Social Sciences). For the modeling effort, Biogeme 2.0 was used, which is an open source freeware designed for the estimation of discrete choice models (48). 


\section{Results}

This section includes the results of the research project. First, results of the online survey are presented and discussed. The second part of this section presents the VTTS estimation based on the revealed-preference data from the survey.

\section{Survey Results}

It was determined that 4,586 individuals opened the survey link and there were 818 total responses, resulting in a nearly 18 percent response rate. The 818 responses yielded 208 usable trip responses for the estimation of the VTTS distribution. For a trip to be included, it needed to occur on one of five specified days in August (Wednesday the 17th through Sunday the 21 ${ }^{\text {st }}$ ) by someone driving a private vehicle who either paid a toll to use the Express Lanes or drove in the general purpose lanes. As such, those who use the Express Lanes for free, including hybrid vehicle owners, motorcyclists, and carpool/vanpool participants, were excluded. In addition, because there are limited entry and exit points for the Express Lanes, the trips had to cover a long enough stretch of I-95 so that using the Lanes was an option for the driver. Finally, all relevant questions needed to be answered by the respondent for the trip to be included in the analysis. Of the 208 final trips, 106 occurred in the general purpose lanes, and 102 were made in the Express Lanes.

To collect a rich set of data that can be used for other applications in the future, several additional questions were included that went beyond those necessary for the VTTS estimation. Because this was the first effort to collect data on individual trips made on the 95 Express facility, it was important to collect as much information as possible while still keeping the survey length manageable for the respondents. In addition to the basic trip and demographic characteristics, respondents were asked to provide trip origin and destination information, including a location defined by the nearest major intersection or landmark. This information was also collected for the respondents' home and work locations. Because recent research suggests the value of time may be influenced by the urgency of a trip or by traveler attitudes toward various commute alternatives (17) (49), questions were included to address those issues. The survey responses indicated that less than two percent of the trips were classified as urgent, meaning that the traveler was running late or had an emergency; thus, this information is not included in the data analysis.

Select survey results and frequency distributions are provided in this section. To see all the questions that were included in the survey, please refer to the Appendix. 
A number of survey questions asked respondents to gauge their attitudes regarding public transportation, auto travel, and congestion pricing in general. Safety concerns seem to be a potentially large deterrent to public transportation for many people. Approximately 13 percent of respondents disagreed with the statement "it is safe to travel by public transportation," while another 17 percent strongly disagreed, according to Figure 17. Slightly more respondents agreed that public transportation feels safe, with 21 percent agreeing strongly and 20 percent agreeing with this sentiment. Nearly one third (28 percent) of respondents had a neutral opinion on the matter.

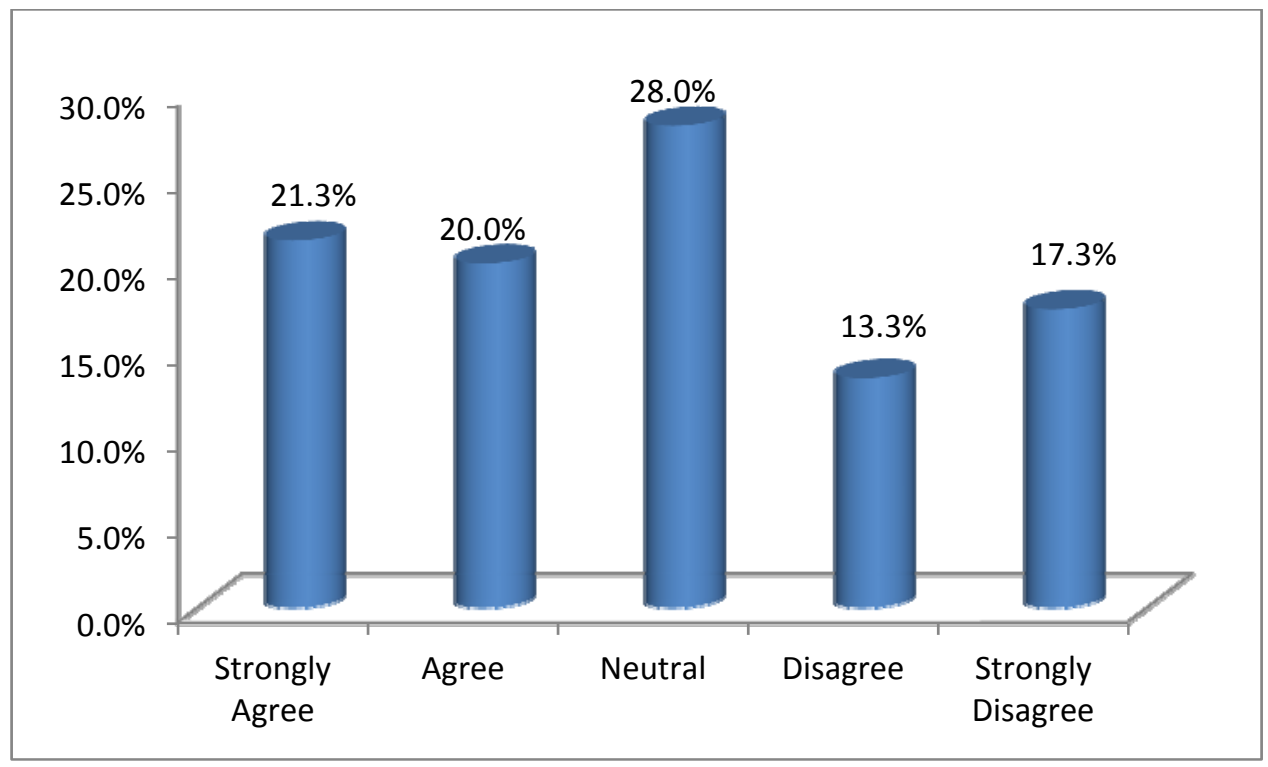

Figure 17: It feels safe to travel by public transportation

Respondents were also asked if they felt comfortable traveling to work via public transportation. As shown in Figure 18, the percentage of respondents who either disagreed or strongly disagreed with this statement (44 percent) was greater than the combined percentage of respondents who either agreed or strongly agreed (33 percent). These results are echoed by another survey question, asking whether measures to improve public transportation should be undertaken. Nearly 90 percent of respondents agreed with this statement, according to Figure 19. 


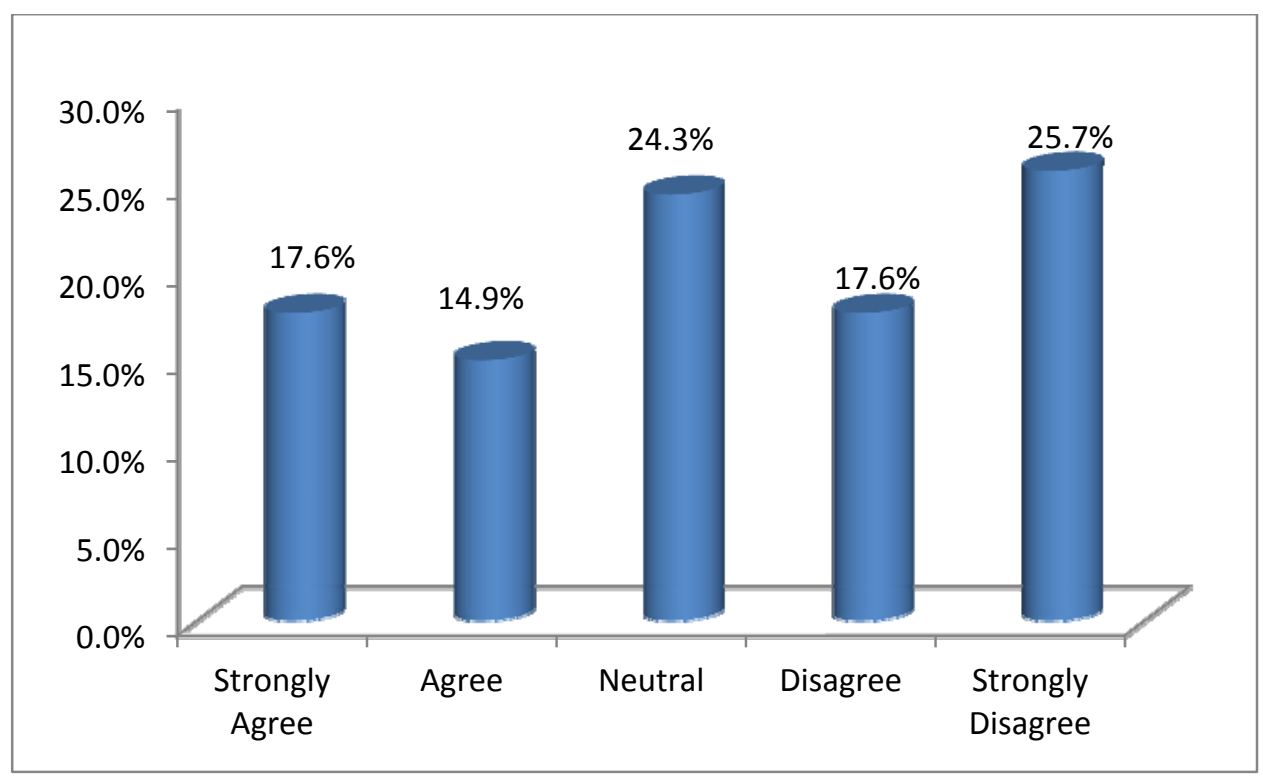

Figure 18: It is comfortable to travel by public transportation for work

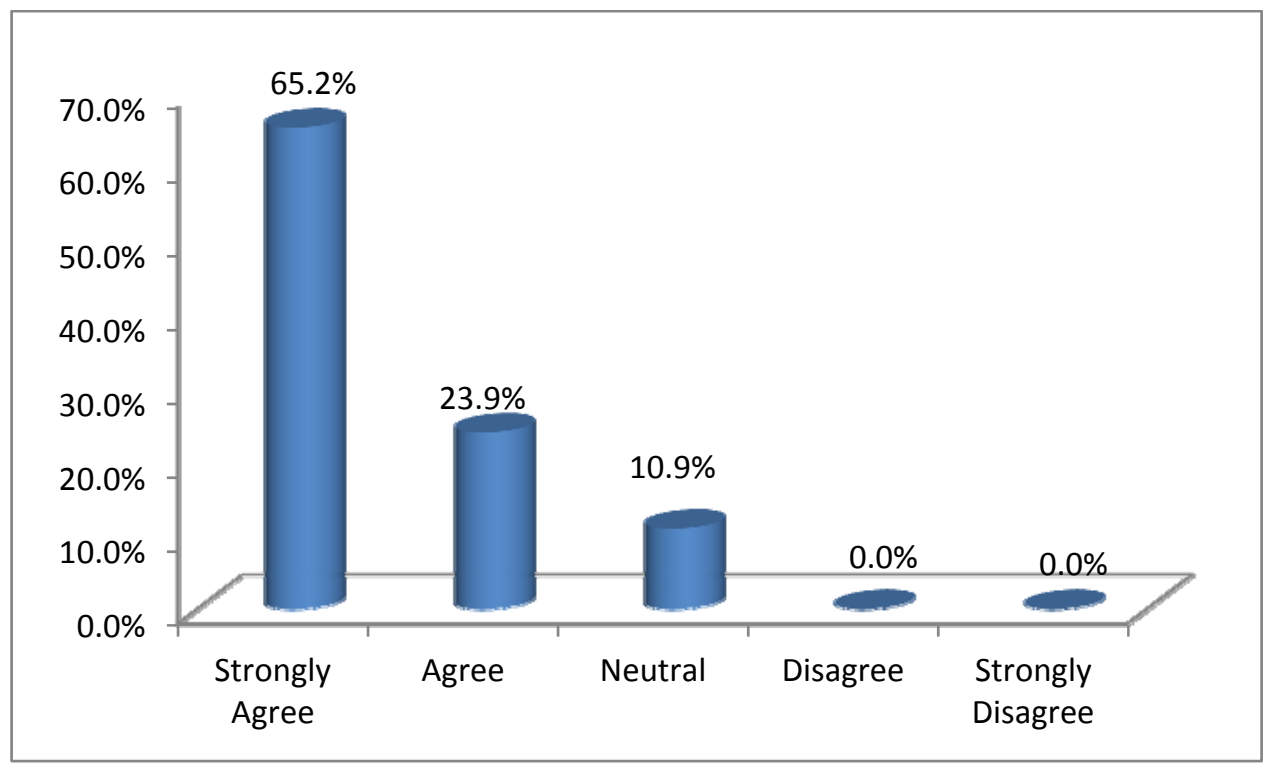

Figure 19: Measures should be taken to improve public transportation

When asked if traveling by public transportation was worth its (comparatively small) price compared to driving a car, nearly 45 percent of respondents agreed or agreed strongly that it was, as seen in Figure 20. Approximately 27 percent of respondents were neutral on the question, and a combined 28 percent of respondents either disagreed or strongly disagreed. 


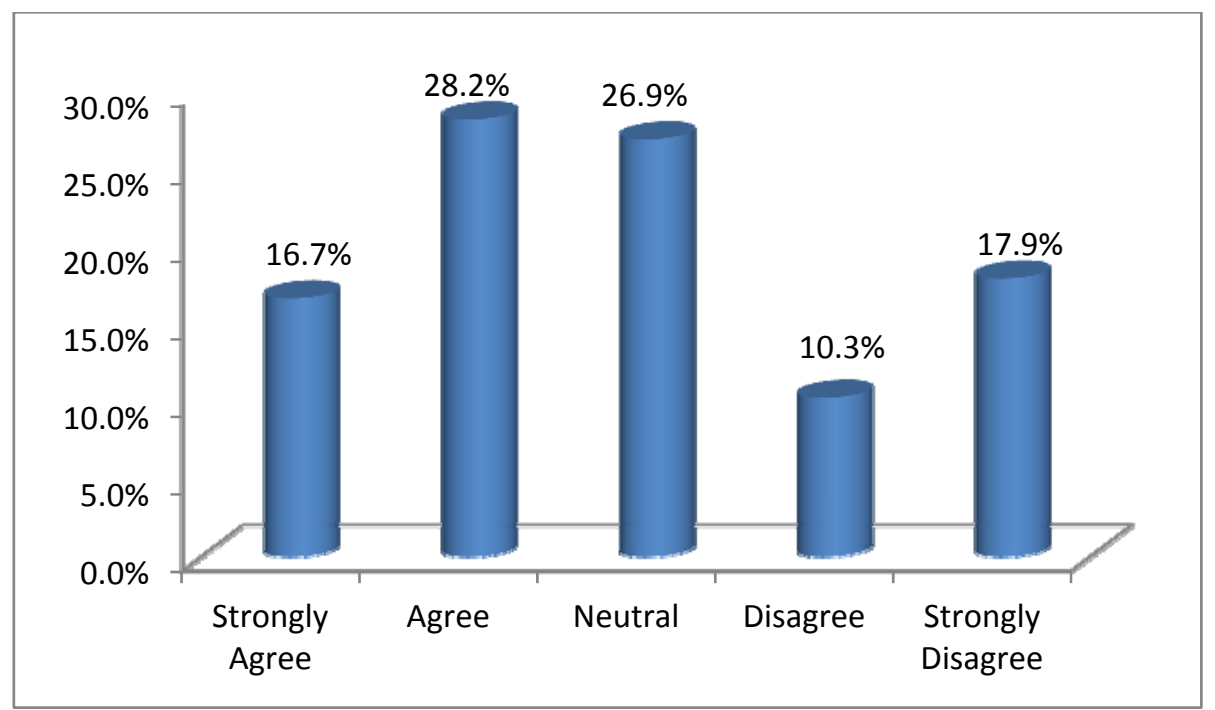

Figure 20: Traveling by public transportation is worth its price compared to traveling by car

The survey also included analogous attitudinal questions concerning the safety and comfort of cars, rather than public transportation, as illustrated in Figures 21 and 22 on the following page. Reported levels of safety and comfort in a car were much higher than for public transportation. Only 16 percent of respondents disagreed or strongly disagreed that it was comfortable to drive to work by car, while nearly three-quarters of respondents (74 percent) either agreed or agreed strongly. In terms of safety, respondents also seemed to feel safer traveling by car than by public transit. Fifty-two percent of respondents agreed or strongly agreed that it feels safe to travel by car, while only 25 percent disagreed or disagreed strongly with this belief. 


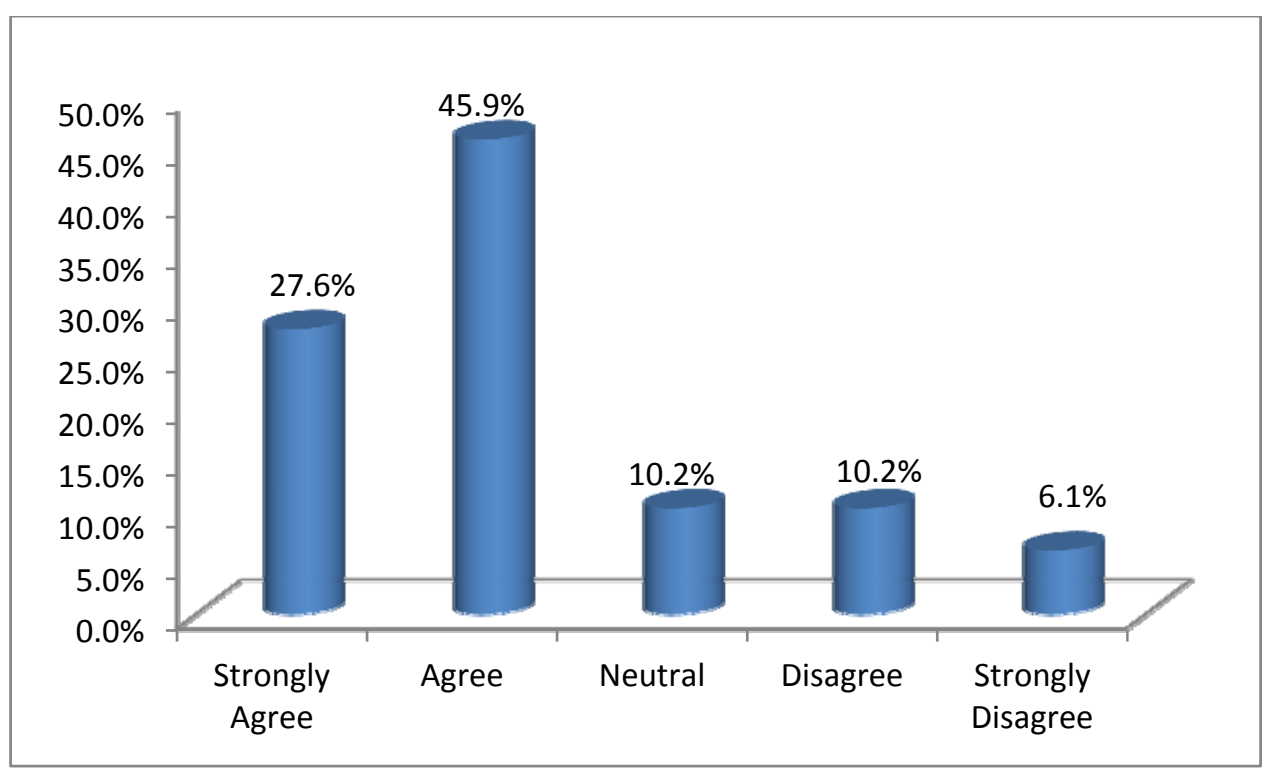

Figure 21: It is comfortable to travel by car to work

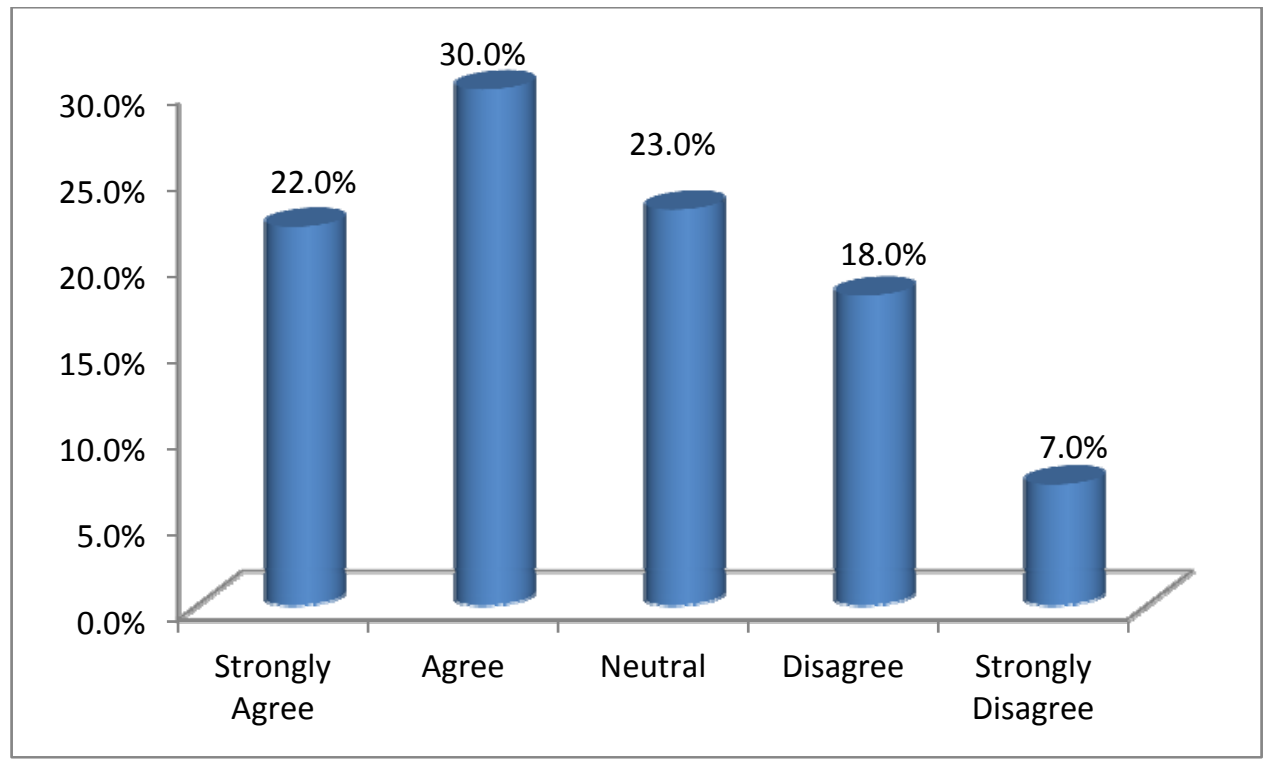

Figure 22: It feels safe to travel by car

Several questions were asked concerning congestion mitigation policies. When asked to agree or disagree with the statement, "I consciously limit my car to reduce emissions," a majority of respondents either agreed (30 percent) or strongly agreed (22 percent), as shown in Figure 23. A large portion of respondents were neutral (32 percent), while only about 17 percent of respondents disagreed with the statement. In addition, a vast majority of respondents agreed 
that it was "important that traffic speed limits are not violated," with only five percent of respondents disagreeing, as depicted in Figure 24.

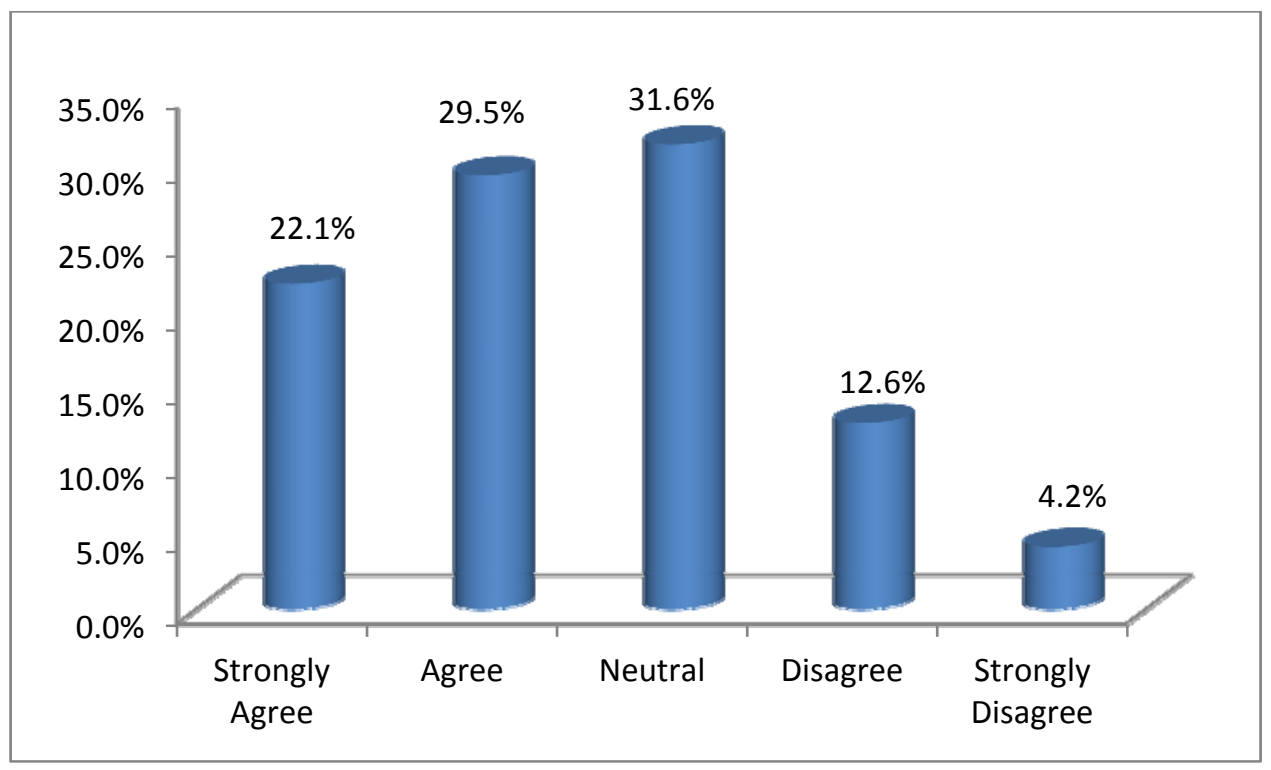

Figure 23: I consciously limit my car use to reduce emissions

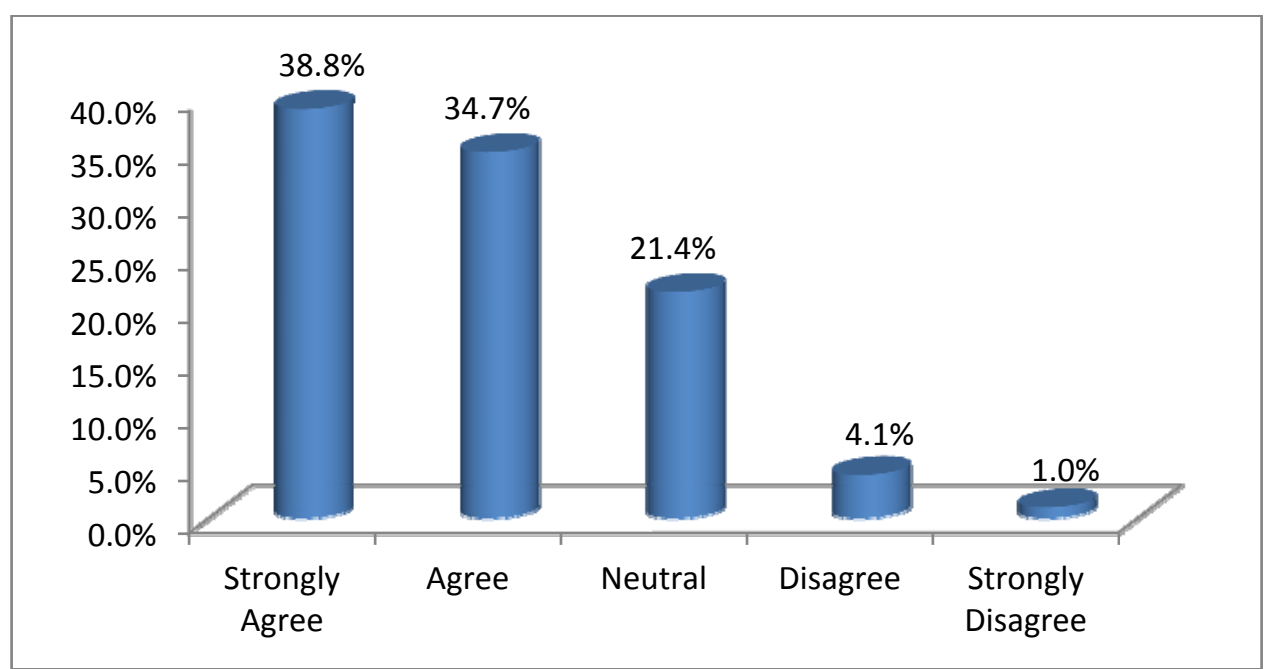

Figure 24: It is important that traffic speed limits are not violated

The survey also indicates a large amount of support for variably-priced tolls. When asked whether they agreed or disagreed with the statement, "I support the use of lanes with tolls that vary depending on the level of traffic congestion," nearly 60 percent of respondents either agreed or agreed strongly, as Figure 25 illustrates. In contrast, only about 26 percent of 
respondents disagreed or disagreed strongly. Another question similarly asked respondents to agree or disagree that "charging tolls that vary with the level of traffic is an effective way to reduce traffic congestion." Support was slightly lower in this case, with approximately 40 percent of respondents either agreeing or agreeing strongly, while 47 percent of respondents either disagreed or disagreed strongly. Approximately 13 percent of respondents remained neutral on the issue. One may support the idea of variable tolling, but may or may not believe it impacts congestion.

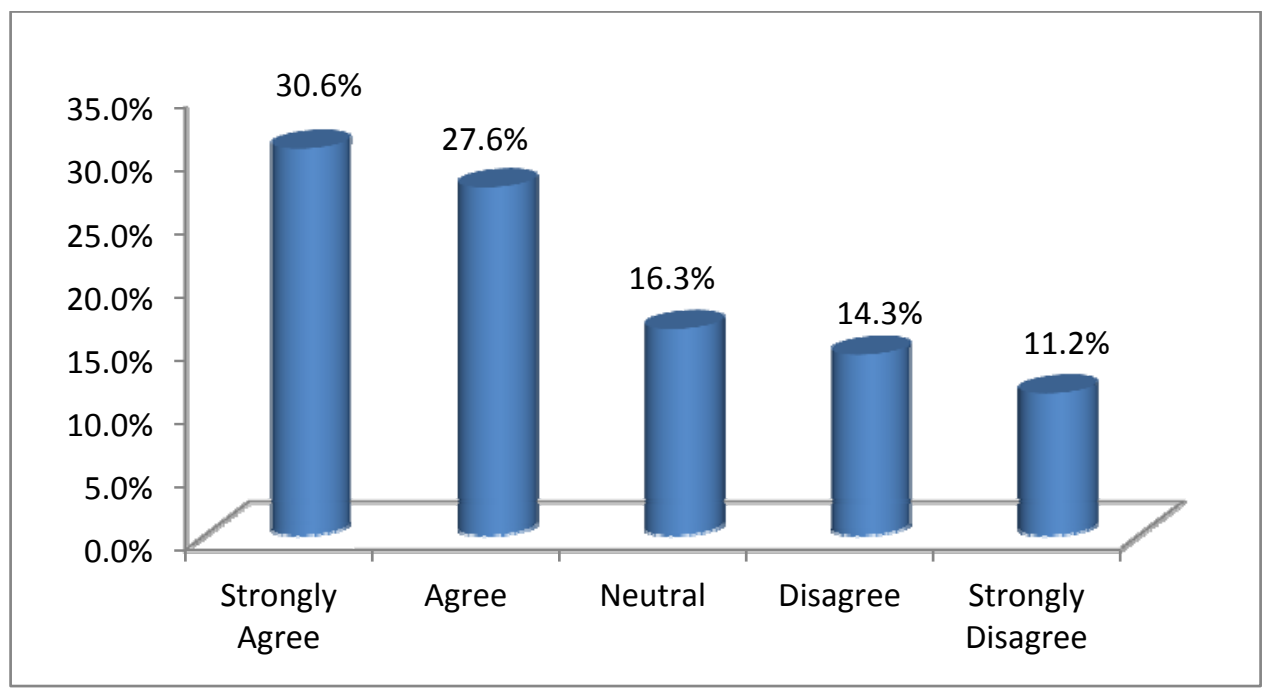

Figure 25: I support the use of lanes with tolls that vary depending on the level of traffic congestion

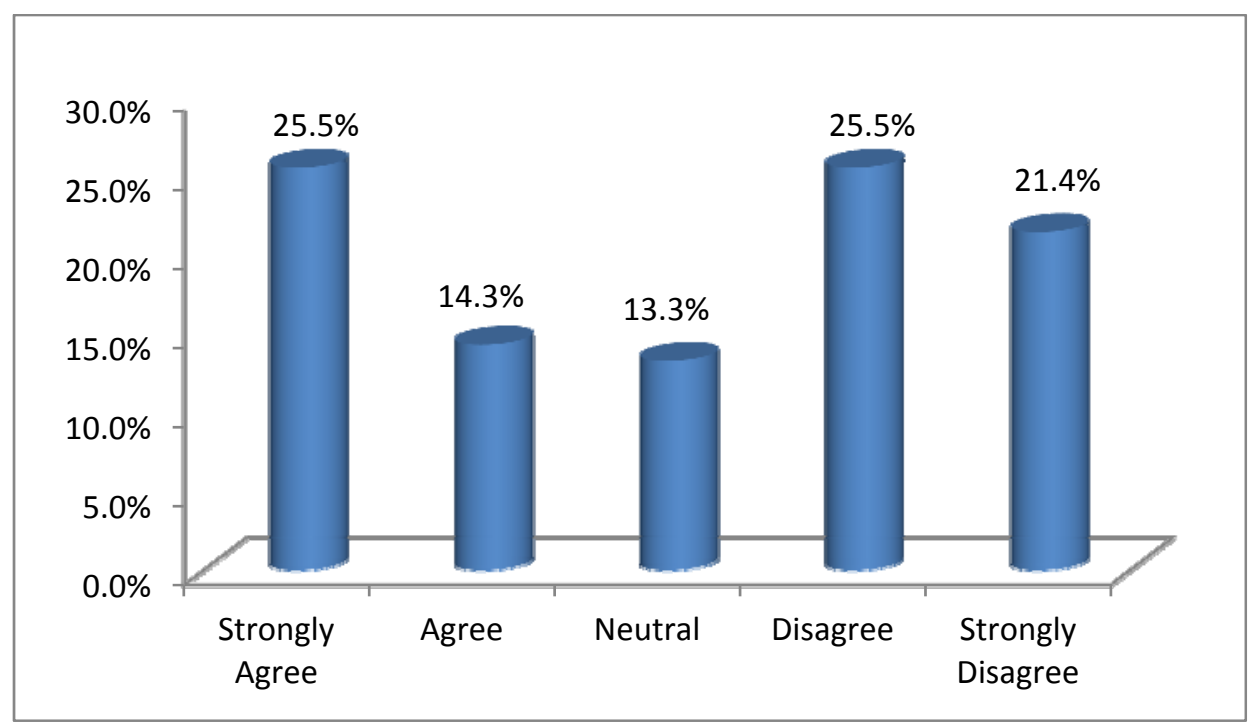

Figure 26: Charging tolls that vary with the level of traffic is an effective way to reduce traffic congestion 
Multiple demographic questions were included in the survey. The responses shown below are only for those respondents whose trips are included in the analysis. Concerning the age of the survey respondents, just over 42 percent identified themselves as being between 50 and 64 years old, as shown in Figure 27. The 35-49 year age group accounted for almost 30 percent of the respondents, while the remaining respondents were split between younger drivers (ages 25-34) and senior citizens (ages 65 and older). It should also be noted that individuals younger than 18 were not able to participate in the survey.

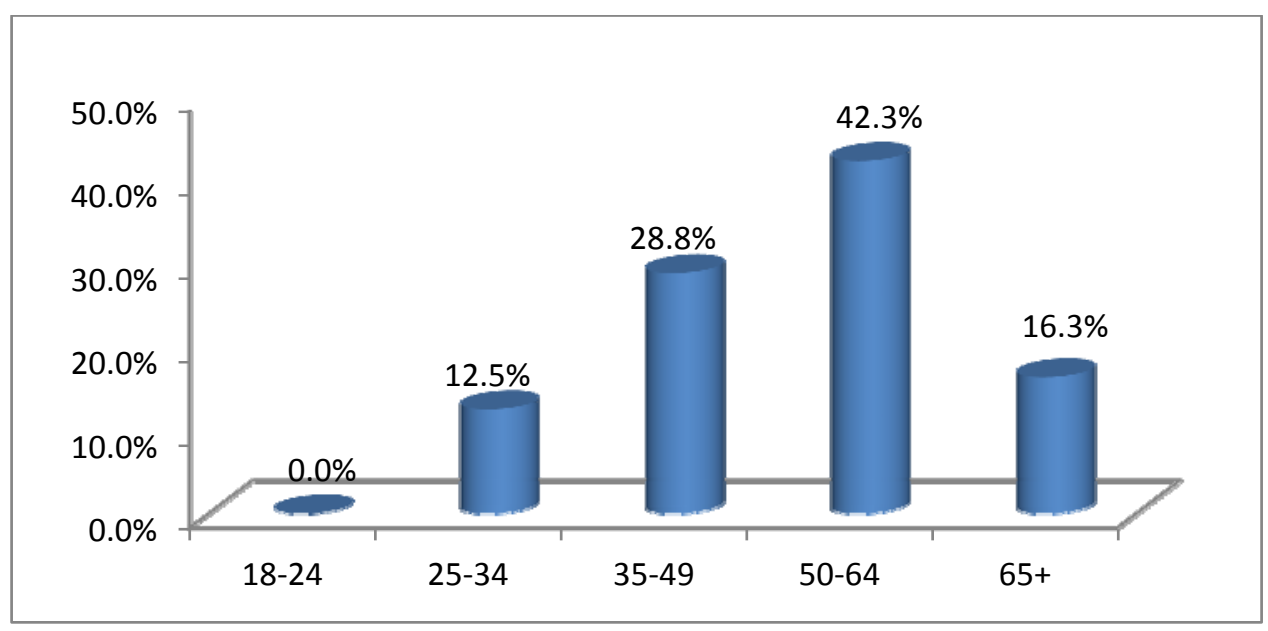

Figure 27: Age

The majority of respondents to this survey (51 percent) live in a two person household, as shown in Figure 28. Nearly 20 percent of respondents also identified themselves as having a three-person household, while another 14 percent belong to four-person households. In addition, nearly 16 percent of respondents have a household with just one child under the age of 16, while the vast majority of respondents had no children under the age of 16 living at home, as evidenced in Figure 29. 


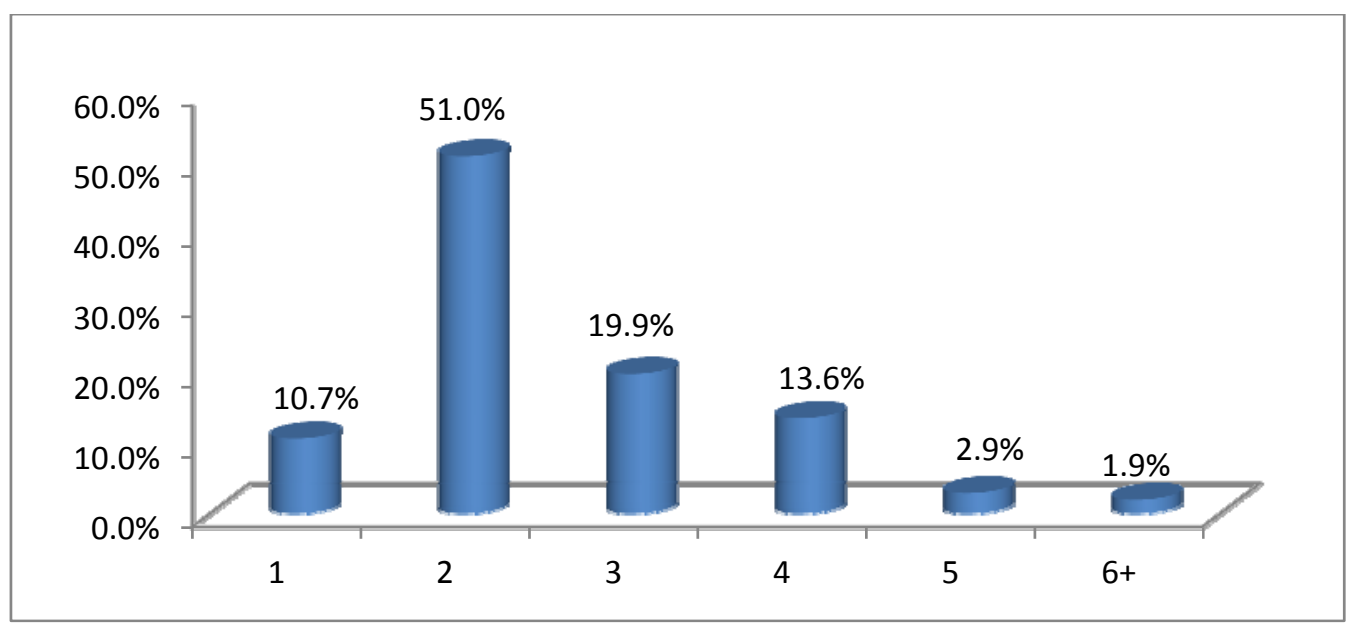

Figure 28: How many people live in your household?

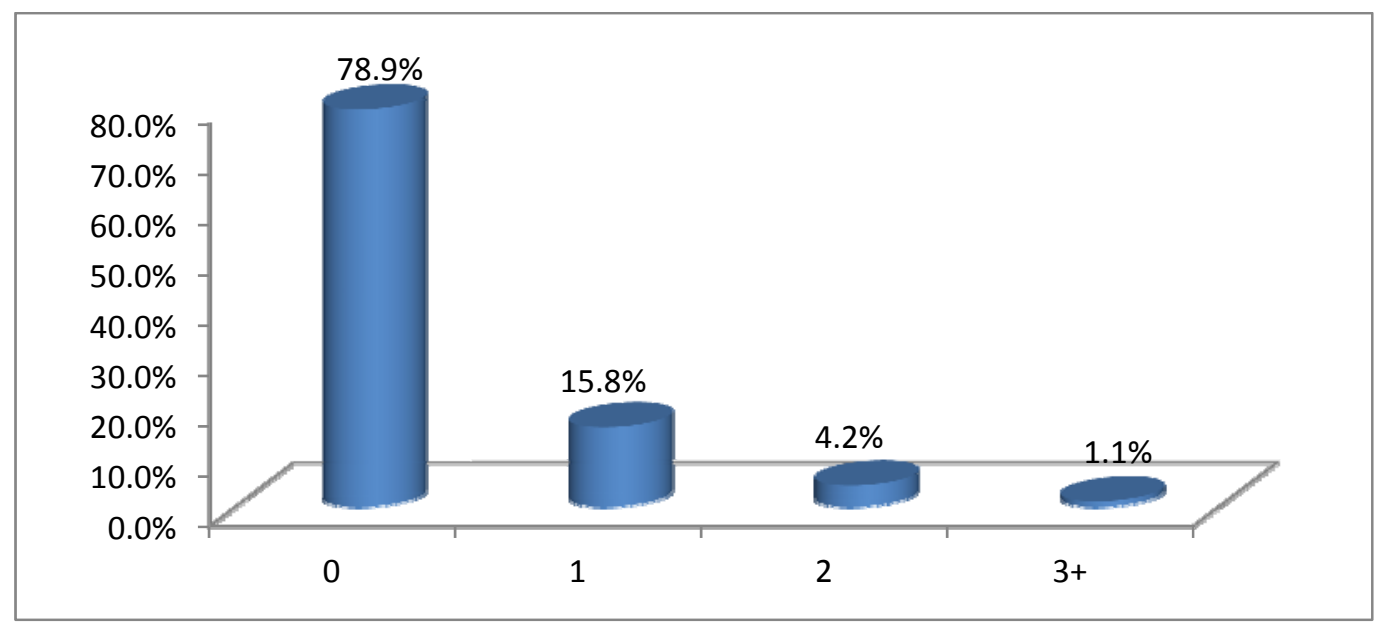

Figure 29: How many people under 16 live in your household?

Most respondents indicated they have either one or two motor vehicles in their household; nearly 30 percent with one vehicle and 46 percent with two vehicles. Only one percent of survey respondents do not own a motor vehicle, as shown in Figure 30. 


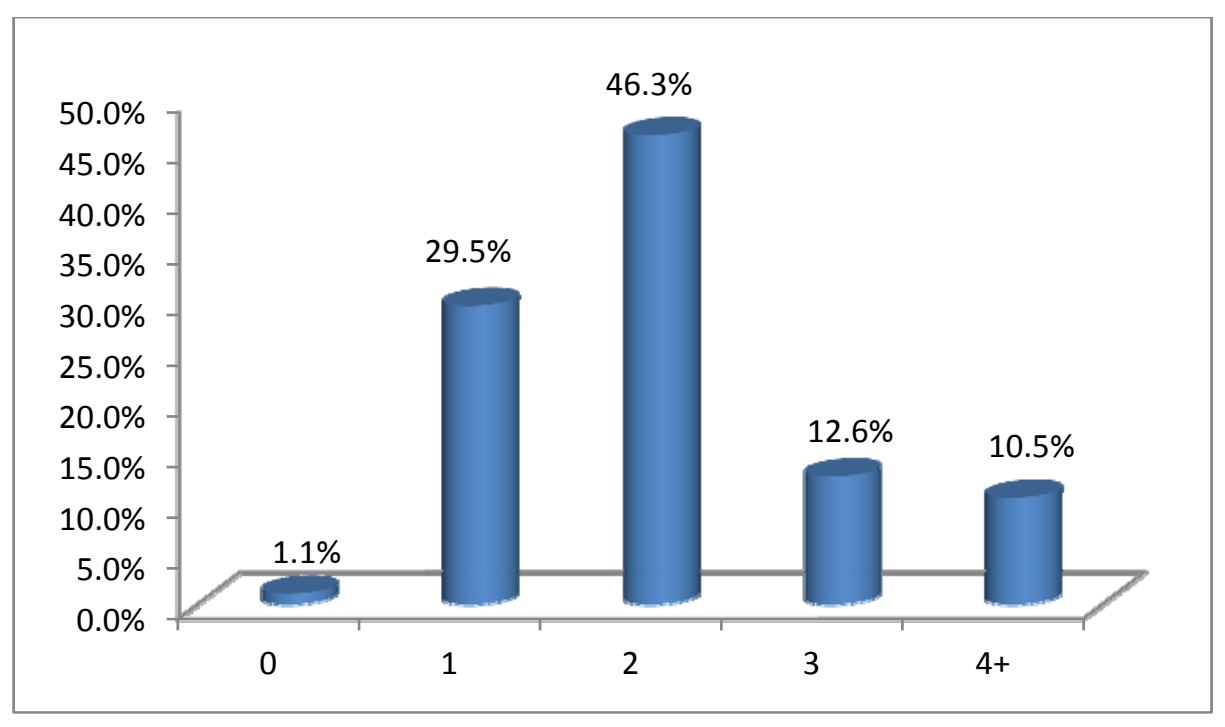

Figure 30: How many cars, motorcycles, minivans, pickup trucks, etc. do you have in your household?

Figure 31 illustrates that the gender breakdown is fairly even, with a slight skew towards a greater number of male respondents. More than 41 percent of respondents identified as female, 48 percent identified as male, and the remaining 11 percent did not identify themselves by gender.

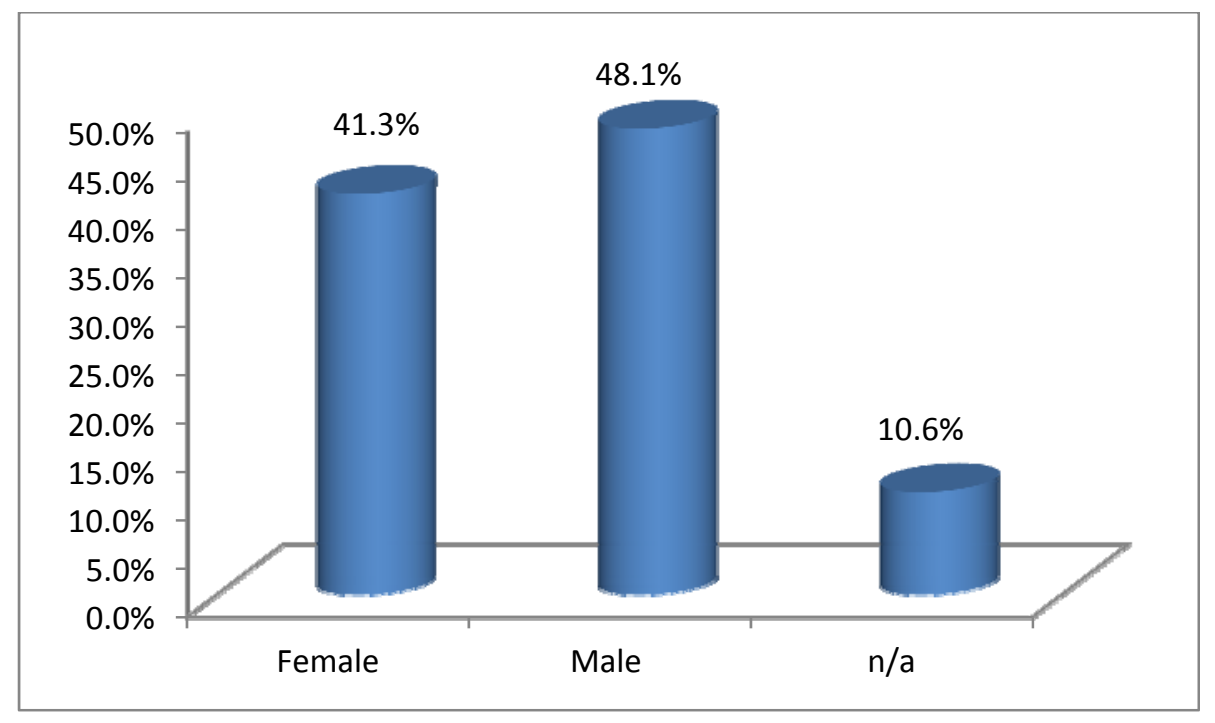

Figure 31: What is your gender? 


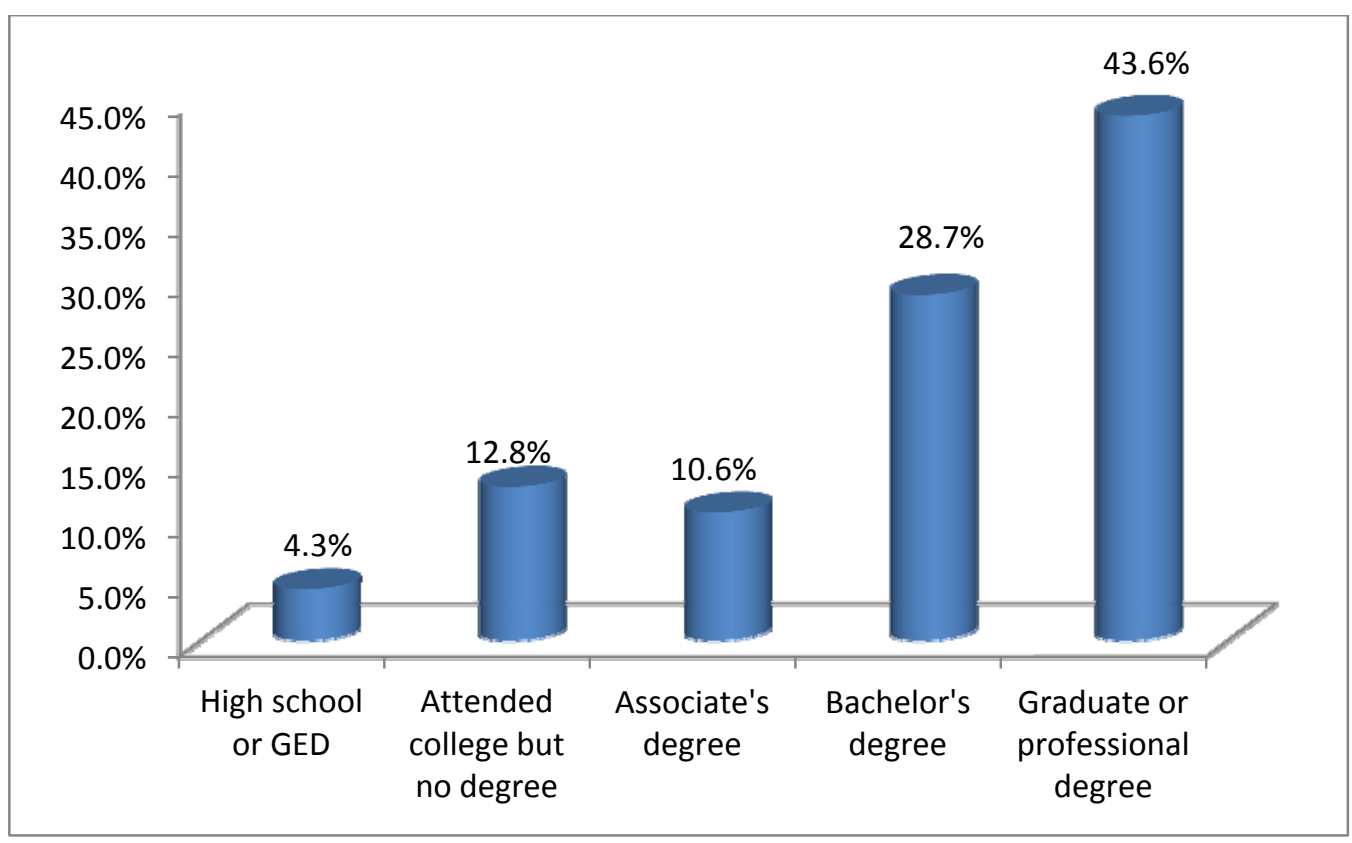

Figure 32: What is the highest level of education or degree that you have completed?

There was a wide range of educational attainment among the survey respondents, according to Figure 32. The largest group was those respondents with a graduate or professional degree, accounting for nearly 44 percent of the responses. Another 29 percent of respondents completed a Bachelor's degree, and 11 percent had attained an Associate's degree. Nearly 13 percent of respondents attended some college but did not graduate, while the remaining four percent had a high school diploma or GED.

Employment status was another demographic question posed to respondents. Results of this question are shown in Figure 33 and show that most are employed full-time. Among the respondents whose trips are included in this analysis, there are no students or homemakers. 


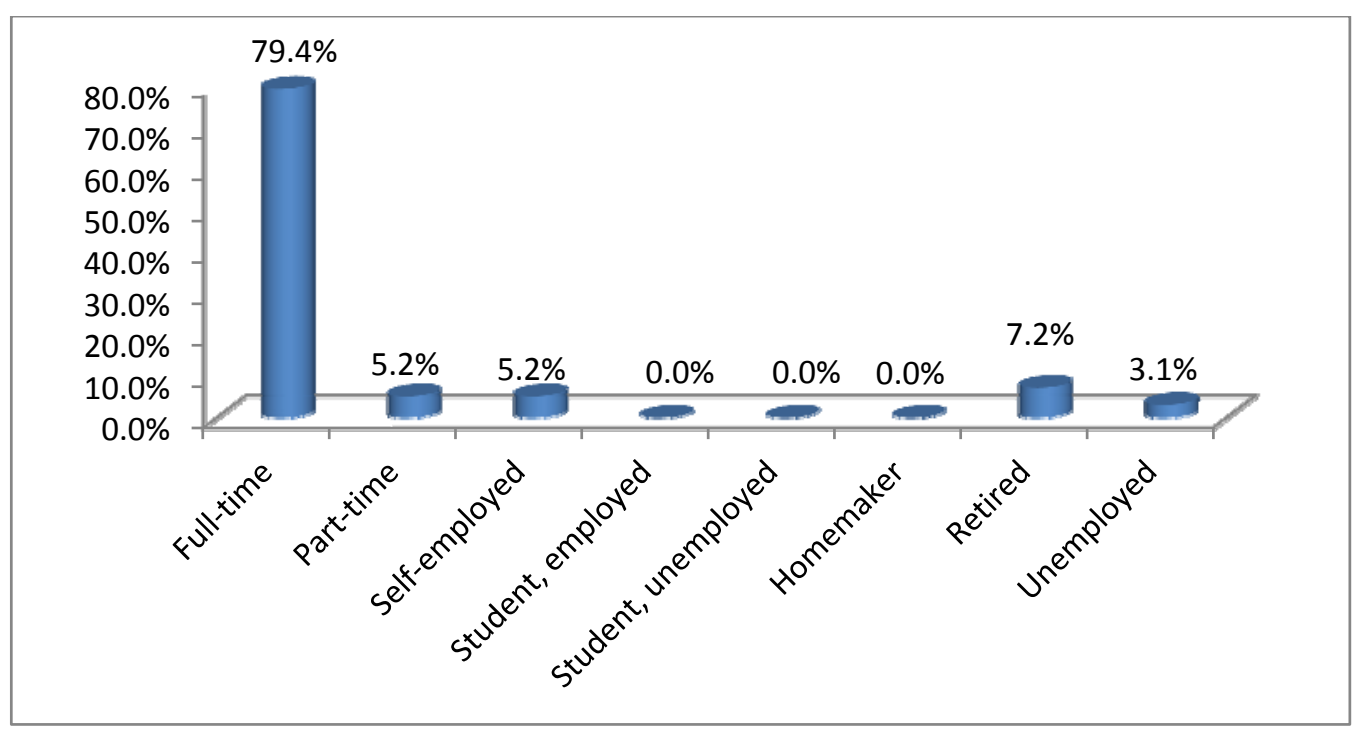

Figure 33: What is your employment status?

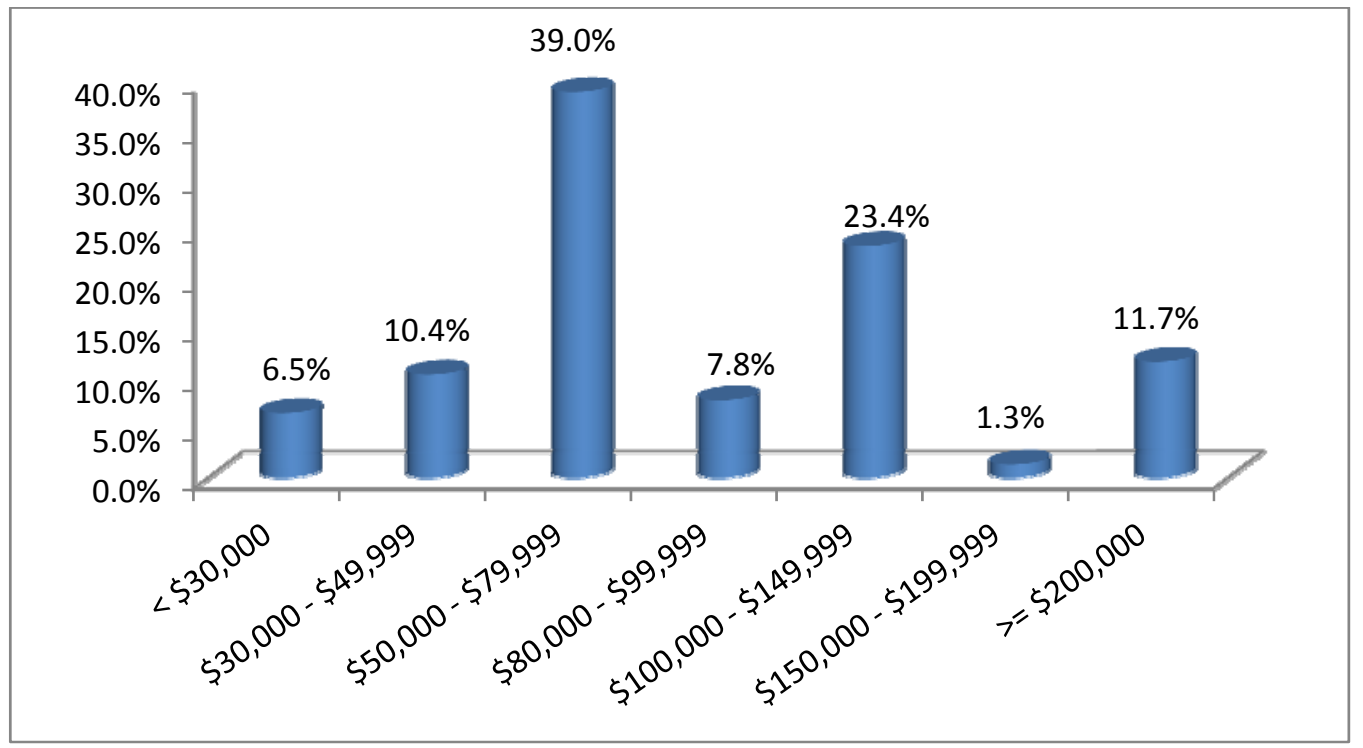

Figure 34: Personal Annual Income

Respondents were also asked to indicate the range of their annual income, in terms of both personal income and household income. Both measures were used in estimating the VTTS distribution. It should be noted that respondents were able to select from 18 narrow ranges of income in an attempt to capture the most accurate representation of their actual income. Figures 34 and 35 show combined categories for easier interpretation. Regarding personal annual income, Figure 34 illustrates that the largest group was in the mid-range $\$ 50,000$ - 
$\$ 79,999$ bracket, accounting for 39 percent of respondents. Over one-fifth of respondents (23 percent) reported earning between $\$ 100,000-149,999$.

Household income was predictably higher, as shown in Figure 35. By this measure, nearly 71 percent of respondents reported that their household earns over $\$ 100,000$, with 21 percent in the highest, $\$ 200,000+$ bracket. Only about three percent of respondents reported being in the lowest income bracket (less than $\$ 30,000$ ).

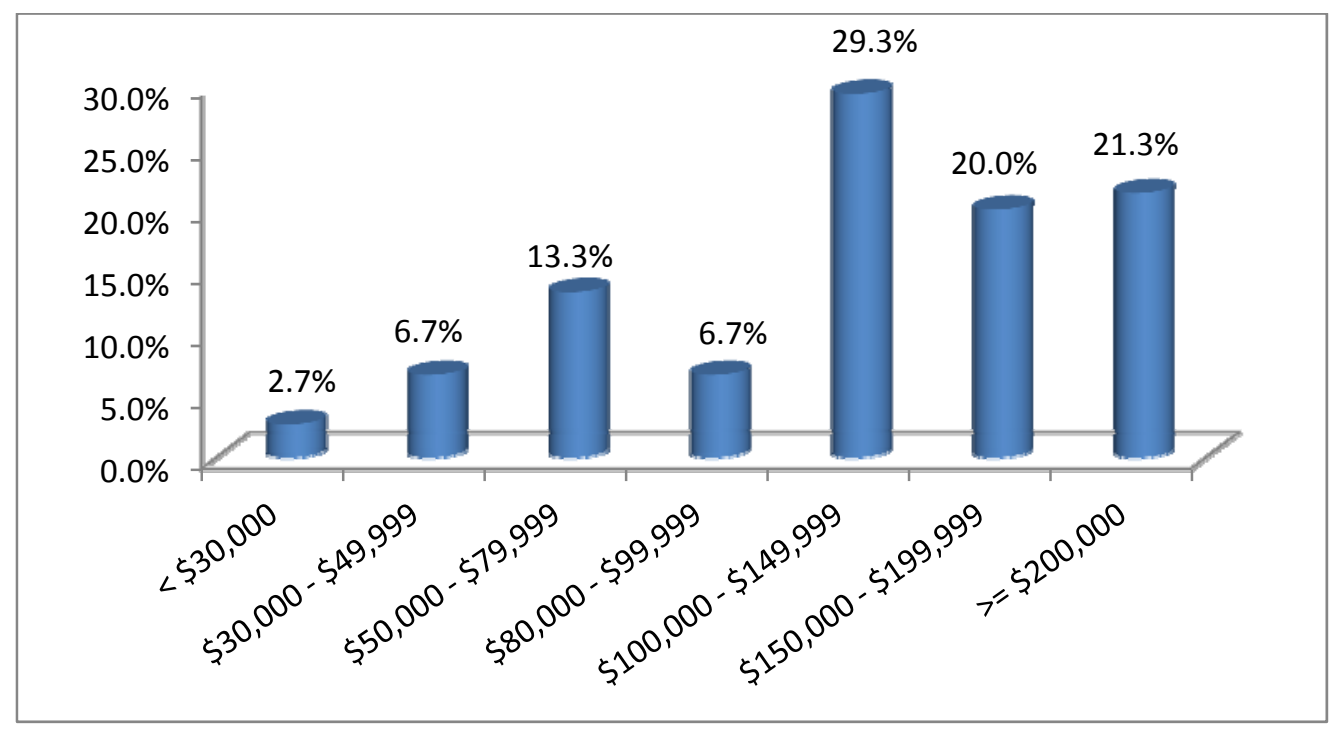

Figure 35: Household Annual Income

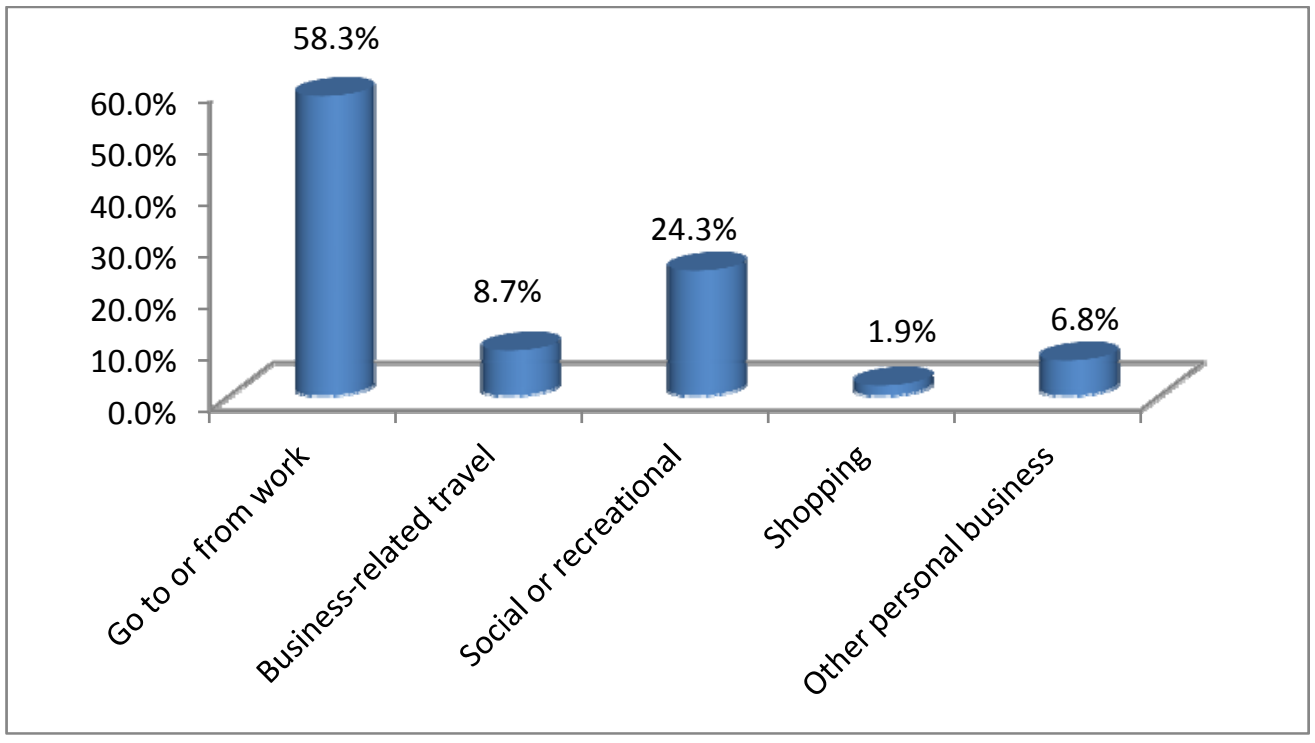

Figure 36: Primary Trip Purpose 
Figure 36 depicts that the majority of survey respondents indicated that their trip on I-95 was made for work purposes, with 58 percent of trips being made to go to or from work, and with another nine percent citing business-related travel. Social or recreational travel accounted for nearly one-quarter of the trips (24 percent), while the remaining trips were either for shopping ( 2 percent) or other personal business (7 percent).

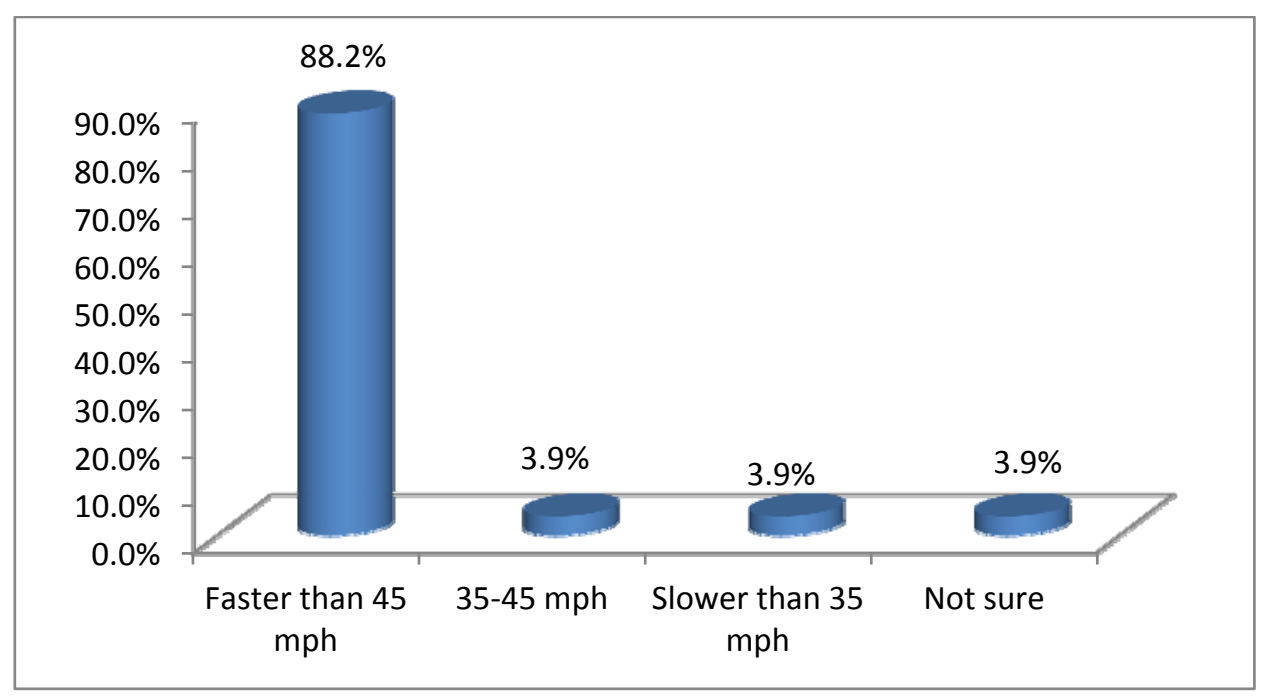

Figure 37: Self-Reported Speed in 95 Express Lanes

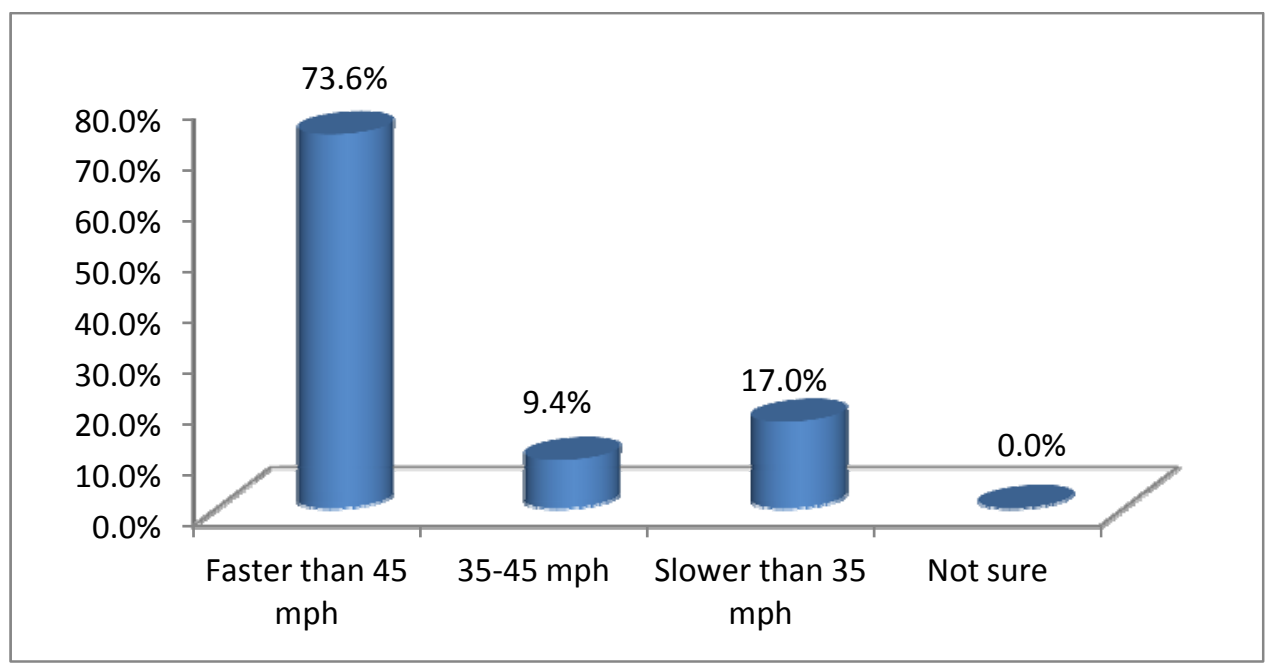

Figure 38: Self-Reported Speed in General Purpose Lanes

Those respondents who traveled on the 95 Express Lanes were asked to gauge their average speed, while respondents who did not use the Express Lanes were asked to do the same for the I-95 general purpose lanes. The Express Lanes, as expected, showed noticeably faster and more 
reliable travel speeds, insofar as respondents can accurately recall this information. The categories were chosen with the assumption that people can better recall if they were traveling greater than $45 \mathrm{mph}$ (likely free flow), or if they were traveling slower than $35 \mathrm{mph}$, which might reflect stop-and-go conditions. If they were not in relatively free-flowing traffic or in stop-and-go traffic, then respondents might indicate that they were traveling at a speed somewhere in between ( $35-45 \mathrm{mph}$ ). It must be stated that actual speeds were available from the MVDS detector data and were used in the discrete-choice modeling efforts.

According to Figure 37, the vast majority, 88 percent of respondents, reported traveling at an average speed of greater than $45 \mathrm{mph}$ in the Express Lanes, while the remaining 12 percent of respondents were split in even thirds (3.9 percent each) between 35 and $45 \mathrm{mph}$, less than 35 $\mathrm{mph}$, and unsure. In contrast, only 74 percent of respondents reported traveling faster than 45 mph on average in the general purpose lanes, as shown in Figure 38. There was also a much larger percentage of respondents that reported considerable traffic in the general purpose lanes, with 17 percent of respondents reporting average speeds of less than $35 \mathrm{mph}$.

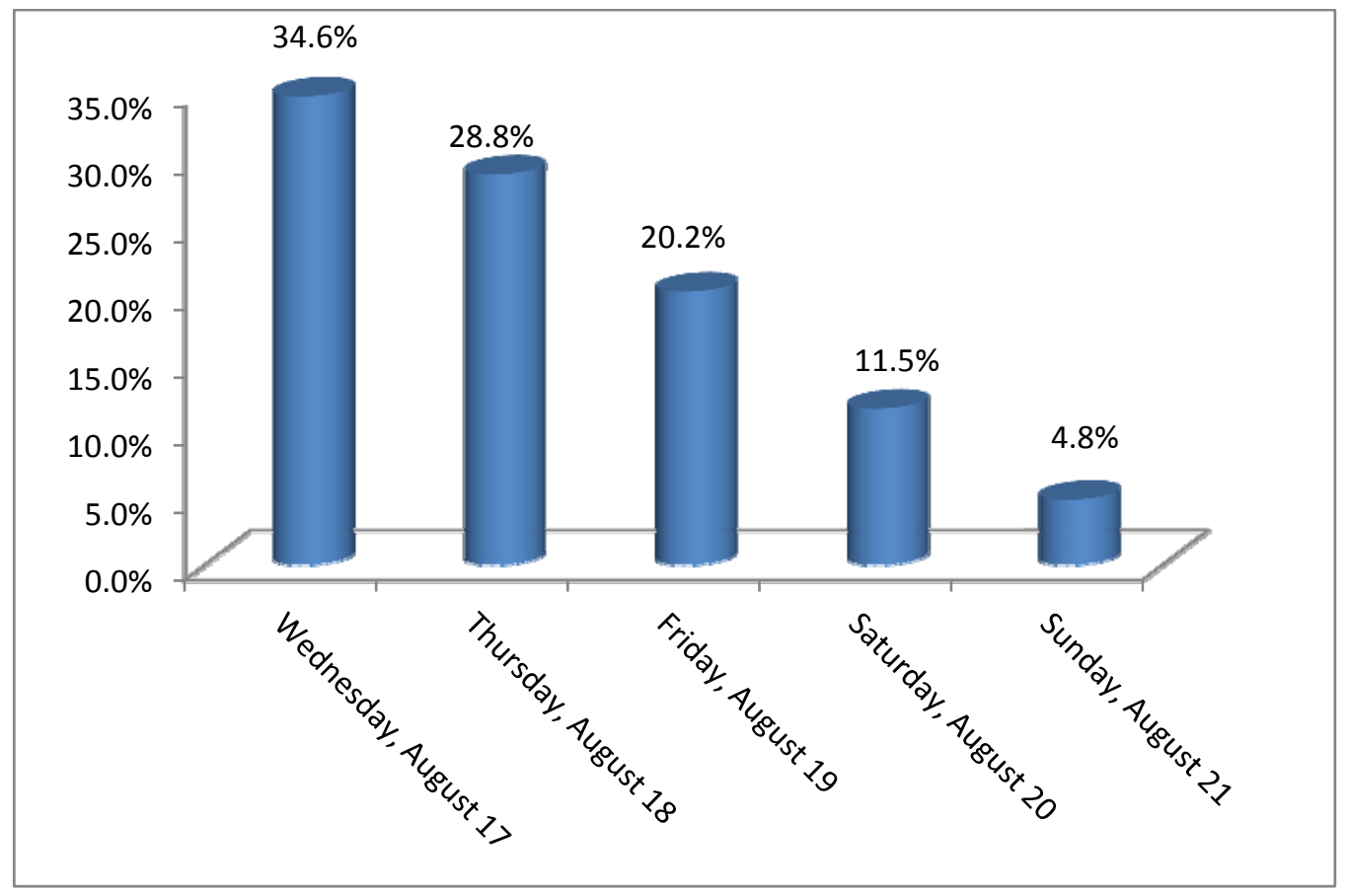

Figure 39: Date of Trip

Respondents were also asked which day during the survey period they made their trip(s) on I-95. The opening day of the survey had the highest volume of reported trips, with nearly 35 percent of all trips, as indicated in Figure 39. The percentage of trips then decreased to 29 
percent the following day, and continued to decline through the weekend and the end of the survey period, with only five percent of the reported trips being made on Sunday.

Several other trip-specific questions were asked. This includes trip direction, shown in Figure 40 , which reveals that almost twice as many of the respondents ( 66 percent vs. 34 percent) were traveling southbound on I-95 rather than northbound. In addition, concerning whether respondents used the I-95 Express Lanes or the general purpose lanes, Figure 41 indicates that there was a nearly even split, with 49 percent of respondents using the Express Lanes, and 51 percent using the general purpose lanes. In terms of initial trip locations and destinations, Figure 42 shows that most trips were made either locally within Miami-Dade County (38.5 percent) or from Broward to Miami-Dade (40.7 percent), with another 16.5 percent of trips running in the opposite direction, from Miami-Dade to Broward.

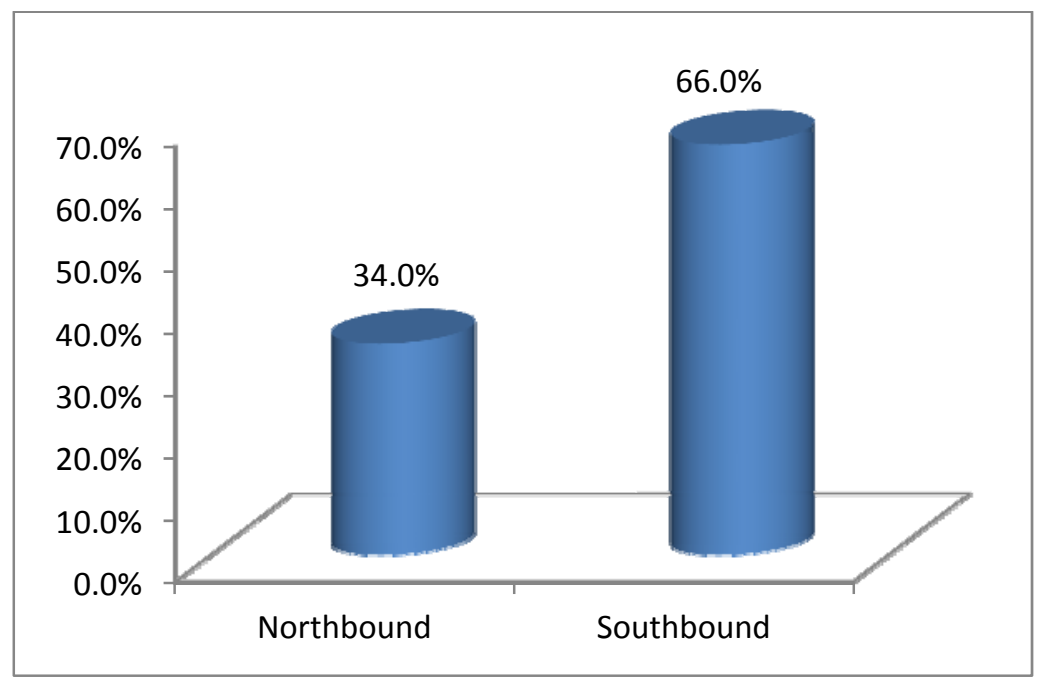

Figure 40: Trip Direction 


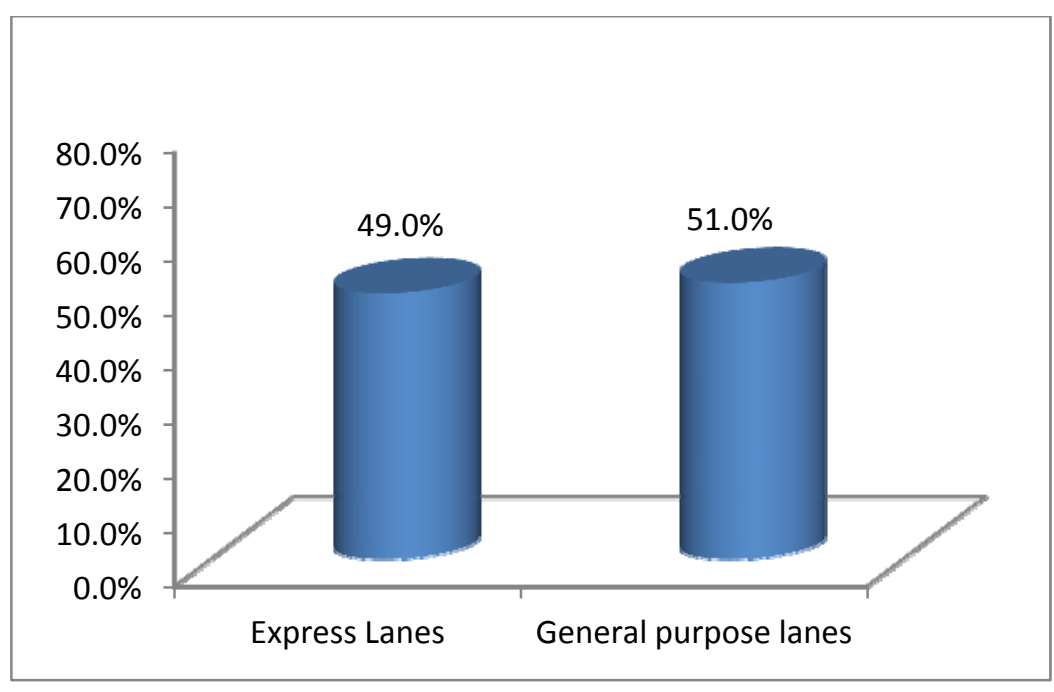

Figure 41: I-95 Lanes Used for Trip

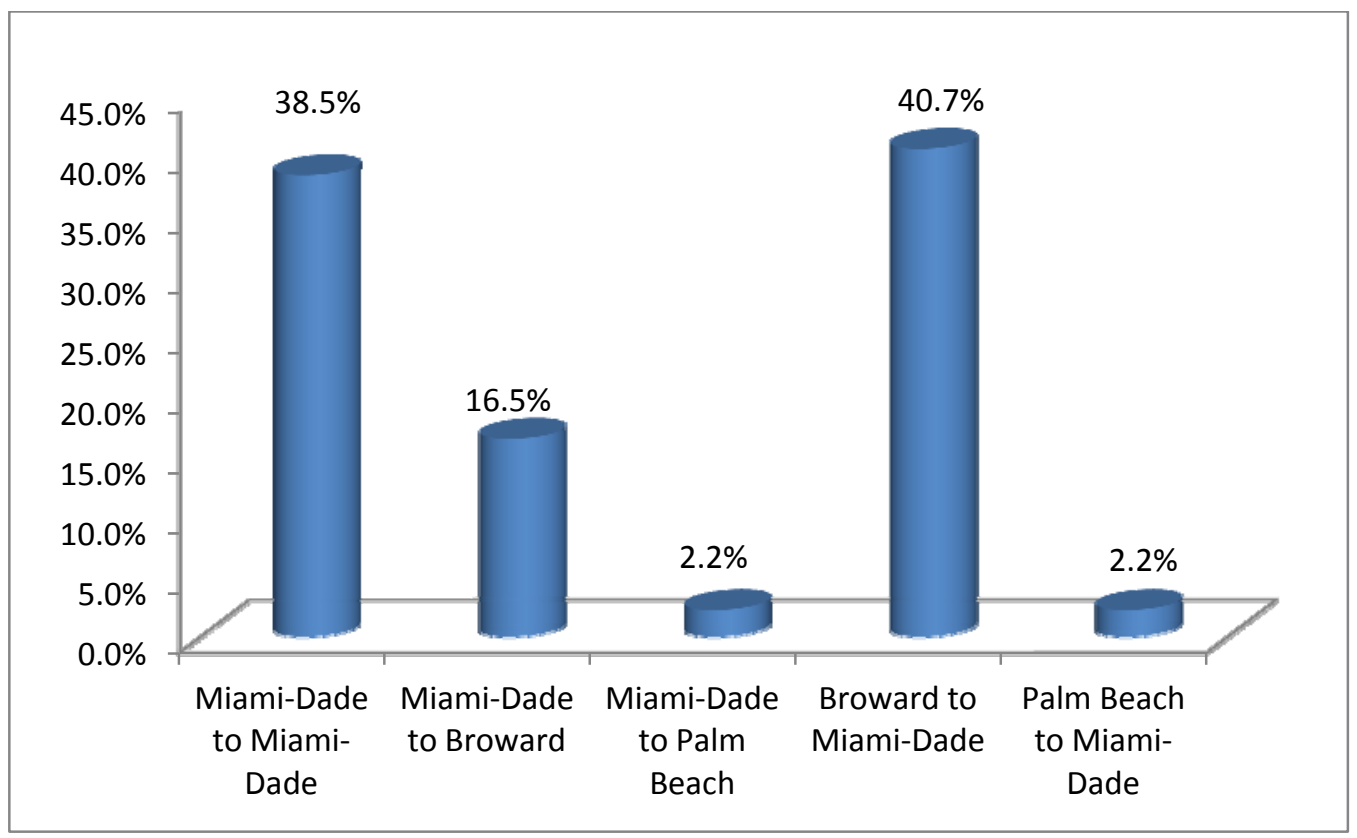

Figure 42: Start County and End County 


\section{Value of Travel Time Savings}

The purpose of this research is to present an improved estimation of VTTS, which is a critical component of travel behavior analysis and transportation project evaluation. Having the most accurate estimations of VTTS is beneficial for the development of successful congestion pricing policies. VTTS has an important role in a traveler's choice among competing modes or travel alternatives. In classical economic theory, VTTS is defined as the willingness to pay for a unit (e.g., minute) of travel time savings (50). It is expected that VTTS would vary among trip characteristics and the demographic characteristics of the traveler. VTTS has also typically been considered to be equivalent to the traveler's value of time (VOT). As shown previously in Equation 2, the VTTS is computed as the ratio of the coefficients of travel time savings and the toll cost from the discrete choice model results.

In this research, the traveler's choice was limited to driving in the 95 Express Lanes and paying the prevailing toll or driving in the adjacent general purpose lanes and paying no toll. Travel time savings was defined as the difference in travel time, in minutes, to cover the 7.3 mile distance of the 95 Express facility using the Express Lanes versus the general purpose lanes at a given point in time. It was computed using the actual speeds on the lanes, which were available through the MVDS data discussed previously. Those who used the Express Lanes experienced a travel time savings over those who traveled in the general purpose lanes. For those who drove only in the general purpose lanes, the travel time savings was zero.

It is assumed that VTTS varies with wage rates. Previous research has accommodated this by defining a variable that combines the toll rate and the traveler's annual income (51). In the survey, respondents were asked to provide information on both their annual household income and their annual personal income. For the models estimated as part of this effort, those that included the annual household income performed better and are included in the final result. The equations for the integrated toll/income variable (toll_householdinc) and the VTTS are shown below.

toll_householdinc $=\frac{\text { toll }}{\text { annual household income } / 2000}$

VTTS $=\frac{\beta_{\text {Time }}}{\beta_{\text {toll_householdinc }}} \times \frac{\text { annual household income }}{2000} \times \frac{60 \text { minutes }}{1 \text { hour }}$ 
where

VTTS = value of travel time savings (\$/hour);

$\beta_{\text {time }} \quad=$ coefficient of the variable time (represents travel time savings); and

$\beta_{\text {toll_householdinc }}=$ coefficient of the variable toll_householdinc (integration of toll and income).

Respondents were asked to choose among 18 different income categories to provide the most accurate representation of their income. The midpoint of those narrow ranges was used in the model, as in Equation 3, and in computing VTTS in Equation 4. Because only annual incomes were reported in the survey, an hourly wage was estimated by dividing the annual income by 2,000 annual work hours.

Figure 43 shows the overall frequency distribution of VTTS for the respondents to this revealed preference survey who travel on I-95 along the 95 Express corridor. The highest percentage of survey respondents (19 percent) have an estimated VTTS ranging from $\$ 45.00$ to $\$ 60.00$ per hour, based on annual household income. The computed VTTS for these I-95 travelers was determined to be approximately 49 percent of their estimated hourly wage. The range was $\$ 2.27$ per hour to $\$ 79.32$ per hour with a mean of approximately $\$ 32.00$ per hour. The shape of the distribution is similar to the shape of the annual household income distribution shown previously in Figure 35. These results are similar to VTTS estimates found in the recent literature, which finds VTTS in the range of 20 percent to 50 percent of the traveler's hourly wage (and higher for revealed preference results) (51) (1).

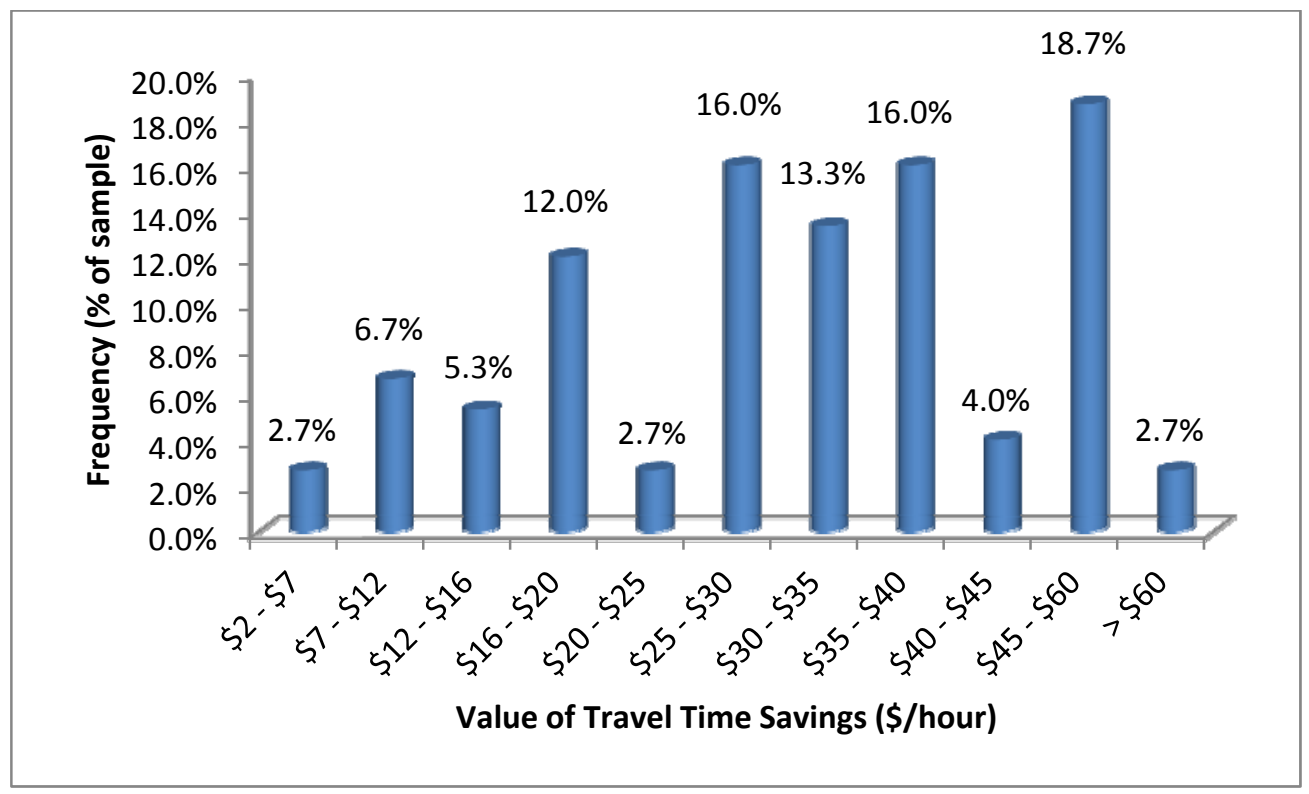

Figure 43: VTTS Distribution for Survey Respondents Traveling on I-95 
Table 1 provides some detail on the model results. The Express Lane choice was selected as the reference case, and so its alternative specific constant is zero. The alternative specific constant for the general purpose lanes (also known as local lanes), however, is computed. The variables of interest are travel time (time) and the toll integrated with annual household income (toll_householdinc). The ratio of these two coefficients is used in the VTTS calculations, and both are statistically significant at the one percent level of significance. Other models were estimated using other trip and demographic characteristics such as age, gender, education, and whether the trip was in the peak periods, but these variables were not significant using the survey data set. The final model shown in Table 1 does incorporate the demographic characteristic of income integrated into the toll variable.

Table 1: 95 Express Model Results

\begin{tabular}{|l|l|c|c|c|}
\hline \multicolumn{1}{|c|}{ Variable } & \multicolumn{1}{|c|}{ Description } & Coefficient & Standard Error & P-Value \\
\hline ASC_EL & $\begin{array}{l}\text { Alternative specific constant for } \\
\text { Express Lanes (used as reference } \\
\text { mode) }\end{array}$ & 0.00 & n/a & n/a \\
\hline ASC_LL & $\begin{array}{l}\text { Alternative specific constant for } \\
\text { general purpose lanes (local lanes) }\end{array}$ & -6.13 & 1.42 & 0.00 \\
\hline time & $\begin{array}{l}\text { Travel time savings for using the } \\
\text { Express Lanes; the value was zero for } \\
\text { the general purpose lanes. }\end{array}$ & -0.09 & 0.02 & 0.00 \\
\hline toll_householdinc & $\begin{array}{l}\text { Toll/(annual household income/2000) } \\
\text { n=208 Log Likelihood Function =-10.458 } \quad \mathrm{Q}^{2}=0.799 \quad \text { adjusted } \mathrm{Q}^{2}=0.741\end{array}$ & 3.55 & 0.00 \\
\hline
\end{tabular}




\section{CONCLUSIONS}

It is the purpose of this new research to build upon the earlier NCTR synthesis on VTTS literature and on other work done on this topic in the last few years. The goal is to present an improved estimation of VTTS, which is a critical component of travel behavior analysis and transportation project evaluation. Having the most accurate estimations of VTTS is beneficial for the development of successful congestion pricing policies. VTTS has an important role in a traveler's choice among competing modes or travel alternatives.

After searching for existing data with which to estimate VTTS for the 95 Express corridor, it was determined that an online survey would be conducted to gather the necessary trip-specific information. In the survey, additional questions were asked beyond what was required for the VTTS estimation. These additional questions addressed door-to-door travel time, trip origin and destination, and the location of trip origins, destinations, homes, and workplaces denoted by the nearest major intersection or landmark. Such data can be used for other future research purposes, although a future effort might involve another survey to capture a wider variety and greater number of trips via distribution to all SunPass holders.

The site for this effort was the 95 Express facility, which operates in Miami-Dade County, Florida. The 95 Express is part of an overall long-term strategy of initiatives with a goal of improving safety, person throughput, and reliability along I-95 in South Florida. Further, the 95 Express has a goal to encourage carpooling and transit usage/performance along the corridor. The project operates with a combination of HOT lanes, carpooling and public transit incentives, ramp metering, rapid incident detection, and other enhanced operational management strategies.

The success of the 95 Express has resulted in improvements in transit usage and performance along the corridor. The increase in traffic speed along the Express Lanes not only saves time for auto drivers, but also has attracted 53 percent new transit riders to the 95 Express Bus service (44). According to the FDOT 95 Express Annual Report, transit travel times between downtown Miami and the Golden Gate Interchange have dropped from 25 minutes to just 8 minutes (41). User perception on travel time, reliability, and seat availability of 95 Express Bus Service has further improved. Through the UPA program, there have been new routes, improved park-andride facilities, and the implementation of TSP along some corridors to provide an advantage to the 95 Express Bus service. 
Further, between 2008 and 2010, ridership on 95 Express Bus service increased 57 percent while travel in local lanes along I-95 and system-wide MDT Metrobus ridership decreased (45). This result shows the success of the Miami UPA program in linking its two main projects - the HOT lanes and the 95 Express Bus Service - to encourage transit patronage, which will bring Miami closer to its goal of reducing congestion along its major roadways.

Another major effort in this research involved a synthesis of managed lane projects in the U.S., including those included as UPA/CRD sites by USDOT. The sections covering the UPA/CRD sites include information on all the congestion management strategies being considered and implemented, in addition to the managed lane elements. While various pieces of information on these projects are widely available, this document summarizes the most pertinent information about each project in one report.

This research aimed to improve the estimation of VTTS by using revealed preference data on trips taken on I-95 along the 95 Express corridor. By using information from the first survey to collect trip-specific data on the 95 Express corridor, it was found that the estimated VTTS of those travelers is approximately 49 percent of their hourly wage based on annual household income, with a range of $\$ 2.27$ to $\$ 79.32$ per hour and a mean of approximately $\$ 32.00$ per hour. These results are in the range of estimated values for VTTS found in the recent literature and represent actual behavior of the survey respondents rather than the more commonly found stated preferences. 


\section{REFERENCES}

1. Concas, Sisinnio, and Alexander Kolpakov. 2009. Synthesis of Research on Value of Time and Value of Reliability. Tampa, Florida: University of South Florida, National Center for Transit Research at the Center for Urban Transportation. Prerpared for the Florida Department of Transportation.

2. Becker, Gary S. 1965. A Theory of the Allocation of Time. The Economic Journal, Vol. 75, No. 299, pp. 493-517.

3. DeSerpa, Allan C. 1971. A Theory on the Economics of Time. The Economic Journal, Vol. 81, No. 324, pp. 828-846.

4. Jara-Diaz, Sergio R. 2003. On the Goods-Activities Technical Relations in the Time Allocation Theory. Transportation, Vol. 30, No. 3, pp. 245-260.

5. Shaw, Douglass W. 1992. Searching for Opportunity Cost of an Individual's Time. Land Economics, Vol. 68, No. 1, pp. 107-115.

6. Jara-Diaz, Sergio R. 2002. The Goods/Activities Framework for Discrete Travel Choices: Indirect Utility and Value of Time. In In Perpetual Motion: Travel Behavior Research Opportunities and Application Challenges, Hani S Mahmassani, ed. Oxford, UK: Elsevier Science Ltd.

7. Gronau, Reuben. 1976. Economic Approach to Value of Time and Transportation Choice. Transportation Research Record, No. 587, pp. 1-5.

8. Reichman, Shalom. 1976. Conceptual Problems in Evaluation of Travel Time. Transportation Research Record, No. 587, pp. 24-29.

9. Anas, Alex. 2007. A Unified Theory of Consumption, Travel, and Trip Chaining. Journal of Urban Economics, Vol. 62, No. 2, pp. 162-186.

10. Anas, Alex, and Xu Rong. 1999. Congestion, Land Use, and Job Dispersion: A General Equilibrium model. Journal of Urban Economics, Vol. 45, No. 3, pp. 451-473.

11. Evans, Alan W. 1972. On the Theory of the Valuation and Allocation of Time. Scottish Journal of Political Economy, Vol. 19, No. 1, pp. 1-17.

12. Train, Kenneth, and Daniel McFadden. 1978. The Goods/Leisure Trade-Off and Disaggregate Work Trip Mode Choice Models. Transportation Research, Vol. 12, No. 5, pp. 349353.

13. Small, Kenneth. Urban Transportation Economics. Chur, Switzerland. Published 1992. 
14. Coulson, Edward N. 1991. Really Useful Tests of the Monocentric Model. Land Economics, Vol. 69, No. 3, pp. 299-307.

15. Timothy, Darren, and William C. Wheaton. 2001. Intra-Urban Wage Variation, Employment Location, and Commuting Times. Journal of Urban Economics, Vol. 50, No. 2, pp. 338-366.

16. Hess, Stephane, Michel Bierlaire, and John W. Polak. 2005. Estimation of Value of Travel Time Savings Using Mixed Logit Models. Transportation Research Part A: Policy and Practice, Vol. 39, pp 221-236.

17. Abou-Zeid, Maya, Mosh E. Ben-Akiva, Michel Bierlaire, Charisma Farheen Choudhury, and Stephanie Hess. 2011. Attitudes and Value of Time Heterogeneity, paper presented at the 90th Annual Meeting of the Transportation Research Board (TRB) Compendium of Papers.

18. LeeWay. 2011. Lee County: Toll Road Information. www.leewayinfo.com, accessed October 4, 2011.

19. Why Use the Greenway? 2011. Dulles Greenway. www.dullesgreenway.com, accessed October 4, 2011.

20. Harris County Toll Road Authority. 2011. Toll Road Information- Overview. http://www.hctra.org/tollroads/, accessed October 18, 2011.

21. Utah Department of Transportation. 2011. Express Lanes: FAQ.

http://www.udot.utah.gov/expresslanes/faqs.php, accessed November 22, 2011.

22. San Diego Association of Governments. 2011. Transportation: I-15 Express Lanes.

www.sandag.org/index.asp?projectid=34\&fuseaction=projects.detail, accessed October 5, 2011.

23. Colorado Department of Transportation. 2011. I-25 HOV Express Lanes.

http://www.udot.utah.gov/expresslanes/faqs.php, accessed October 5, 2011.

24. New Jersey Turnpike Authority. 2011. Traffic Resources: Toll Rates.

http://www.nj.gov/turnpike/toll-rates.html\#rates, accessed October 6, 2011.

25. State Road and Tollway Authority. 2011. PeachPass website. www.peachpass.com, accessed July 1, 2011.

26. Georgia Department of Transportation. 2011. I-85 HOT Lanes Information.

www.dot.state.ga.us/travelinggeorgia/expresslanes/I85hotlanes/Pages/default.aspx, accessed July 1, 2011.

27. Georgia Department of Transportation. 2011. I-85 HOT Lanes: I-85 Express Lanes Market Research. http://www.dot.state.ga.us/travelingingeorgia/expresslanes/I85hotlanes/, accessed July, 1, 2011. 
28. State Road and Tollway Authority. 2011. Partnership for Progress Team- HOT Lane Commuter Research. www.peachpass.com/uploads/HOTRESEARCH_report.pdf, accessed January 12, 2011.

29. US Department of Transportation: Metro Research and Development Department. 2010. Los Angeles County Congestion Reduction Demonstration National Evaluation Plan.

http://www.metro.net/projects_studies/expresslanes/images/performance-measures-nationalevaluation-plan.pdf, accessed July 1, 2011.

30. Los Angeles Department of Transportation (LADOT). 2010. Express Park: Intelligent Parking Management. http://ladot.lacity.org/pdf/PDF217.pdf, accessed July 13, 2011.

31. US Department of Transportation. 2007 HOV Annual Report. Los Angeles County Congestion Reduction Demonstration National Evaluation Plan.

http://metro.net/projects_studies/expresslanes/images/performace-measures-nationalevaluation-plan.pdf, accessed January 13, 2011.

32. US Department of Transportation. 2010. San Francisco Urban Partnership Agreement National Evaluation Plan. http://www.upa.dot.gov/docs/fhwajpo10022/sanfranupa.pdf, accessed July 1, 2011.

33. San Francisco Municipal Transportation Agency. 2011. SFpark. http://sfpark.org, accessed July 13, 2011.

34. San Francisco County Transportation Authority (SFCTA). 2010. Mobility, Accessibility, and Pricing Study. http://www.sfcta.org/content/view/302/148, accessed July 1, 2011.

35. Washington State Transportation Commission. 2011. United States Department of Transportation Urban Partnership Agreement: Seattle. http://upa.dot.gov/agreements/seattle.htm, accessed June 29, 2011.

36. United States Department of Transportation. 2009. Urban Mobility Report. Seattle-Lake Washington Corridor Urban Partnership Agreement National Evaluation Plan. http://www.upa.got.gov/docs/fhwajpo10017/seattleupa.pdf.

37. Munnich, Lee W. 2008. Minnesota's Proposal for Urban Partnerhsip Agreement: Case Study of Political and Institutional Issues in Congestion Pricing. Transportation Research Record, Vol. 2079, pp. 15-20.

38. US Department of Transportation. 2011. Urban Partnership Agreement- Minneapolis. http://upa.dot.gov/agreements/minneapolis.htm, accessed July 6, 2011.

39. MnPass. 2011. MnPass Customer Satisfaction Results. https://support.mnpass.net/survey/results.php?sid=29, accessed July 1, 2011. 
40. US Department of Transportation. 2011. Minnesota: Innovative Choices for Congestion Relief Annual Report. http://upa.dot.gov/docs/fhwajpo11039/arminn1.pdf.

http://upa.dot.gov/docs/fhwajpo11039/arminn1.pdf, accessed July 1, 2011.

41. Florida Department of Transportation. 2010. I-95 Express Annual Report.

http://www.sunguide.org/sunguide/images/uploads/tmc_reports/95X_P1_UPA_Eval_FY_10_A

nnual_Report_01_21_2010_FINAL.PDF, accessed July 1, 2011.

42. SunGuide. 2010. 95 Express: 95 Express Survey Results Phase 1B.

http://www.sunguide.org/sunguide/images/uploads/tmc_reports/95_Phase_1B_Survey_Summa ry_Report.pdf, accessed June 29, 2011.

43. 95 Express Website. 2011. Tolling and Typical Toll Rates. http://www.95express.com, accessed November 9, 2011.

44. Pessaro, Brian, and Caleb Van Nostrand. 2010. Miami Urban Partnership Agreement (UPA) Project Phase 1 Transit Evaluation Report. Tampa, Florida: University of South Florida, National Center for Transit Research at the Center for Urban Transportation. prepared for US Department of Transportation, Federal Transit Administration. available at http://www.nbrti.org/docs/pdf/Miami\%20UPA\%20Phase\%201\%20Transit\%20Evaluation\%20Re port\%20-\%20FINAL.pdf.

45. Florida Department of Transportation District 6. 2011. 95 Express Monthly Operations Report. http://www.sunguide.org/sunguide/images/uploads/tmc_reports/2011_05_31_95_EL_Monthly_ Apr_11_RJS_Final.pdf, accessed July 1, 2011.

46. Wilbur Smith Associates. 2008. Chapter 4: Stated Preference Survey Results and Appendix. Comprehensive Traffic and Revenue Study for the I-595 Express Toll Lanes.

47. Carrion-Madera, Carlos, and David Levinson. 2010. Value of Reliability: High Occupancy Toll Lanes, General Purpose Lanes, and Arterials. Presented at the 90th Annual Transportation Research Board (TRB) Conference, Washington, D.C.

48. Bierlaire, M. 2003. BIOGEME: A free package for the estimation of discrete choice models. In Proceedings for the $3^{\text {rd }}$ Swiss Transport Research Conference, Ascona, Switzerland, March 19-21, 2003. Lausanne, Switzerland: Ecole Polytechnique Federale de Lausanne. www.strc.ch/conferences/2003, accessed October 18, 2011.

49. Shaw, Douglass W., Sunil Patil, Mark Burris, and Sisinnio Conas. 2011. Variation in the Value of Travel Time and its Impact on the Benefits of Managed Lanes. Transportation Planning and Technology, Vol. 34, No. 6, pp. 547-567.

50. Brownstone, D., and K.A. Small. 2005. Valuing Time and Reliability: Assessing the Evidence from Road Pricing Demonstrations. Transportation Research Part A: Policy and Practice, Vol. 39, No. 4, pp. 279-293. 
51. Burris, Mark and Lei Xu. 2006. Potential Single-Occupancy Vehicle Demand for HighOccupancy Vehicle Lanes. Transportation Research Record, Vol. 1960, pp. 108-118. 


\section{APPENDIX - I-95 SURVEY QUESTIONS}

1. Do you agree with the terms and conditions?
a. Yes
b. No

2. Which category represents your age?
a. Under 18
b. 18 to 24
c. 25 to 34
d. 35 to 49
e. 50 to 64
f. 65 or older

3. In the last five days, have you driven or taken a Miami-Dade Transit Bus on I-95 in Miami Dade County?
a. Yes
b. No

Please recall two trips made within the past five days (Wednesday, August $17^{\text {th }}-$ Sunday, August 21 $1^{\text {st }}$ ) using I-95 in Miami Dade County. The trip refers to a ONE-WAY portion of travel. For example, a trip from your home to work is a one-way trip. We do NOT want you to describe a round-trip (home to work and then back to home). If possible, please provide one work and one non-work trip.

For your first trip:

4. How did you travel on I-95 for this trip?
a. Drive alone in personal vehicle
b. Drive with others in personal vehicle
c. Drive alone in company vehicle
d. Drive with others in company vehicle
e. Registered Carpool with 3 or more members
f. Vanpool
g. Registered Hybrid vehicle
h. I-95 Express Bus
i. Motorcycle

Questions 5-7 were only asked if the respondent selected I-95 Express Bus for Question 4. 
5. How did you pay for the I-95 Express Bus trip?
a. Full fare [\$2.35]
b. Discount fare $[\$ 1.15]$
c. One month pass $[\$ 100]$
d. Discount one month pass [\$50]
e. One month pass group discount - 4 to 99 passes [\$90]
f. One month pass group discount - 100 or more passes [ $\$ 85]$
g. 7 day pass [\$26]
h. Discount 7 day pass $[\$ 13]$
i. 1 day pass [\$5]
j. Discount 1 day pass [\$2.50]
k. College / Adult Education Center monthly pass [\$50]
1. Golden Passport [free]
m. Patriot Passport [free]

6. Did your employer pay for this fare?
a. Yes
b. No

7. Could you have driven a vehicle instead of taking the I-95 Express Bus?
a. Yes
b. No

Questions 8-9 were only asked if the respondent did not select I-95 Express Bus or Motorcycle for Question 4.

8. Other including you, how many people were in the car on this trip?
a. 1 (Drove alone)
b. 2
c. 3
d. 4
e. 5
f. 6 or more

9. If drove or rode with others, please specify who else was in the car for this trip.
a. Members of your household
b. Friends or relatives who live elsewhere
c. Coworkers
d. Other prearranged carpoolers 
10. Did you travel on the I-95 Express Lane on this trip?
a. Yes
b. No

Questions 11-13 were only asked if the respondent selected yes for Question 10.

11. What type of I-95 Express Lane user are you when traveling?

a. I use my SunPass to pay the toll.

b. I am in a registered 3+ Carpool and use the lanes toll free.

c. I participate in a South Florida Vanpool and use the lanes toll free.

d. I am a registered hybrid driver and use the lanes toll free.

e. I drive a motorcycle and use the lanes toll free.

f. Other.

Questions 12-13 were only asked if the respondent selected 'I use my SunPass to pay the toll' or 'Other' for Question 11.

12. What was the amount of the toll for this trip?

13. Does your employer pay for or reimburse you for your I-95 Express Lane tolls when you travel for work/business related purposes?
a. Yes
b. No

14. How fast did you seem to be going for most of your trip?
a. Slower than $35 \mathrm{mph}$
b. $35-45 \mathrm{mph}$
c. Faster than $45 \mathrm{mph}$

15. What entrance did you use to get onto I-95?

The respondent was given a list of entrances from Miami-Dade County, Broward County, Palm Beach County and the Treasure Coast region to choose from.

16. What exit did you use to get off of I-95?

The respondent was given a list of exits from Miami-Dade County, Broward County, Palm Beach County and the Treasure Coast region to choose from. 
17. What day of the week was your trip made?
a. Wednesday, August 17
b. Thursday, August 18
c. Friday, August 19
d. Saturday, August 20
e. Sunday, August 21

18. What time did your trip begin?

19. If your trip began outside peak periods (6-9am or 4-7pm), did you choose to make this trip at that time to avoid delays due to traffic conditions?
a. Yes
b. No

20. What was the primary purpose of this trip on I-95?
a. Go to or from work
b. Go to or from school
c. Business related travel (such as a meeting, sales call, etc.)
d. Shopping
e. Social or recreational (such as visiting a friend or going to the movies)
f. Other personal business (such as a medical appointment)

21. Was this an urgent trip (i.e. running late or an emergency)?
a. Yes
b. No

22. The next few questions will ask you about where your trip started and ended. Did your trip..?
a. begin at home
b. end at home
c. neither

23. In what direction were you traveling?
a. North
b. South

24. What was the zip code of where your trip began?

25. Where did your trip begin? Please indicate the closest major intersection or nearest major location or landmark.

a. Closest major intersection:

b. Near a major landmark or location (airport, university, mall, etc.) 
26. What was the zip code of where your trip ended?

27. Where did your trip end? Please indicate the closest major intersection or nearest major location or landmark.

a. closest major intersection:

b. Near a major landmark or location (airport, university, mall, etc.)

28. How much time did you spend traveling, door to door? Please enter total travel time (in minutes).

29. How much of the total trip time was spent on I-95 (in minutes)?

30. How often do you make this same trip in this direction?

a. Less than once a week.

b. Once per week.

c. Twice per week.

d. Three times per week.

e. Four times per week.

f. Five times per week.

g. Six or more times per week.

The respondent was now asked to recall a second trip and repeat Questions 4-30.

Attitude Questions:

Please rate the following statements.

31. It is comfortable to go by public transportation to work.
a. Strongly agree
b. Agree
c. Neutral
d. Disagree
e. Strongly disagree

32. It feels safe to go by public transportation.
a. Strongly agree
b. Agree
c. Neutral
d. Disagree
e. Strongly disagree 
33. Going by public transportation is worth its price compared to going by car.
a. Strongly agree
b. Agree
c. Neutral
d. Disagree
e. Strongly disagree

34. It is comfortable to go by car to work.
a. Strongly agree
b. Agree
c. Neutral
d. Disagree
e. Strongly disagree

35. It feels safe to go by car.
a. Strongly agree
b. Agree
c. Neutral
d. Disagree
e. Strongly disagree

36. It is very important that traffic speed limits are not violated.
a. Strongly agree
b. Agree
c. Neutral
d. Disagree
e. Strongly disagree

37. Measures to improve public transportation should be undertaken.
a. Strongly agree
b. Agree
c. Neutral
d. Disagree
e. Strongly disagree

38. I consciously limit my car use to reduce emissions.
a. Strongly agree
b. Agree
c. Neutral
d. Disagree
e. Strongly disagree 
Demographics:

This final section of the survey is about your household.

39. What is your home zip code?

40. Where is your home located? Please indicate the closest major intersection or nearest major location or landmark.

a. Closest major intersection:

b. Near a major landmark or location (airport, university, mall, etc.)

41. How many people live in your household?
a. 1
b. 2
c. 3
d. 4
e. 5
f. 6 or more

42. How many people under the age of 16 live in your household?

43. How many cars, motorcycles, pickup trucks, minivans, etc. are there in your household?
a. 0
b. 1
c. 2
d. 3
e. 4
f. 5 or more vehicles

44. What is your gender?
a. Male
b. Female

45. What is the highest level of school or degree that you have completed?
a. Less than high school
b. High school or GED
c. 1 or more years of college but not a degree
d. Associate's degree
e. Bachelor's degree
f. Graduate or professional degree 
46. What is your employment status?
a. Full-time worker
b. Part-time worker
c. Self-employed
d. Student
e. Student and employed
f. Homemaker
g. Retired
h. Unemployed

47. Which of the following industries best describes your place of employment?
a. Administrative Support
b. Arts, Entertainment \& Recreation
c. Construction
d. Delivery
e. Education
f. Finance \& Insurances
g. Food Services
h. Government
i. Healthcare \& Social Assistance
j. Hospitality \& Travel
k. Information \& Technology
1. Legal Services
m. Manufacturing
n. Professional / Management
o. Real Estate
p. Trade
q. Transportation
r. Utilities
s. Warehousing
t. Other

48. What is the zip code where you work?

49. Where is your work located? Please indicate the closest major intersection or nearest major location or landmark.

a. Closest major intersection

b. Near a major landmark or location (airport, university, mall, etc.) 
50. Which category best represents your personal annual income before taxes?
a. Under $\$ 10,000$
b. $\$ 10,000-\$ 19,999$
c. $\$ 20,000-\$ 29,999$
d. $\$ 30,000-\$ 39,999$
e. $\$ 40,000-\$ 49,999$
f. $\$ 50,000-\$ 59,999$
g. $\$ 60,000-\$ 69,999$
h. $\$ 70,000-\$ 79,999$
i. $\$ 80,000-\$ 89,999$
j. $\$ 90,000-\$ 99,999$
k. $\$ 100,000-\$ 124,999$
1. $\$ 125,000-\$ 149,999$
m. $\$ 150,000$ - $\$ 174,999$
n. $\$ 175,000$ - $\$ 199,999$
o. $\$ 200,000-\$ 299,999$
p. $\$ 300,000$ - $\$ 399,999$
q. $\$ 400,000$ - $\$ 499,999$
r. $\$ 500,000$ or more

51. Which category best represents your household's annual income before taxes?
a. Under $\$ 10,000$
b. $\$ 10,000-\$ 19,999$
c. $\$ 20,000$ - $\$ 29,999$
d. $\$ 30,000-\$ 39,999$
e. $\$ 40,000$ - $\$ 49,999$
f. $\$ 50,000-\$ 59,999$
g. $\$ 60,000-\$ 69,999$
h. $\$ 70,000$ - $\$ 79,999$
i. $\$ 80,000-\$ 89,999$
j. $\$ 90,000-\$ 99,999$
k. $\$ 100,000-\$ 124,999$
1. $\$ 125,000-\$ 149,999$
m. $\$ 150,000$ - $\$ 174,999$
n. $\$ 175,000$ - $\$ 199,999$
o. $\$ 200,000$ - $\$ 299,999$
p. $\$ 300,000-\$ 399,999$
q. $\$ 400,000-\$ 499,999$
r. $\$ 500,000$ or more 
